University of San Diego

Digital USD

2015-8

\title{
The Relationship Between Toxic Leadership, Organizational Citizenship, and Turnover Behaviors Among San Diego Nonprofit Paid Staff
}

Melanie J. Hitchcock

University of San Diego

\section{Digital USD Citation}

Hitchcock, Melanie J., "The Relationship Between Toxic Leadership, Organizational Citizenship, and Turnover Behaviors Among San Diego Nonprofit Paid Staff" (2015). Dissertations. 2.

https://digital.sandiego.edu/dissertations/2 
The Relationship Between Toxic Leadership, Organizational Citizenship, and Turnover Behaviors Among San Diego Nonprofit Paid Staff

by

Melanie J. Hitchcock

A dissertation submitted in partial fulfillment

of the requirements for the degree of

Doctor of Philosophy

August 2015

Dissertation Committee

George E. Reed, Ph.D., Chair

Fred J. Galloway, Ed.D., Member

Zachary Gabriel Green, Ph.D., Member

Linnea M. Axman, Dr.P.H., MSN, Member

University of San Diego 

(C) Copyright by Melanie J. Hitchcock

All Rights Reserved 2015 


\begin{abstract}
Toxic leadership is associated with a number of negative consequences to the long-term health and welfare of people in organizations. Destructive leader styles redirect employee efforts from mission accomplishment to self-protection and survival behaviors, undermining the organization. Increased demand and decreased funding are characteristic of the nonprofit sector. Therefore, successful nonprofit organizations tend to rely on creativity and innovation to ensure their communities are appropriately and sufficiently sustained. Supportive, not toxic, leadership helps foster organizational environments that encourage prudent risk-taking and innovation.

This concurrent mixed methods study explored the relationship between toxic leadership and organizational citizenship and turnover behaviors among 471 survey respondents from a sample of San Diego nonprofit paid staff, and considered the influence commitment has on those relationships. An open ended question for those who reported experiencing toxic leadership provided additional context and depth as to why employees stayed in an organization in spite of abusive supervision. The findings of the study are of interest to leaders and managers of nonprofit organizations to develop policies and training processes as they strive to recruit, retain and develop talented employees.

Toxic supervision was found to exist in San Diego nonprofit organizations. However, its effect on organizational citizenship (OCB) and turnover behaviors was inconclusive, as was the influencing effect of commitment, in this study. However, both commitment and OCB-like ideas emerged as stated reasons that participants did not leave the organization, as did career, resilience and opportunity concepts. These identified variables suggest complex relationships that act in concert to influence staff retention indicating possible important opportunities for future research.
\end{abstract}




\section{ACKNOWLEDGEMENTS}

As noted by my USD colleague, COL James Dobbs, the process of completing this course of study is not possible without help, support and guidance from many. To all of you who have done so for me over the last many years, thank you all. Particularly, I must thank my Chair, Dr. George Reed for his enthusiasm and balanced approach to the myriad aspects of leadership, Dr. Fred Galloway, a truly supportive and encouraging educator, who inspires all of us, his students, to think and consider rather than react and repeat, Dr. Zachary Green who engages my unfocussed excitement about leadership, its connections and applications, elevates my thinking and challenges me to bring forward my underlying reasoning - a skill not easily taught (or learned) and always superbly offered, and Dr. Linnea Axman - a good friend - whose gentle guidance helped me understand this work at a much deeper level. Thank you all for your steadfast support.

I owe a special debt of gratitude to my advisor, Dr. Robert Donmoyer, who brought me into research in the nonprofit sector and opened up a new path for me. Mostly, though, he reminded me what I could and should bring to the table. For that, I will always be grateful.

A special thank you to Lenore Lowe and Stephanie McCullers, this study could not have happened without them, and for recognizing good leadership is important to the sector.

This process can have many barriers to progress. No one helped me break them down as well as Dr. Mary McDonald - a gifted and gentle teacher

There are many friends and colleagues at USD who have supported, helped and inspired me through a very long journey, especially, Dr. Owen Smith who made me think harder and everything more fun, Dr. Nathaniel Dunigan, a stalwart friend and supporter, Dr. Lyn Taylor Peyton Roberts who makes "the data" an exciting dive every time, Elaine Lewis, a good friend, who gives me my own advice when I need it better than I do, Elizabeth Castillo who has an inspiring message and started me in my new career - thank you, Alma Ortega whose unique approach to the subject helps me stretch my understanding, and, Heather Gibb, who has endless patience and such good humor.

I want to thank those from the The Caster Family Center for Nonprofit and Philanthropic Research where my many passionate colleagues led me to the third sector, particularly Dr. Laura Deitrich, Dr. Heather Carpenter, Dr. Audrey Barrett, Dr. Jennifer Jones, Dr. Lindsey McDougle, Bethan Theunissen, Jennifer Yebba and Pat Libby.

I also greatly appreciate my many United Way colleagues and friends who have had such great confidence in me, especially my boss, Ryan Morris, who with such good grace gave me time to finish this, talk about it and supported me throughout. I also 
appreciate a great United Way supporter, Dr. Kathleen Fernandes for generously giving her time to our mission, and insight to me to create a better foundation for this study.

Finally, I'd like thank my friends and family for their support, Theresa A. Hawkins Phelan, CDR Vanessa Wyndham, Dr. Lisa Stone, Vivian Steffans and CAPT Thomas Lange for being true friends over time and distance, Carol Williams, a good friend, who embodies great leadership in any context and time, without whom, I could not have finished, Dr. Adrienne Gotz for always "giving me a pass" during this process and making sure my best friends and family are well cared for - and not least, Audrey Jeanne Bittman Lovaglia, my mother, who always believed I would finish. 


\section{TABLE OF CONTENTS}

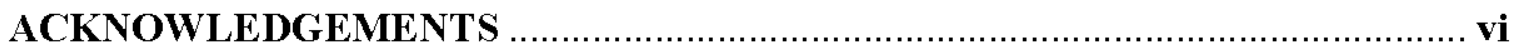

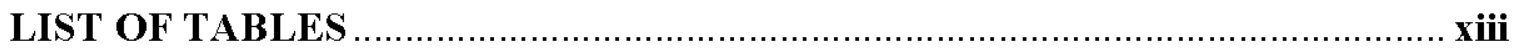

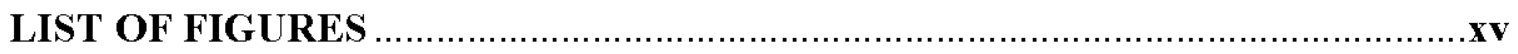

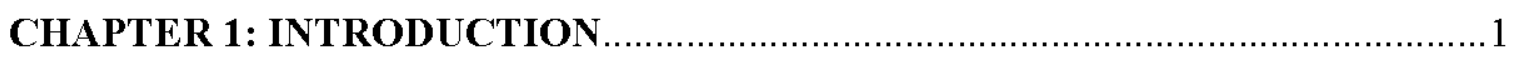

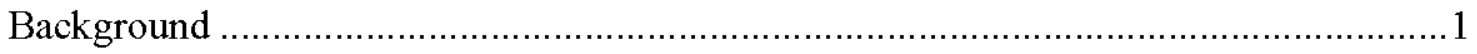

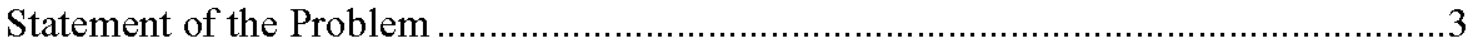

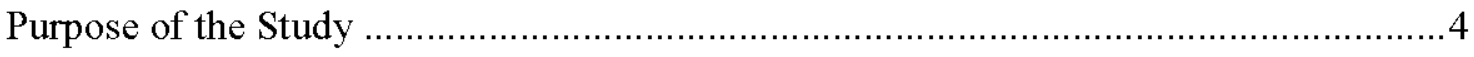

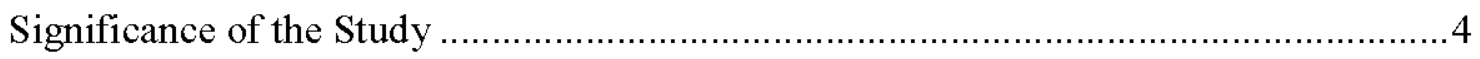

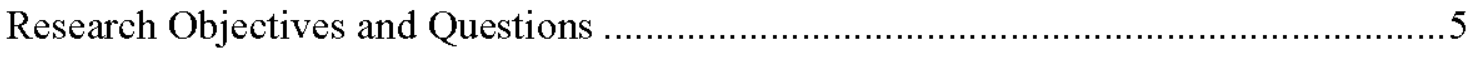

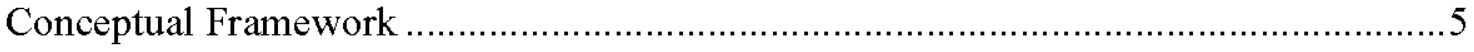

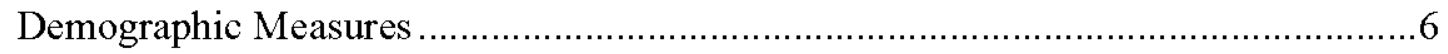

Measures of Organizational Success ................................................................. 6

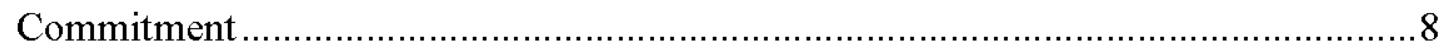

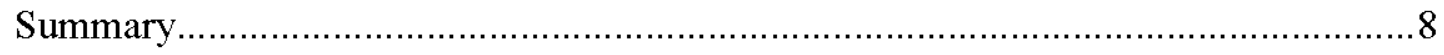

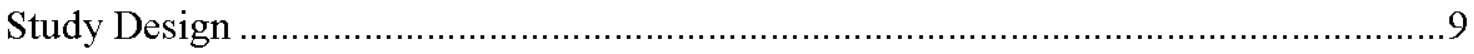

CHAPTER 2: REVIEW OF THE LITERATURE ............................................10

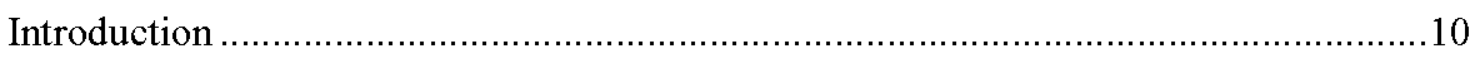




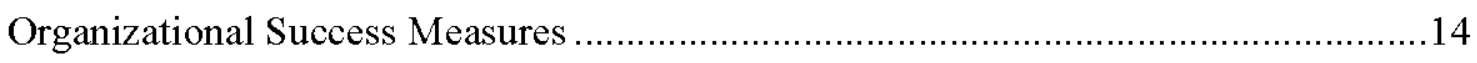

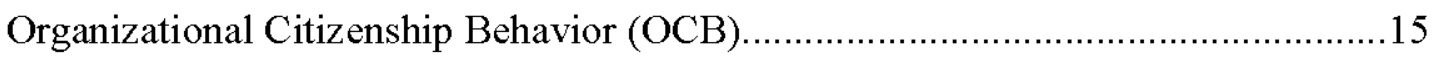

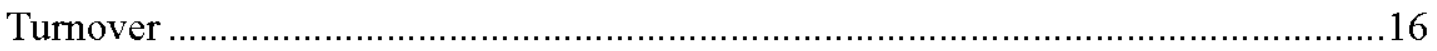

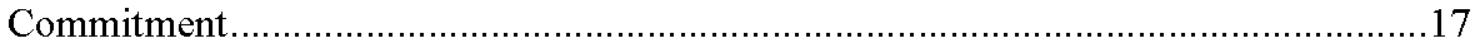

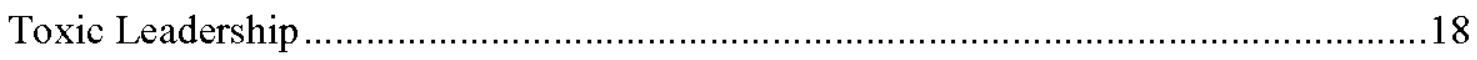

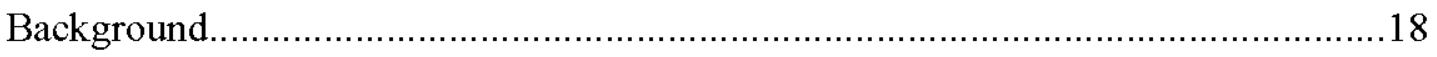

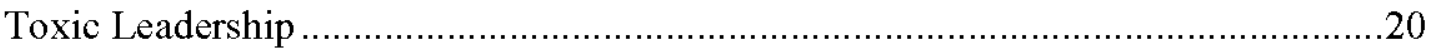

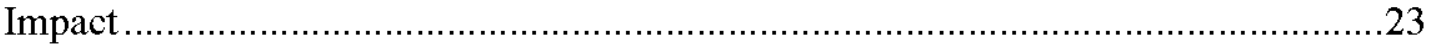

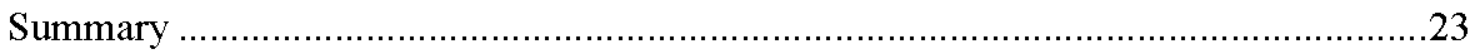

CHAPTER 3: METHODOLOGY AND PROCEDURES ….............................25

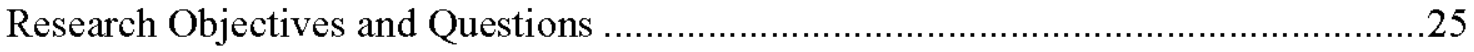

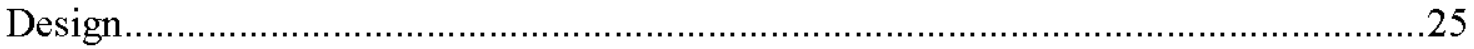

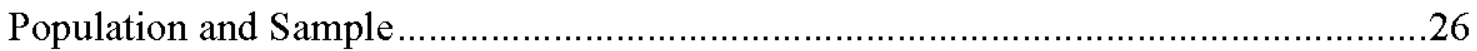

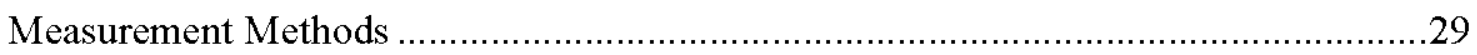

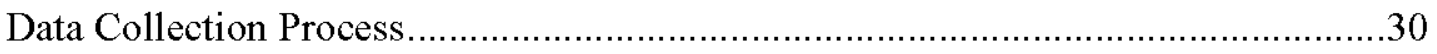

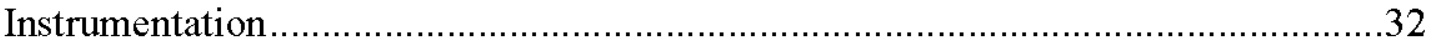

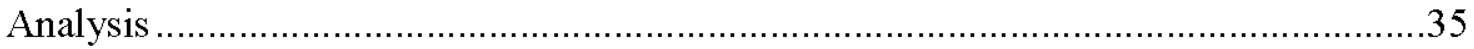

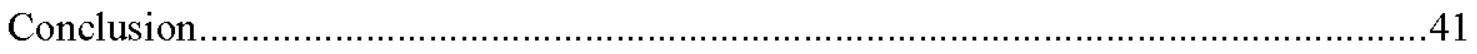

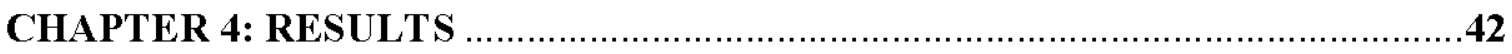


Sample

Challenges to Sampling.

Data Collection and Preparation

Coding of Quantitative Data Scale Scores

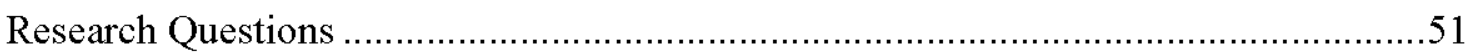

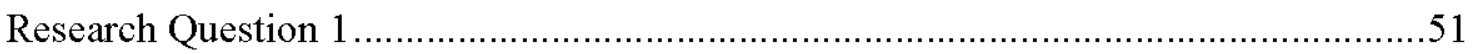

Demographics of Respondents Experiencing Toxicity …..................................52

Destructive Leader Questionnaire (DLQ) Items ..............................................57

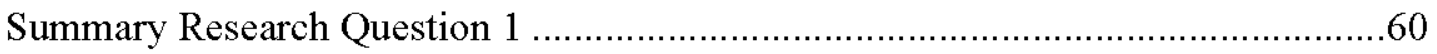

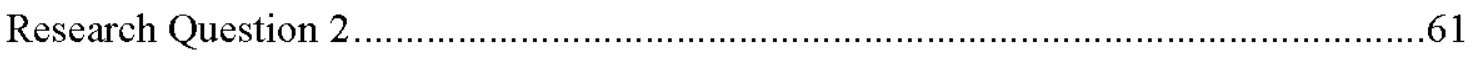

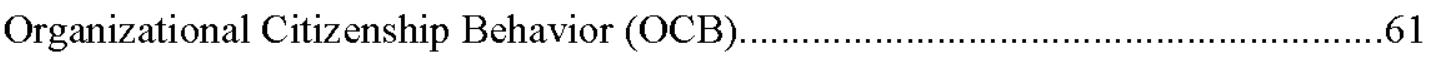

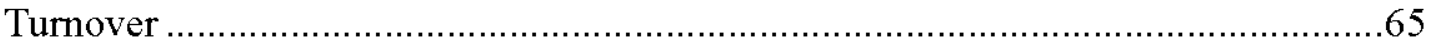

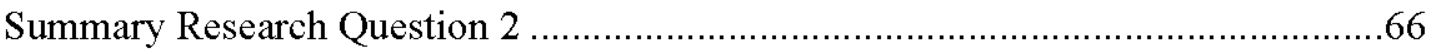

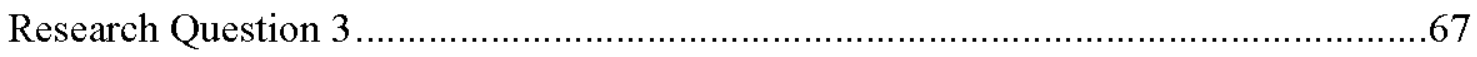

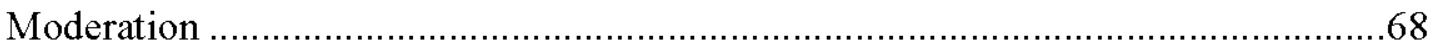

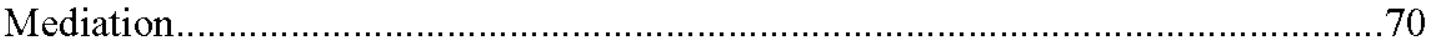

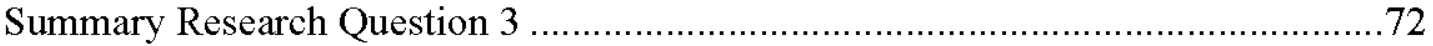

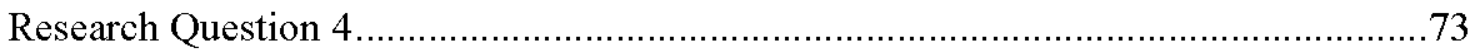

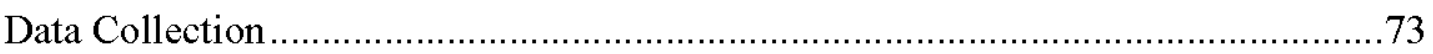


Analysis

Quality and Integrity.....

Categories and Themes.

Summary Research Question 4

Summary of Results

Statement of the Problem

Purpose of the Study

Review of the Methodology

Findings

Research Question 1

Research Question 2

Research Question 3

Research Question 4

Limitations

Implications

Recommendations for Future Research

Conclusions 
Appendix A Complete List of national Taxonomy of Exempt Entities (NTEE) Major

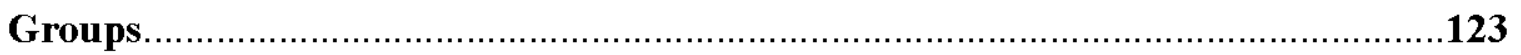

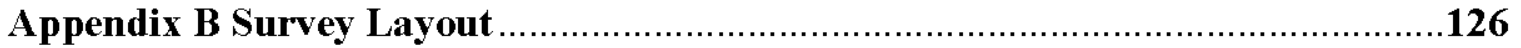

Appendix C Open-ended Question Codes and Frequencies .................................131 


\section{LIST OF TABLES}

Table 1: Organizational Types for NTEE major group (12)......................................13

Table 2: Variables - Type and Measurement ……………........................................30

Table 3: Scale and Subscale Reliability Scores for Instruments Used in the Survey ........34

Table 4: Survey Instrument Question Group Sequence................................................35

Table 5: San Diego Sector Comparison with Respondents' Organizations ......................45

Table 6: Comparison of Staff Level and Type of Organization by Agency and Sample ..46

Table 7: Total Gender and Gender Experiencing Toxic Supervision.............................53

Table 8: Respondents Who Worked for a Toxic Supervisor by Race/Ethnic Group ........54

Table 9: Highest Education Attainment of Respondents Who Worked for a Toxic

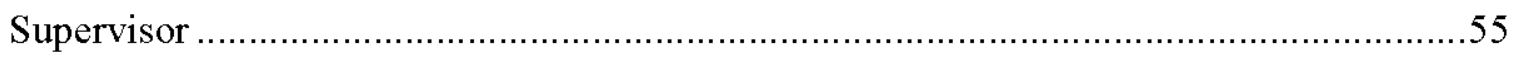

Table 10: Position Held While Working for a Toxic Supervisor ....................................56

Table 11: Comparison of San Diego Organization Categories with Total Agency Clients and Respondents Working for a Toxic Supervisor ....................................................57

Table 12: Toxic Supervision Scale Variable Items, Response Totals and Means .............58

Table 13: Cronbach's Alpha Values for Toxic Supervision, OCB Scale and Subscale

Variables

Table 14: Significant Models for the Outcome Variable OCB, OCB Subscales, and

Predictors Toxic Supervision and Toxic Subscales ..................................................64

Table 15: Results of the Moderation Regressions for the OCB Dependent Variable .......70 
Table 16: Manifest Category Frequencies and Codes

Table 17: Job Search Category Illustrative Comments............................................... 79

Table 18: Compensation Category Illustrative Comments ......................................... 80

Table 19: Career Management Category Illustrative Comments .................................. 81

Table 20: Latent Category Frequencies and Codes ............................................... 83

Table 21: Resilience and Lost Confidence Categories Illustrative Comments.................85

Table 22: Commitment Category Illustrative Comments ....................................... 86

Table 23: Organizational Citizenship Behavior Category Illustrative Comments ...........87 


\section{LIST OF FIGURES}

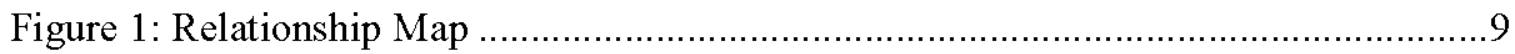

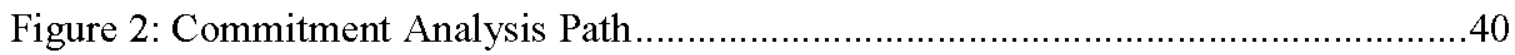

Figure 3: Toxic Supervision Variable Data Histogram from SPSS Output.....................49

Figure 4: Organizational Citizenship Behavior Variable Data Histogram from SPSS

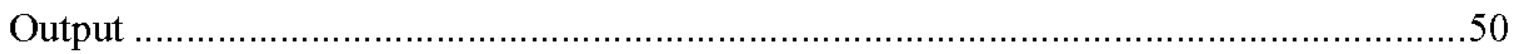

Figure 5: Commitment Variable Data Histogram from SPSS Output ...........................51

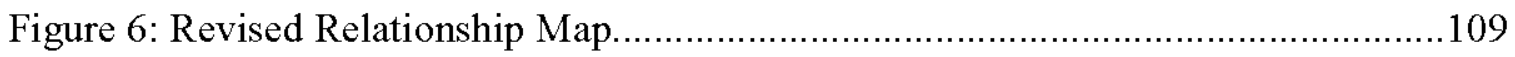




\section{Chapter 1: Introduction}

Nonprofit organizations support communities in myriad ways. During times of recession, like the 2008 downturn, these organizations see an increase in demand for services as well as a fall in funding from private, individual, government and investment sources (Head, 2003). Additionally, federal and state agencies have privatized some social service programs, contracting a large portion of it to nonprofit organizations (Feiock \& Andrew, 2006). While the government reimburses through contracts for those services, there are often other management costs incurred that were not previously experienced for the services provided, requiring other already strained funding sources to support that shortfall (Jang \& Feioch, 2007, p.6). As the recovery continues, charitable giving has been returning to prerecession levels (MacLaughlin, 2015). However, as during recession, and despite this recovery, nonprofit organizations need to continually reevaluate their work to provide services as effectively and efficiently as possible.

This type of innovation may challenge organizational purpose and mission. To embrace such risk-taking and innovation and to keep their organizations successful, employees require supportive leadership (Maak \& Pless, 2006). However, sometimes leadership may be unsupportive or even characterized as bad, destructive, or toxic. Toxic leadership undermines employees in many ways, stifling creativity and cutting-edge thinking, negatively impacting the organization in both the short and long term (Allen, Hitt \& Greer, 1982; Kellerman, 2004; Reed, 2004; Lipman-Blumen, 2005).

\section{Background}

Some leadership scholars argue that to ignore the negative, or toxic, side of leadership fails to address the whole of organizational leadership (Conger, 1990; 
Whicker, 1996; Kellerman, 2004). Toxic behaviors range from managerial incompetence to genocide (Conger, 1990; Ashforth, 1994; Whicker 1996; Kellerman, 2004; Reed, 2004; Hogan \& Kaiser, 2005; Lipman-Blumen, 2005). Most organizations, however, experience toxicity in a more limited way. For example, leaders are often psychologically and emotionally abusive, and/or threatening to the livelihood and social connectedness of the employees (Whicker, 1996; Kellerman, 2004; Lipman-Blumen, 2005; Einarsen, Aasland \& Skogstad, 2007). Toxic leaders also may torment subordinates to the detriment of the mission and long-term health and welfare of the people in it (Conger, 1990; Ashforth, 1994; Whicker, 1996; Kellerman, 2004; Reed, 2004; Hogan \& Kaiser, 2005; Lipman-Blumen, 2005; Einarsen, Aasland \& Skogstad, 2007; DeAngelis, 2009; Kusy \& Holloway, 2009; Reed \& Olsen, 2010). As a result, their behavior redirects employee efforts from the mission to self-protection and other unproductive behaviors (Harris, Kacmar \& Zivnuska, 2007). Not surprisingly, the harm employees suffer can devastate organizational success (Ashforth, 1994; Reed, 2004; Lipman-Blumen, 2005; Tepper, 2007; Reed \& Olsen, 2010).

Organizational success is usually measured by financial outcomes. However, nonprofits use a different business model that provides services and support instead of distributing profit (Koys, 2001; O’Niell, 2002). In light of that, measures of success need to focus on something other than the financial bottom line. Since leadership involves a relationship between followers and leader, the organizational success measures considered in this dissertation focused on followers. Two measures that use employee focused success measures are turnover and organizational citizenship behaviors (OCB) 
(Organ, 1997; Contino, 2002; Goetzel et al., 2003; Reed, 2004; Reed \& Bullis, 2009, Reed \& Olsen, 2010).

Toxic leader behaviors exhibited by supervisors or other organizational leaders decrease organizational citizenship behaviors (OCB) in for-profit employees, and contribute to higher turnover (Podsakoff, MacKenzie, Paine \& Bachrach, 2000; Zellars et al., 2002; Rafferty \& Restubog, 2011). However, the effect toxic behavior has on nonprofit professionals' turnover and organizational citizenship is not well documented.

Additionally, nonprofit professionals differ from their for-profit counterparts by their commitment to the work they do, often accepting lower pay and less favorable working conditions (Wittmer, 1991). This suggests that nonprofit employees' level of commitment may influence the effect of toxic leadership, lessening the impact it has on these two measures of organizational success. This influence has not been tested empirically.

\section{Statement of the Problem}

The nonprofit sector in San Diego County provides services to residents who might otherwise be without them in areas from health and education, to the arts and sports. Furthermore, nonprofits often serve the most vulnerable populations for basic needs such as food, shelter, and safety. In times of shrinking resources, nonprofit organizations need to be innovative and creative in how they continue to deliver services. While toxic leader behaviors have been shown to undermine organizational success in for-profits and public organizations, it is not well documented how, or even if, toxicity is related to San Diego nonprofit professionals and their organizations' success (Conger, 1990; Ashforth, 1994; Whicker, 1996; Kellerman, 2004; Reed, 2004; Hogan \& Kaiser, 
2005; Lipman-Blumen, 2005; Einarsen, Aasland \& Skogstad, 2007; DeAngelis, 2009; Reed \& Olsen, 2010). More specifically, there is no empirical evidence of the effect toxic leader behaviors have on nonprofit paid staff's organizational citizenship and turnover behaviors; nor, is there evidence of the influence their commitment to the organization may have on that relationship.

\section{Purpose of the Study}

The purpose of this concurrent mixed-methods study was to identify whether or not toxic leader behavior exists in San Diego nonprofits and, if it does, to measure the extent to which it occurs. This study also measured the effect of toxic leader behavior on nonprofit professionals' organizational citizenship and turnover behaviors, while also considering the influence of commitment on those relationships. Finally, it identified reasons individuals stay in an organization in spite of toxicity.

\section{Significance of the Study}

This study was an opportunity to obtain empirical evidence of the effect toxic leader behaviors have on two measures of employee focused organizational success OCB and turnover behavior. It also explored the influence of commitment on the effect of toxicity on paid staff's organizational citizenship and turnover behaviors. The information from this study may be used by Boards of Directors for organizational development, and for internal leadership development, as well as other types of organizations, such as educational institutions and consultant groups, for broader training and education. Such findings are of interest to leaders and managers of nonprofit organizations as they strive to recruit, retain and develop talented employees and volunteers. 


\section{Research Objectives and Questions}

The objective of this study was to explore the constructs of toxic leader behavior and its effect on the individual's OCB and intent to stay in the nonprofit organization. The hypothesis was that staff members in nonprofit organizations tend to stay in a nonprofit despite toxic leadership. Questions that address this objective are:

1. To what extent does toxic leader behavior exist in San Diego nonprofits?

2. To what extent does toxic leader behavior explain variation in both organizational citizenship behavior and turnover behavior in San Diego nonprofits?

3. Does level of commitment significantly mediate and/or moderate the effect of toxic leadership on both organizational citizenship behavior and turnover behavior in San Diego nonprofits?

4. What reasons do individuals give for remaining with a nonprofit organization despite toxic leadership in San Diego nonprofits?

\section{Conceptual Framework}

Toxic leadership includes managerial incompetence, threatening, controlling and illegal behaviors, and physical and non-physical abuse that are intentionally hostile or detrimental to both individuals and groups (Conger, 1990; Ashforth, 1994; Whicker 1996; Kellerman, 2004; Reed, 2004; Hogan \& Kaiser, 2005; Lipman-Blumen, 2005; DeAngelis, 2009; Kusy \& Holloway, 2009). At the nation-state and pseudo nation-state levels, toxic leaders occasionally commit atrocities including genocide (Kellerman, 2004). While incompetent leadership is not uncommon and incompetence often leads to toxicity, it is not by itself considered toxic for this dissertation. Moreover, assault and murder, even though part of the larger toxic leadership taxonomy, are not part of a 
normal work day in an American nonprofit. Therefore, this study focuses on individual and group manipulation, explicit and implied threats, and activities that undermine and create barriers to employee success that serve to intentionally intimidate, marginalize and degrade employees, causing them harm, and threatening the success of the organization, by their supervisors or organizational leadership.

\section{Demographic Measures}

Leete (2006) found that nonprofit employees tend to more often be white and female, with higher levels of educational attainment, than their for-profit and public sector counterparts. In the military, some findings indicate that despite higher levels of abusive leader behaviors, employees with greater seniority have lower turnover rates (Reed \& Bullis, 2009). Research also suggests that the mission focus, or type of organization, yields different staff member behavioral characteristics (Boris \& Steuerle, 2006). In 2010, a report found that the majority of San Diego nonprofit employees were in education, health, and human service organizations (Hitchcock, Deitrick, Cesarini, McDougal, Roberts \& Zinser, 2010). Therefore, type of organization was also included. Type of organization was based on the National Taxonomy of Exempt Entities that will be explained later (Urban Institute, 2013). Based on this research, this study included gender, age, race/ethnicity, level in organization and educational attainment as demographic variables.

\section{Measures of Organizational Success}

The harm toxic leadership can cause employees is an important issue from both the perspective of its effect on people and its impact on organizational success, both systemic and economic. Organizational outcomes, above and beyond the financial 
bottom line, can be affected by toxic leader behaviors. Therefore, as nonprofit organizations' missions provide services and support, other measures of success are needed (O’Neil, 2002). This study used two impact measures of employee focused organizational success: OCB and turnover (Koys, 2001).

Organizational citizenship behavior (OCB). Organizational Citizenship Behavior (OCB) includes those actions of one employee to another, or one group to another, that enhance the long-term productivity of the organization that are not considered part of the individual's or group's primary or contractual position requirements (Organ, 1997). High performing organizations look for this type of behavior in their employees (Hogan \& Kaiser, 2005). It has been found that it is increased by the belief that the leader is supportive (Smith, Organ \& Near, 1983). While successful organizations have employees who help each other and hold a positive attitude toward the organization, toxicity tends to quash these behaviors and attitudes (Zellars et al., 2002; Rafferty \& Restubog, 2011).

Turnover. Turnover is another measure of organizational success and is related to toxicity. Turnover is expensive for organizations in the short term outlays and can, in the long term, lower productivity further impacting revenue (Hinkins \& Tracey, 2000; Contino, 2002; Hillmer, Hillmer \& McRoberts, 2004; Kacmar, Andrews, Rooy, Steilberg \& Cerrone, 2006). Toxic leadership is associated with reduced morale and increased intention to leave (Steele, 2011), although Reed \& Bullis (2009) suggest that senior level managers are less inclined to exit an organization than those who are lower in the organizational hierarchy. Turnover is also associated with OCB in that lower OCB has been linked to increased turnover (Podsakoff, MacKenzie, Paine \& Bachrach, 2000). 


\section{Commitment}

Handy and Katz (1989) found that nonprofit employees accept less favorable employment conditions, such as lower pay, to work for a cause to which they feel strongly committed. An inverse relationship has been found between organizational commitment and turnover (Blau \& Boal, 1987; Allen \& Meyer, 1990). However, commitment's mediating influence on turnover intentions when the employee is faced with a toxic leader is not well established. This influencing effect may be important if it modifies the negative impact of toxicity since that negative impact could adversely impact organizations. Further, identifying whether or not commitment influences the effect of toxic leadership on OCB and turnover may be useful in finding improvements as yet unrecognized in the nonprofit sector.

\section{Summary}

The preceding discussion identified the effect of toxic leader behaviors normally found in U.S. organizations on two measures of organizational success related to individual employee attitude and activity: OCB and turnover behavior. Additionally, the influence of commitment to the organization on that effect was discussed. By better understanding the extent to which toxicity exists in San Diego nonprofit organizations and the impact of it on paid staff, actions can be taken to improve toxic situations that may lead to improvements in these organizations related to mission. These improvements may help to better serve the communities' needs with fewer resources. This study explored the effect of toxic leader behaviors on nonprofit paid staffs' OCB and turnover behavior, and the possible influence of commitment on those relationships. See Figure 1. 


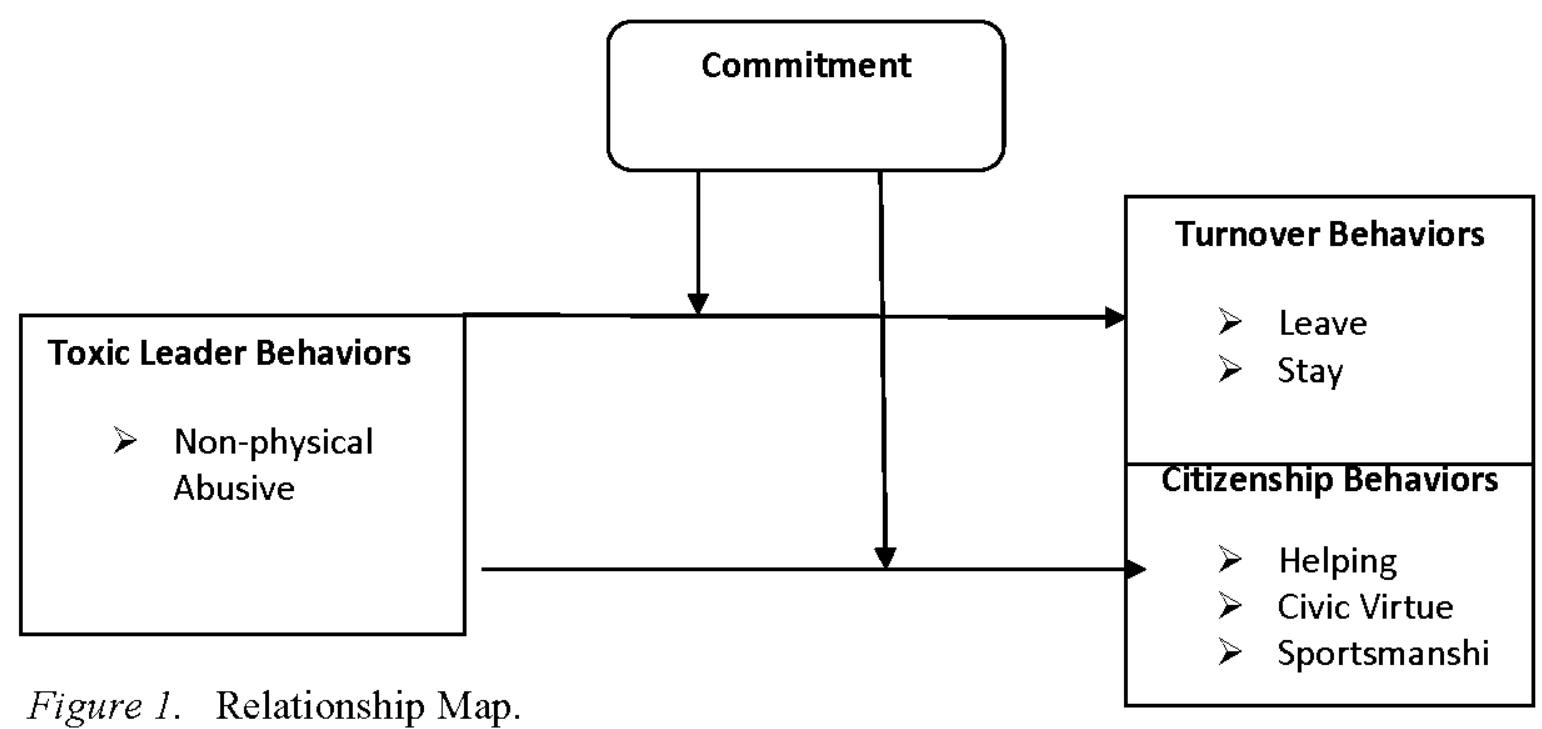

\section{Study Design}

This study used a concurrent cross-sectional mixed methods design intended to determine the degree to which toxic leadership exists in San Diego nonprofits, its effect on paid staff's organizational citizenship and turnover behaviors, and the influence of commitment on that effect. This design was chosen to address both the breadth and depth of this effect (Johnson \& Onwuegbuzie, 2004). It employed an electronic 63 item survey using scales for Toxic Leadership, Organizational Citizenship Behavior, and Commitment, a dichotomous question to address turnover, and an open-ended question to more deeply understand why people who work for a toxic leader stay in the organization. The sample consisted of San Diego nonprofit paid staff members whose organizations use a large San Diego human resources firm that provides personnel and training services. The client organizations represent some but not all categories of nonprofit organizations. Additionally, there was a small sample of a local nonprofit professional networking organization. 
Chapter 2: Review of the Literature

This chapter includes the literature regarding the key aspects of this dissertation.

The scale variables -- toxic leadership, organizational citizenship behavior (OCB), turnover behavior and commitment -- are discussed along with the included demographic variables and the nonprofit organization type or category variable. The relationships between some of these variables will also be explored.

\section{Introduction}

Research in the for-profit and government sectors has found a relationship between abusive leadership and organizational citizenship and turnover behaviors (Podsakoff \& MacKenzie, 1997; Zellars et al., 2002; Reed, 2004; Kusy \& Holloway, 2009; Eatough, Miloslavik, Chu-Hsaing, \& Johnson, 2011; Rafferty \& Restubog, 2011; Steele, 2011). Nonprofit employees specifically have been found to tend toward certain demographic characteristics more than in the other sectors. They tend to be more often white, female, and have higher levels of educational attainment than their for-profit and public sector counterparts (Leete, 2006). Research has also determined that the level of position the employee holds and amount of time the employee has in the organization influences turnover behavior. Reed and Bullis (2009) found that despite higher levels of abusive leader behaviors, employees with greater seniority turn over less frequently (Reed \& Bullis, 2009). Other research also suggests that the mission focus, or type of organization, yield different staff behavior characteristics (Boris \& Steuerle, 2006).

\section{Nonprofit Organizations}

The nonprofit sector in San Diego County provides residents with services in areas ranging from health and education, to the arts and sports. Furthermore, nonprofits 
often serve the most vulnerable populations for basic needs such as food, shelter, and safety. In times of shrinking resources, nonprofit organizations need to be innovative and creative in how they continue to deliver services. While the corporate sector measures financial success outcomes, the nonprofit business model measures mission effectiveness (Larkin, 2013). These measures vary by mission type (Herman \& Renz, 2008).

Internally, the context of the organization, its environment, mission, and staff characteristics determine personnel policies and procedures that will be effective in supporting the staff (Akingbola, 2012). Wilensky and Hansen (2001), found that nonprofit leadership considered some of the most important aspects of their job was to motivate staff within the context of the mission and to keep the organization on track, especially through organizational change. Additionally, they found that these leaders believed that removing obstacles in order for their staffs to better perform took a large part of their time. These reported leader activities are antithetical to toxic behaviors that de-motivate and raise barriers.

In general terms, there is some indication that nonprofit employees differ from for-profit employees in personality, values and behavior (Schepers, De Gieter, Pepermans, Du Bois, Caers \& Jegers, 2005). They also tend to differ in their individual demographics. For example, they tend to be white, female, and have higher levels of educational attainment than their for-profit and public sector counterparts (Leete, 2006). Moreover, nonprofit professionals have been found to accept lower pay and less favorable working conditions than in the for-profit sector in order to serve a cause to which they are committed (Wittmer, 1991). This is evidenced by findings that nonprofit employees are less likely to turnover under less than ideal circumstances than employees 
in other sectors (Blau \& Boal, 1987; Allen \& Meyer, 1990). Additionally, the mission focus, or type of organization, yields different staff behavior characteristics (Boris \& Steuerle, 2006).

The Internal Revenue Service assigns each nonprofit organization a category and accompanying code determined by its primary mission focus (Urban Institute, 2013). There are twenty-six codes based on the National Taxonomy of Exempt Entities (NTEE) (Urban Institute, 2013). See Appendix A for the complete list. These codes or categories are also parsed into larger groupings. These are called the NTEE major group (10) and major group (12) (Urban Institute, 2014). Table 1 shows the NTEE major group (12) categories. The difference between the groupings is that the Higher Education and Education categories are combined, as well as the Hospital and Health categories in the NTEE major group (10). 
Table 1

Organizational Types for NTEE major group (12)

NTEE Major Group (12)

Title of Major Group

$\begin{array}{ll}\text { AR } & \text { Arts, culture, and humanities } \\ \text { BH } & \text { Higher Education } \\ \text { ED } & \text { Education } \\ \text { EH } & \text { Hospitals } \\ \text { EN } & \text { Environment/Animals } \\ \text { EH } & \text { Health } \\ \text { HU } & \text { Human services } \\ \text { IN } & \text { International } \\ \text { MU } & \text { Mutual/member benefit } \\ \text { PU } & \text { Public and societal benefit } \\ \text { RE } & \text { Religion } \\ \text { UN } & \text { Unknown }\end{array}$

The major group (12) is used in this dissertation with some modification. In 2010, the Caster Family Center released a study on the local nonprofit sector. It modified the major group (12) combining hospitals with Health and separated Medical Research into its own category based on the impact and unique aspects of the local economy (Hitchcock, Deitrick, Cesarini, McDougal, Roberts \& Zinser, 2010). It also reported that the majority of San Diego nonprofit employees were in education, health, and human service organizations. 
Success for nonprofit organization is not determined by financial measures alone. Nonprofit employees have different characteristics than employees in other sectors. In light of these unique aspects of the nonprofit sector, the measures used in this dissertation for organizational success were organizational citizenship behavior and turnover because they focus on the employee, and the relationships of toxicity on these measures were evaluated using a measure of commitment.

\section{Organizational Success Measures}

There are compelling reasons to control abusive leadership, with some estimates that it costs U. S. business up to 23.8 billion dollars annually in lower productivity, higher turnover, absenteeism and legal costs (Tepper, Duffy, Henle \& Lambert, 2006). Abusive supervision lowers productivity, increases turnover, causes less favorable attitudes toward the job and organization in employees, and creates greater psychological distress in them (Tepper, 2000; Harris, Kacmar \& Zivnuska, 2007). The financial burden and decreased productivity organizations incur from abusive leadership suggests that it is important to identify if organizations have toxicity, to what extent it exists, and its consequences. Turnover and organizational citizenship (OCB) behaviors are measures of organizational success that focus on the employee's reactions and perspectives (Koys, 2001). This is more appropriate for a nonprofit study since nonprofit organizations do not distribute profit. Additionally, measuring success based on mission accomplishment is specific to each unique mission and varies prohibitively amongst organizations within the same categories, as well as, across different categories of nonprofits (Koys, 2001; O'Neil, 2002). Also, when considering organizational success in the face of toxic leadership, the influence of commitment is important. 


\section{Organizational Citizenship Behavior (OCB)}

Organizational Citizenship Behaviors (OCB) are actions between one employee and another, or one group to another that enhances the long-term productivity of the organization. A key element of OCB is that it is not a technical or contractual performance requirement (Organ, 1997). Specifically, OCB is behavior that helps coworkers, is courteous, and gives a good impression of the organization to outsiders (Zellars, Tepper \& Duffy, 2002). These behaviors are collaborative, helpful and supportive. The results are not always tangible but lead to increased organizational success (Organ, 1997). The help one employee gives another that results in the improved performance of the latter is a major component of OCB. Furthermore, OCB is done with no expectation for direct reward or compensation. High performing organizations look for this type of behavior in employees (Hogan \& Kaiser, 2005).

Some studies have found that the altruism of OCB is increased by the belief that the leader is supportive (Smith, Organ \& Near, 1983). However, employees have been found to exhibit less OCB under a toxic leader (Podsakoff \& MacKenzie, 1997; Zellars et al., 2002; Eatough, Miloslavik, Chu-Hsaing, \& Johnson, 2011; Rafferty \& Restubog, 2011). This is the crux of the problem. Successful organizations have employees who help each other and project a positive attitude of the organization, while toxicity undermines this; therefore, a negative impact on efficiency and effectiveness could be anticipated if colleagues are unwilling to help each other outside of explicitly delineated requirements. Despite no monetary cost being directly associated with lower OCB activity, its impact affects productivity that does relate to financial success. While 
successful organizations have employees who help each other and project a positive attitude of the organization, toxicity quashes these desired behaviors.

\section{Turnover}

Turnover occurs when employees leave an organization of their own volition (Lee, 2009). It is expensive for organizations in both dollar outlays and work degradation (Hinkins \& Tracey, 2000; Contino, 2002; Hillmer, Hillmer \& McRoberts, 2004; Kacmar, Andrews, Rooy, Steilberg \& Cerrone, 2006). For example, Reed (2004) found a relationship between decreased intent to stay with increased levels of toxic leadership. Steele (2011) associated reduced morale and increased intention to leave with toxicity. Kusy and Holloway (2009, p. 14) found 50 percent of those reporting experiencing toxicity with anyone in the organization contemplated leaving, while 12 percent actually did (Kusy \& Holloway, 2009, p. 14).

Turnover costs can be broken into two types. The first are the direct costs associated with staff time to process the employee's departure, then finding, interviewing, hiring, and training a new employee, and the costs associated with modifying technology for the new employee.

The second type of turnover costs are indirect and include lost productivity during the new person's learning period, supervisor time to deal with problems related to the learning period, other employees' time to support the new person (required support), and industry specific issues that affect customers and clients (Hinkins \& Tracey, 2000; Contino, 2002; Hillmer, Hillmer \& McRoberts, 2004; Kacmar, Andrews, Rooy, Steilberg \& Cerrone, 2006). For example, it can cost nearly $\$ 34,000$ to replace a nurse (Contino, 2002 ), and nearly $\$ 22,000$ to replace a retail call center customer service representative 
(Hillmer, Hillmer \& McRoberts, 2004). Considering that some industries have turnover as high as sixty percent annually (Hillmer et al., 2004), this becomes a significant part of the organization's budget.

To counter this, emphasis is being given to improving personnel programs to discourage turnover, especially in high turnover areas such as sales and service industries. Unfortunately, these programs focus on employee growth and development (Hinkins \& Tracey, 2000); but not apparently on decreasing abusive supervision. Moreover, there is an established relationship between turnover and Organizational Citizenship Behaviors (OCB).

Lower OCB has been linked to higher turnover (Podsakoff, MacKenzie, Paine \& Bachrach, 2000). However, nonprofit employees have been documented as accepting less favorable employment conditions such as lower pay to work for a cause to which they are committed (Handy \& Katz, 1989). In light of this, understanding commitment's influence on the relationship between toxic leadership and OCB and turnover is important since these behaviors impact the organizations' success. This possible mediating or moderating effect of commitment, underscores this unique dimension of nonprofit employees behavior.

\section{Commitment}

Commitment is the attitude that causes one to continue working in an organization in spite of an abusive or difficult environment that may be attributable to the type of mission or work of the organization (Blau and Boal, 1987; Handy \& Katz, 1998). It is associated with people giving greater effort to work activities without external incentives or threats (Goulet \& Frank, 2013). This suggests that nonprofit employees' commitment 
may influence the effect of toxic leadership, lessening the effect it has on turnover and OCB. Identifying this influence may be useful in improving performance in the nonprofit sector and ultimately improve service to nonprofit clients and communities. Before exploring the relationships between toxicity and organizational success, a review of the development and varying views and aspects of toxic leadership, or abusive supervision, is important to build the working definition used in this dissertation.

\section{Toxic Leadership}

Bad, toxic, abusive, destructive, incompetent, and unethical all enter the lexicon of toxic leadership. This makes any discussion of the subject confusing and limited by the constant debate about what does and does not constitute the construct in question. Moreover, some toxic leadership is global and violent (e.g. genocide), while other toxicity is nonviolent and frequently experienced in organizational life. Because of the variation in toxic behaviors, some attempts have been made to create taxonomies of toxic leadership such as Williams (2005), Schmidt (2008) and Pelletier (2009) that help define behaviors rather than the toxic leader profiles used by Whicker (1997) and Kellerman (2004). This teasing out of individual behaviors allows researchers to focus on those areas that are relevant to the population studied. For example, in a typical American company, physical abuse and murder are, fortunately, outside the scope of accepted or normal behavior.

\section{Background}

Toxic leadership concepts grew from major leadership theories and models, particularly the Transformational Leader Model. In this construct, the leader brings a vision of prosperity, develops strategies and tactics to animate the vision, and identifies, 
develops and motivates the team that will make the organization successful in its present and future environments (Burns, 1974; Western, 2008). This model focuses on the positive and successful aspects of leadership. Some, however, questioned the model's efficacy if it did not consider the negative side of leadership, as well (Whicker, 1996; Bass \& Steidlemeier, 1999; Kellerman, 2004).

The taxonomy of toxic or abusive leadership includes a broad variety of behaviors. Some believe managerial incompetence is toxic because it undermines organizational nimbleness and effectiveness (Conger, 1990; Whicker 1996; Kellerman, 2004; Hogan \& Kaiser, 2005). Most accept abusive and illegal behaviors as toxic. Generally, frequency and intentionality are included in the definition and hostility that directly and negatively impact individuals and groups is prevalent in the descriptions (Ashforth, 1994; Whicker, 1996; Kellerman, 2004; Reed, 2004; Lipman-Blumen, 2005). More recently, DeAngelis (2009) has focused on those toxic behaviors that are passive aggressive, identifying them as more commonly found in organizations. Some definitions include those behaviors found at the nation-state and pseudo nation-state levels, including genocide (Kellerman, 2004). Underlying these behaviors, toxic leadership causes harm to employees and negatively impacts organizational success (Ashforth, 1994; Lipman-Blumen, 2005; Tepper, 2007; Kusy \& Holloway, 2009). As can be seen from the varied behaviors mentioned above that are included in the toxic and abusive leadership literature, many organizations in the United States do not suffer with all of them. Murder and physical abuse are rarely, if ever, experienced. Additionally, managerial incompetence, while often coincidental with other toxic behaviors, is not considered by itself to be toxic for this dissertation. Therefore, this 
dissertation used abusive behaviors directed toward individuals and groups that manipulate them with explicit and implied threats, and act to undermine and create barriers. These behaviors intentionally intimidate, marginalize and degrade the employees, causing them harm, as well as threatening the success of the organization. They will be discussed below in more detail.

\section{Toxic Leadership}

Abusive leaders blame, divide, marginalize, undermine, and intimidate employees (Whicker, 1996; Kellerman, 2004; DeAngelis, 2009; Kusy \& Holloway, 2009). They torment their subordinates to the detriment of both the mission and people, undermining a positive organizational climate (Conger, 1990; Ashforth, 1994; Whicker, 1996;

Kellerman, 2004; Reed, 2004; Hogan \& Kaiser, 2005; Lipman-Blumen, 2005; Einarsen, Aasland \& Skogstad, 2007; Reed \& Olsen, 2010). Their behaviors create an environment that builds walls, and crushes creativity and loyalty. Not surprisingly, incivility from anyone, leader or colleague, has been found to impact productivity. For example, Kusy and Holloway (2009, p. 14) found that 50 percent of those who experienced incivility reported spending time worrying about it instead of working, and 25 percent explicitly said they cut back their work activity (p. 14). These responses suggest that long term toxicity can and often does decrease creativity and innovation. This is what toxicity can do, but what do toxic leaders do to be toxic?

Abusive supervisors discipline arbitrarily and enforce unreasonable standards. They intimidate and marginalize their subordinates who, in response, prioritize safety over productivity (Ashforth, 1994; Whicker, 1996; Kellerman, 2004; Reed, 2004; Lipman-Blumen, 2005; Reed \& Olsen, 2010). In their attempts to maintain control, they 
create out-groups and scapegoats to take the blame for any and all problems (Conger, 1990; Ashforth, 1994; Whicker, 1996; Kellerman, 2004; Lipman-Blumen, 2005).

Supervisors can be arrogant and autocratic, exhibiting varying degrees of emotional instability that undermine a positive organizational climate (Conger, 1990; Ashforth, 1994; Whicker, 1996; Lipman-Blumen, 2004; Kellerman, 2005; Reed, 2004; Hogan \& Kaiser, 2005; Einarsen, Aasland \& Skogstad, 2007; Kusy \& Holloway, 2009; Reed \& Olsen, 2010). Public verbal abuse, withholding praise or support, and vindictiveness are common toxic leader behaviors (Tepper, 2007). This type of leader undermines employees for their own self-interest.

Toxic leaders use out-groups and scapegoats to blame for any and all problems and maintain control, and in so doing maintain power (Conger, 1990; Ashforth, 1994; Whicker, 1996; Kellerman, 2004; Lipman-Blumen, 2005). Toxic leaders may also disregard the needs and wants of outsider groups while supporting their in-group (Conger, 1990; Kellerman, 2004; Pelletier, 2009). People are either with them or against them, and those against them are actively punished (Whicker, 1996). Worse, they work on having their group coalesce around fighting other groups (Conger, 1990). These situations distract people from their work. These toxic leaders are punishment-oriented, and cannot separate their personal feelings from professional matters (Whicker, 1996; Kellerman, 2004).

Toxic leaders manipulate, identifying and appealing to the needs of their supporters who may have been hired for their loyalty rather than their capabilities. This, in turn, keeps their supporters loyal, spending their time infighting, living in an 
environment of mistrust. People are kept occupied fighting each other and trying to protect themselves, rather than taking care of the business of the organization.

Toxic leaders maintain a chokehold on information, and they either subvert or change the systems in place to regulate power such as hiring and firing practices, bringing in cronies and incompetent supporters to imbue loyalty and fear. The toxic leader becomes increasingly focused on loyalty and conformity, discouraging followers from informal interaction and association. They create fear by insisting the organization is under siege and survival depends on followers' loyalty. This is why it is important for this type of leader to maintain a tight control over the flow of information. Rarely do the facts support their hyperbole. As this behavior progresses, the leader's attempts to maintain power expand throughout the organization (Whicker, 1996). This process helps to stifle criticism and effectively eliminate dissent, initiative and creativity (Conger, 1990; Ashforth, 1994; Lipman-Blumen, 2005; DeAngelis (2009; Kusy \& Holloway, 2009).

Conflict avoidance is also an observed trait. It may seem contradictory for an abusive person to be conflict avoidant, but this is particularly expressed in the passive aggressive toxic leader literature. Instead of confronting people, they marginalize and intimidate to suppress any conflict, inflating their own egos and reputations. They also tend to over task their best employees with no intention of rewarding them, then taking credit for the good work. They are intentionally disrespectful to assert their power, enjoying petty devices such as coming very late to meetings they scheduled (DeAngelis, 2009). Kusy and Holloway (2009) found these types of behaviors at all levels of organizations and among the most reported (p. 218). 


\section{Impact}

Toxic leadership represents patterns of behavior that intentionally intimidate, marginalize and degrade employees, and threaten the organization's success. The degree to which employees are ill affected by abusive supervision varies from person to person. Many factors influence one's response to toxicity such as personality and individual situation (Tepper, Duffy \& Shaw, 2001). Systemic toxic leadership undermines organizational cohesion (Ashforth, 1994; Reed \& Olsen, 2010). Interestingly, Tepper (2007) found that victims become more resistant to direction on the job, show more aggressive behavior to fellow employees, and even experience problems in their family life (p. 279). Two measures of organizational success: organizational citizenship behavior (OCB) and turnover are both affected by toxic leader behaviors, and they are success measures that focus on employees instead of financials or production line activity (Koys, 2001).

Goulet and Frank (2013) found that commitment is associated with people giving greater effort to work activities. There is an inverse relationship between organizational commitment and turnover, and a direct relationship between OCB and commitment (Blau \& Boal, 1987; Allen \& Meyer, 1990; Meyer, Stanley, Herscovitch \& Topolnytsky, 2002). This may suggest that nonprofit employees' commitment could influence the effect of toxic leadership, lessening the effect it has on turnover and OCB (Goulet \& Frank, 2013).

\section{Summary}

Toxic leader behaviors range from incompetence to genocide (Kellerman, 2004). Despite this expansive list of behaviors, most organizations experience toxicity in a more limited way. Such leader behaviors are psychologically and emotionally abusive, and/or 
threatening to the livelihood and social connectedness of the employees (Whicker, 1996; Kellerman, 2004; Lipman-Blumen, 2005; Einarsen, Aasland \& Skogstad, 2007). Toxic leaders torment subordinates to the detriment of the mission and the long-term health and welfare of the people in it (Conger, 1990; Ashforth, 1994; Whicker, 1996; Kellerman, 2004; Reed, 2004; Hogan \& Kaiser, 2005; Lipman-Blumen, 2005; Einarsen, Aasland \& Skogstad, 2007; DeAngelis, 2009; Reed \& Olsen, 2010). Their behavior redirects employee efforts from the mission to self-protection and other unproductive behaviors (Harris, Kacmar \& Zivnuska, 2007). The harm to employees caused by toxic leadership can also devastate mission success by reducing OCB and increasing turnover (Ashforth, 1994; Podsakoff, MacKenzie, Paine \& Bachrach, 2000; Zellars, Tepper \& Duffy, 2002; Reed, 2004; Lipman-Blumen, 2005; Tepper, 2007; Reed \& Olsen, 2010; Rafferty \& Restubog, 2011).

Turnover and OCB are two measures of organizational success focused on employees rather than financials. Lower OCB has been linked to increased turnover (Podsakoff, MacKenzie, Paine \& Bachrach, 2000). Commitment may mitigate the effect of toxicity on OCB and turnover in light of the fact that nonprofit employees have been found to accept poorer working conditions in order to work for their chosen cause. 
Chapter 3: Methodology and Procedures

This chapter discusses the concurrent cross-sectional mixed-methods research design used to address the objectives and questions of this study. The research tools, sample, and data collection and analysis methods are presented. Additionally, methods to provide evidence in support of the validity and reliability of the research instrument will be described. Finally, the study's limitations will be explained.

\section{Research Objectives and Questions}

The objective of this study was to explore the constructs of toxic leader behavior and its effect on the individual's organizational citizenship behavior (OCB), and the individuals' intent to stay in that nonprofit organization. The overarching hypothesis was that staff members in nonprofit organizations stay in a nonprofit despite toxic leadership. Questions that address this objective are:

1. To what extent does toxic leader behavior exist in San Diego nonprofits?

2. To what extent does toxic leader behavior explain variation in both organizational citizenship behavior and turnover behavior in San Diego nonprofits?

3. Does level of commitment significantly mediate and/or moderate the effect of toxic leadership on both organizational citizenship behavior and turnover behavior in San Diego nonprofits?

4. What reasons do individuals give for remaining with a nonprofit organization despite toxic leadership in San Diego nonprofits?

\section{Design}

While there is much discussion around the value and validity of mixed methods design, the past 15 years have shown that these types of designs are appropriate for many 
research studies in the social sciences (Johnson \& Onwuegbuzie, 2004; Creswell \& Clark, 2011). For this study, a concurrent cross-sectional mixed-methods research design was chosen for its flexibility and applicability to complex questions in which there is a desire to "drill down" into one aspect of a study, while also addressing more general relationship questions (Mazzola, Walker, Shockley \& Spector, 2011). Specifically, the relationships between toxic leadership, and OCB and turnover behavior were examined for the effect of toxicity on organizations and employees; while the reasons employees stay in an organization in spite of toxic leadership was simultaneously evaluated using both quantitative and qualitative methods. These methods included descriptive statistics, content analysis, a partial path analysis to determine if commitment influences the relationship between toxic leadership and OCB and turnover behavior, and multiple regression analysis to determine correlations among the variables of interest.

\section{Population and Sample}

San Diego County is home to over 75,000 paid nonprofit employees in nearly 2,000 nonprofit firms (Hitchcock, Deitrick, Cesarini, McDougal, Roberts \& Zinser, 2010). This study used a convenience sample of San Diego nonprofit employees whose organizations use a San Diego human resources firm that provides personnel and training services. The firm agreed to send the survey via email to their client organizations' staffs. There were approximately 3,500 organizations and 5,507 paid staff in the client base. Additionally, a local nonprofit professional networking organization agreed to allow the survey to be sent to members of its listserv. There was no further information on the listserv or membership except that there were approximately 3,000 e-mail addresses. 
There is a large taxonomy for the various types of nonprofits referred to as the National Taxonomy of Exempt Entities (National Center for Charitable Statistics, 2013). This taxonomy includes twenty-six major categories and as many as forty-eight subcategories. The final sample was described by, and compared to, the organization populations' demographics to determine representativeness.

Even though this was a convenience sample, the type of organization the respondents were employed in at the time of the toxicity was captured. This allowed a comparison of the prevalence of toxicity by organizational type and share of the population of client organizations of the agency, as well as the population of San Diego charities. From this, the discussion notes whether the respondents' organizations tended to be from certain agency taxonomies, or whether they represented the client-base of both the management company and San Diego County, as a whole.

The Internal Revenue Service assigns each nonprofit organization a category and accompanying code determined by its primary mission focus (Urban Institute, 2013). There are twenty-six codes based on the National Taxonomy of Exempt Entities (Urban Institute, 2013). See Appendix A for the complete list. These codes or categories are also parsed into larger groupings. These are called the NTEE major group (10) and major group (12) (Urban Institute, 2014). Table 1 shows the NTEE major group (12) categories. The difference between the groupings is that the Higher Education and Education categories are combined, as well as the Hospital and Health categories in the NTEE major group (10).

In 2010, the Caster Family Center at the University of San Diego released a study on the local nonprofit sector. It modified the major group (12) combining Hospitals with 
Health (like the major group (10) and separated Medical Research into its own category based on the impact on the local economy (Hitchcock, Deitrick, Cesarini, McDougal, Roberts \& Zinser, 2010). It also reported that the majority of San Diego nonprofit employees were in education, health, and human service organizations. Therefore, in this dissertation, the major group (12) categories were modified to include Medical Research as a separate category and eliminated the Unknown category because the respondents knew their type of organization.

\section{Sample Size and Power}

The sample primarily consisted of San Diego nonprofit paid staff whose organizations used a large San Diego human resources firm that provides personnel and training services, and a small group of respondents from San Diego nonprofit professional networking group. The human resources firm's client organizations represent some, but not all of the categories of nonprofit organizations.

Sample size was calculated to meet the needs of each of the analytic techniques. Initially sample size was calculated to achieve 95 percent confidence level, five percent sampling error, a conservative $50 / 50$ split on the proportion of the population expected to select any one of the responses, and an approximate known sample size of 7,000 (Fault, Erdefelder, Buchner, \& Lang, 2009). Adding 20 percent for loss, the required sample size to conduct the multiple regression analysis was 385 respondents.

The minimum sample size for the regression analysis was calculated to be 131 considering a 20 percent loss factor with 80 percent power, a medium effect size and including eight independent or predictor variables (See Table 1). The empirical power tables as described by Fritz and MacKinnon (2010) were used to determine an 
appropriate sample for the mediation and moderation analysis. Based on this, a sample size of at least 405 responses was required. Additionally, 20 percent loss was included requiring at least 505 responses. Since one dependent or outcome variable was dichotomous (Turnover), a sample size was also determined for the logistic regression. Referencing Faul, Erdefelder and Lang's G*Power 3.1 (2009), the logistic regression sample size was 522, again including a 20 percent loss factor. Therefore, 522 responses were needed to conduct all aspects of the design's analysis. All sample requirements were met except for the logistic model with 471 responses to the survey. Bootstrapping, addressed later in Chapter 4, was used to determine if the logit regression would become significant; however, it turned out not to be.

\section{Measurement Methods}

Ten variables were used to address the research questions. All demographic variables except age were categorical (Gender, Level in Organization, Highest Level of Education at Time of Experience, Type of Organization) and were selected because they were identified in the literature as being statistically significant with at least one of the latent variables used in this study. These latent variables -- Commitment, OCB and Toxic Leadership - were measured using Likert-type response scales. Finally, the variable Turnover was addressed with a dichotomous (Yes/No) question. Table 2 describes these variables and the ways that they were measured. 
Table 2

Variables - Type and Measurement

\begin{tabular}{|c|c|c|c|c|}
\hline & Variable & Type & $\begin{array}{l}\text { Level of } \\
\text { Measurement }\end{array}$ & How Measured \\
\hline 1 & $\begin{array}{l}\text { Age at Time of } \\
\text { Experience }\end{array}$ & Independent/Demog/Covariate & Categorical & $\begin{array}{l}\text { Questionnaire } \\
\text { Item }\end{array}$ \\
\hline 2 & Gender & Independent/Demog/Covariate & Categorical & $\begin{array}{l}\text { Questionnaire } \\
\text { Item }\end{array}$ \\
\hline 3 & $\begin{array}{l}\text { Level in } \\
\text { Organization at } \\
\text { Time of } \\
\text { Experience }\end{array}$ & Independent/Demog/Covariate & $\begin{array}{l}\text { Categorical/ } \\
\text { Ordinal }\end{array}$ & $\begin{array}{l}\text { Questionnaire } \\
\text { Item }\end{array}$ \\
\hline 4 & Age Now & Independent/Demog/Covariate & $\begin{array}{l}\text { Categorical/ } \\
\text { Ordinal }\end{array}$ & $\begin{array}{l}\text { Questionnaire } \\
\text { Item }\end{array}$ \\
\hline 5 & $\begin{array}{l}\text { Highest Level of } \\
\text { Education at Time } \\
\text { of Experience }\end{array}$ & Independent/Demog/Covariate & $\begin{array}{l}\text { Categorical/ } \\
\text { Ordinal }\end{array}$ & $\begin{array}{l}\text { Questionnaire } \\
\text { Item }\end{array}$ \\
\hline 6 & $\begin{array}{l}\text { Type of } \\
\text { Organization }\end{array}$ & Independent/Demog/Covariate & $\begin{array}{l}\text { Categorical/ } \\
\text { Interval }\end{array}$ & $\begin{array}{l}\text { Questionnaire } \\
\text { Item }\end{array}$ \\
\hline 7 & Toxic Supervision & Independent/Latent variable & Ordinal/Interval & $\begin{array}{l}\text { Questionnaire } \\
\text { Subscales } \\
\text { Likert items }\end{array}$ \\
\hline 8 & $\begin{array}{l}\text { Intent to Stay at } \\
\text { Time of } \\
\text { Experience }\end{array}$ & Dependent/Manifest variable & $\begin{array}{l}\text { Categorical } \\
\text { (Binomial) }\end{array}$ & $\begin{array}{l}\text { Questionnaire } \\
\text { Item }\end{array}$ \\
\hline 9 & $\begin{array}{l}\text { Organizational } \\
\text { Citizenship } \\
\text { Behavior }\end{array}$ & Dependent/Latent variable & Ordinal/Interval & $\begin{array}{l}\text { Questionnaire } \\
\text { Subscales } \\
\text { Likert items }\end{array}$ \\
\hline 10 & Commitment & Independent/Latent variable & Ordinal/Interval & $\begin{array}{l}\text { Questionnaire } \\
\text { Subscales } \\
\text { Likert items }\end{array}$ \\
\hline
\end{tabular}

\section{Data Collection Process}

After receiving Institutional Review Board (IRB) approval, potential participants were approached via an invitational email sent out by either the human resources (HR) organization or through the networking organization's listserv. Each email included the 
study's purpose, risks, benefits, informed consent and contact information for the Principle Investigator (PI) and the PI's dissertation advisor. Consent was granted by the respondent indicating on the survey their consent was given and then by submitting the survey. This means of giving consent was explained both in the email and on the survey, itself. The survey was accessed through a link in an introductory email that asked the recipient to participate, explaining the value of the study to both them and the larger San Diego nonprofit community. An electronic survey was chosen over a paper format in consideration of both time and cost constraints. While Lin and Van Ryzin (2012) note a consistently lower response rate from electronic surveys over paper, the sample was sufficiently large to anticipate an acceptable response rate.

Coding and Scoring. Toxic Supervision, Commitment and OCB used 7 point Likert-type response scales. The item response scores were totaled with no weighting to create variable scores. Commitment had six reverse coded items and OCB had three all of which were handled in SPSS.

The qualitative question was manually coded and diagramed using Atlas.ti qualitative analysis software. A priori codes were developed using the major constructs from the non-physical abusive toxic leadership and turnover literature. Additionally, open coding techniques were used to identify reoccurring codes and eventually themes (Glesne, 2005).

Latent content analysis was used to discover the underlying themes and meanings of the coded words and phrases included the building of conceptual maps or networks to visualize the findings (Hsieh \& Shannon, 2005). These networks provided a structure for the analysis of relationships between codes, quotations, and concepts (Patton, 2002; 
Creswell, 2009). The a priori codes included commitment since the study explored commitment's impact on the relationship between toxicity, as well as, turnover and OCB.

Manifest content analysis included the counting of codes, quotations, and concepts (Hsieh \& Shannon, 2005). Frequency distributions were reported showing the number of times coded words and phrases appeared in order to help understand the importance of both words and phrases.

\section{Instrumentation}

While discussions of toxic leadership and its components have been ongoing, scale measures have been developed more recently such as those offered by Ashforth (1994), Tepper (2000), Schmidt (2008), Pelletier (2009) and Shaw, Erickson and Harvey (2011). Particularly, Shaw, Erickson and Harvey developed an instrument to identify and measure destructive leadership in organizations that purposefully and comprehensively addresses the diversity of toxicity as informed by Kellerman (2005) (Shaw, Erickson \& Harvey, 2011). It was the most comprehensive measurement instrument found to deal with each aspect of toxic leader behavior defined in this study. As such, the toxic supervision variable was formed from six subscales of the Shaw, Erickson and Harvey (2011) Destructive Leadership Questionnaire. See Table 3 for the scales used and their reliability scores, Table 4 for question sequence, and Appendix B for the layout of the survey. The subscales conform to Cronbach's alpha criteria for reliability (Santos, 1999) in that five of the factors had an alpha above .8, while one was .75 (p. 581-583). Since the instrument was developed three years ago it conforms to the .7 or above threshold for newer instruments. 
Organizational Citizenship Behavior was measured using the Podsakoff, Ahearne and MacKenzie (1997) instrument, the OCB Measure, with three scales: Helping Behavior, Civic Virtue, and Sportsmanship, with each using a 7-point Likert response scale. Sportsmanship was reverse coded. The reliability scores reported in the literature for these three scales are $.95, .96$ and .88 respectively (Podsakoff, Ahearne \& MacKenzie, 1997, p. 266).

Commitment was measured using The Organizational Commitment Questionnaire (Mowday, Steers \& Porter, 1979) consisting of fifteen questions with six reverse-coded using a 7-point Likert response scale. Because the instrument was developed using multiple samples, the reliability scores ranged from .82 to .93 with a median of .90 (p. 232).

A dichotomous question that addressed whether or not the respondent remained in the organization despite working for a toxic leader identified those who chose to remain in the organization despite the existence of toxicity. The sorting question was "Were you ever treated in a manner that caused you to seriously consider leaving the organization?" (Reed \& Olsen, 2010). If the respondent answered "yes" then they were asked "Did you leave?" If "yes" then they skipped to the next section of the survey. If the answer was "no" they moved to the open-ended question. The open-ended question asked respondents to describe and explain why they stayed despite working for a toxic leader. "Please explain in as much detail as possible why you decided to remain in the organization?"

The survey also included demographic variables that the literature indicated influenced the impact of toxicity on OCB and turnover. They were gender, 
race/ethnicity, type of organization, age, level or position in the organization, time since the experience, and highest level of education attained (Boris \& Steurle, 2006; Leete, 2006).

The toxic leadership, organizational citizenship, turnover and commitment items were asked as either recollection questions or based on the respondent's present situation. If it was a recollection question for the respondent, an inclusive time boundary of 24 months was used to minimize recall bias. The directions at the beginning and throughout the survey reiterated this time boundary.

Table 3

Scale and Subscale Reliability Scores for Instruments Used in the Survey

Instrument $\quad$ Factor Name $\alpha$

Destructive Leadership Questionnaire (Shaw, Erickson \& Harvey, 2011, p. 581)

Destructive Leadership Questionnaire (Shaw, Erickson \& Harvey, 2011, p. 581)

Micro-managing and Over

Destructive Leadership Questionnaire (Shaw, Erickson \& Harvey, 2011, p. 582)

Playing Favorites and Other Divisive $\quad .91$ Behavior

Destructive Leadership Questionnaire (Shaw, Erickson \& Acting in an Insular Manner Relative .75 Harvey, 2011, p. 582) to Other Groups in the Organization

Destructive Leadership Questionnaire (Shaw, Erickson \& An Inconsiderate Tyrant

Harvey, 2011, p. 583)

Destructive Leadership Questionnaire (Shaw, Erickson \& Harvey, 2011, p. 581)

Organizational Commitment Questionnaire (Mowday, Smith \& Porter, 1979, p.232)

Lying and Other Unethical Behavior $\quad .96$

Median of all 12 samples

Organizational Citizenship Behavior Measure

Helping

(Podsakoff, Ahearne \& MacKenzie, 1997, p. 266)

Organizational Citizenship Behavior Measure

Civic Virtue

(Podsakoff, Ahearne \& MacKenzie, 1997, p. 266)

Sportsmanship 
As noted above, Table 4 indicates the sequence of variable items in the survey instrument. The toxic items were immediately after the demographic variables because only those respondents who indicated in the sorting question that they had worked for a toxic supervisor answered them. Those who indicated they did not were sent to organizational citizenship and commitment items. Respondents who had worked for a toxic supervisor answered the OCB and commitment items after the turnover question positioned at the end of the toxic scale items.

Table 4

Survey Instrument Question Group Sequence

Variables $\quad$ Range and Order in Survey Instrument

Demographic variables

$1-7$

Toxicity scales

Turnover

Organizational Citizenship Behavior

$36-48$

Commitment

$49-63$

\section{Analysis}

Descriptive statistics, multiple regression, a partial path analysis to determine influence, and content analysis were used to explore the constructs of toxic leader behavior and its effect on the individual's OCB and intent to stay in their nonprofit organization (Meyers, Gamst \& Guarino, 2006). Additionally, the psychometric characteristics of each instrument based on the responding sample are presented. For a 
variable to be considered statistically significant, the $p \leq .05$ level is used throughout the analysis.

The objective of this study was to explore the constructs of toxic leader behavior and its effect on the individual's organizational citizenship behavior, and intent to stay in that nonprofit organization. The specific analytical tools used to address each research question are described below.

Research Question 1. To what extent does toxic leader behavior exist in San Diego nonprofits?

Analysis began with a description of each variable and an evaluation for normality. The frequency distribution for the toxic leadership, OCB and Commitment variables were run and visually inspected to determine data normality; additionally, the skewness and kurtosis statistics were run and evaluated. The variables were considered to have reasonably normal distributions. To answer Research Question 1, the level of toxicity was determined by evaluating the mean, mode and quartiles of the toxic leader scale variable, and the means of 25 items of the toxic supervisor scale variable.

Additionally, a comparison was made to Shaw's, Erickson's and Harvey's (2011) findings.

Since these authors evaluated each item's mean, the means of each item that comprised the toxic leader variable in this study were also calculated. The previous study only reported the highest and lowest means, so those were compared to the highest and lowest item mean for the toxic leader behavior variable in this study. The means were found to be higher in this study, which was understandable since only those people who 
self-identified as working for an abusive supervisor responded, while the previous study included anyone, regardless of whether or not they felt they had worked for a toxic boss. Research Question 2. To what extent does toxic leader behavior explain variation in both organizational citizenship behavior and turnover behavior in San Diego nonprofits?

For the relationship between toxic leadership and $\mathrm{OCB}$, multiple linear regression was used to estimate the model because there was not enough available literature to suggest appropriate ordering of the variables for sequential regression. Multicollinearity, which exists when two predictor variables are highly correlated, was examined through a two-step process (Meyers, Gamst \& Guarino, 2006, p. 180). To ensure this was not occurring with Toxic Leadership Behavior, Commitment and OCB, simple correlations were run and any coefficient of .9 or greater was considered for elimination (Tabnachik \& Fidell, 2001, p. 84). Secondly, tolerance and variance inflation factors (VIF) was run to identify any tolerance value greater than 10 (Meyers, Gamst \& Guarino, 2006, p. 212). Fortunately, there were none, indicating that the independent variables were not measuring the same things.

Pearson correlations with the dependent variable and the covariates, as well as Beta coefficients were used to evaluate the contributions of each variable to the regression model. While predictor variables should not be too highly correlated so they are not measuring the same thing, they should also be significantly related to the dependent variable. Therefore, Bartlett's test for sphericity was used to determine if there was sufficient correlation between the variables in the model. R-square and an F-test 
determined the explanatory capacity of the variables (Tabnachik \& Fidell, 2001, Miles \& Shevlin, 2010).

For the relationship between toxic leadership and turnover, a logistic regression model was used; this was required because the dependent variable, turnover, was the dichotomous response (yes/no) to the question: "Did you leave?" (Tabachnik \& Fidell, 2001; Miles, Shevlin, 2010). For this variable, No served as the reference category.

A goodness of fit Chi Square test was also used to identify if the model could sufficiently explain the relationship of the variables. Operationally, this process first finds the sum of the predicted and actual probabilities that the respondent will turnover for each case. These sums are added together for each model giving a log-likelihood for the model. In this case, the larger model consisted of the predictor variable (Toxic Leadership Behavior) and the smaller model was the intercept only model. In order for the log-likelihood to behave like a chi square, the intercept only model is subtracted from the predictor model (Tabachnik \& Fidell, 2001, p. 525).

To further determine the validity of the model, the percentage of variance of the dependent variable explained by the independent variable was examined using both the Cox and Snell, and Nagelkerke tests (Meyers, Gamst \& Guarino, 2006, p. 239). In addition, a Wald test was used to determine the contribution of each covariate to the model (Meyers, Gamst \& Guarino, 2006).

Research Question 3. Does level of commitment significantly mediate and/or moderate the effect of toxic leadership on both OCB and turnover behavior in San Diego nonprofits? 
A moderator variable influences the relationship between a covariate and the dependent variable in two ways. It may influence the degree of the relationship between the variables (strength) or change which variable effects the other (direction) (Baron \& Kenny, 1986). For example, an employee may think about leaving an organization because of toxic leader behavior, but decide to stay because of commitment. In order to determine if the commitment variable had a moderating influence on the effect of toxicity on turnover behavior, correlations were examined. Baron and Kenny (1986) suggest that the interaction of the predictor and moderator variables should be correlated to the outcome variable, but the moderator and predictor variables separately should not be significantly correlated to the outcome variable. To the extent that these relationships exist, four regression models were evaluated:

- The effect of the predictor variable (toxic supervision) on the outcome variable (turnover or $\mathrm{OCB}$ )

- The effect of the moderator variable (commitment) on the outcome variable (turnover or $\mathrm{OCB}$ )

- The effect of the interaction of the predictor (toxic supervision) and the moderator (commitment) together on the outcome variable (turnover or OCB)

- The effect of the interaction term, the moderator and predictor on the outcome variable (turnover or OCB) (Baron \& Kenny, 1986).

A mediator variable influences the effect of the covariate on the dependent variable because of some aspect of the respondent; the how and why of the variable relationship (Baron \& Kenny, 1986). For example, commitment might mediate the effect of toxicity on turnover so that an employee would not leave the organization, despite 
experiencing toxic leader behaviors. To test for mediation, a partial path analysis was used. As recommended by Baron and Kenny (1986, p. 1177), three regressions were run to show that 1) the Independent Variable (IV) or predictor variable effects the mediator; 2) the predictor affect the dependent variable (DV) or outcome variable; and, 3) the mediator affects the outcome variable. See Figure 2.

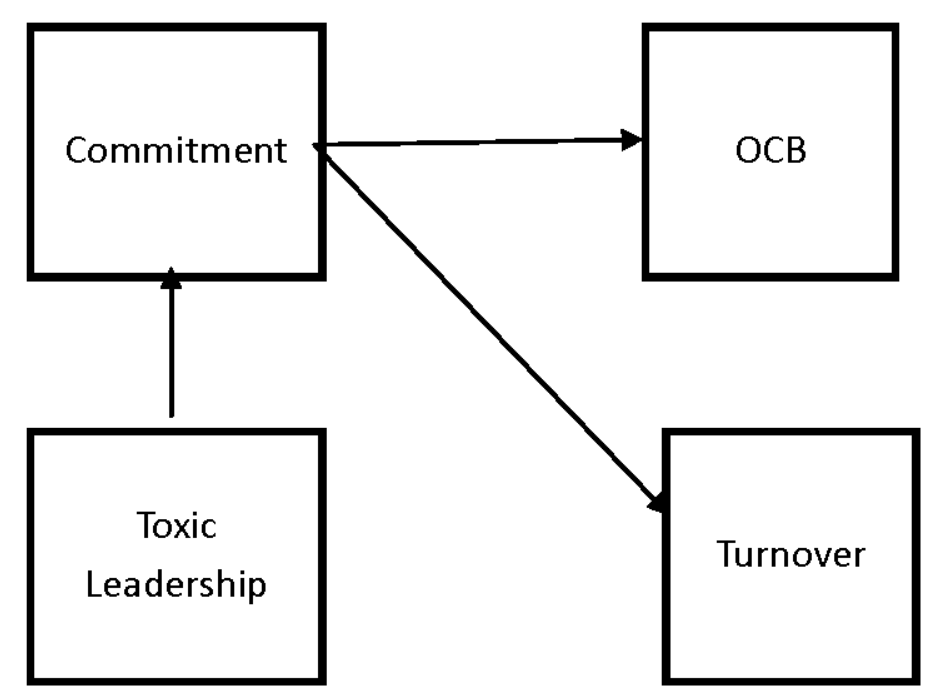

Figure 2. Commitment Analysis Path.

Research Question 4. What reasons do individuals give for remaining with a nonprofit organization despite toxic leadership in San Diego nonprofits?

Content Analysis explicated the reasons the respondents gave for staying in the organization despite the presence of toxicity. The software program, Atlas.ti, was used to pictorially depict the categories developed from the codes and facilitate the development of the themes that emerged from the data. These codes led to themes that showed the general constructs underlying why the respondents decided to stay. These themes and constructs were analyzed to find possible patterns and connections that might shed light on these issues of retention despite toxicity (Glesne, 2005). 


\section{Conclusion}

As an employer, the San Diego nonprofit sector expenditures represented 5.6 percent of San Diego County's Gross Metropolitan Product (GMP) in 2010 (Hitchcock, Deitrick, Cesarini, McDougal, Roberts \& Zinser, 2010). More than 1,800 of the sector's organizations employ over 75,000 staff members who earn nearly $\$ 745,000$ in wages. Understanding the nonprofit leadership landscape, particularly with respect to abusive or toxic behaviors, and its effects on those who fulfill their organizational missions is important to the future success of nonprofits as they face a future with continued constrained resources and growing need. 


\section{Chapter 4: Results}

The purpose of this study was to examine if toxic leadership exists in a convenience sample of San Diego nonprofit organizations, and to derive insights to its effect on organizational success as measured by organizational citizenship and turnover behaviors. Descriptive findings are presented first for the responding sample, followed by the results for each of the four research questions.

\section{Data Collection}

Respondents were drawn from paid staff members in San Diego nonprofit organizations affiliated with a local human resources support and training organization, and a local nonprofit professional networking organization. The human resources organization sent the survey with an introductory email encouraging participation and four separate reminders in a five-month period. It reported 5,507 addresses that were updated weekly. This suggested an opportunity for reaching the target number of 522 responses to properly conduct the logistic regression needed for the mediating and moderating analysis of the dichotomous turnover outcome variable, even though electronic surveys traditionally yield a lower response rate (Lin \& Van Ryzin, 2012).

Since the organization sends periodic surveys to its constituents, survey fatigue was a concern (Van Mal, 2015). Van Mal suggests that email reminders encouraging participation can overcome some of this fatigue. As noted, four reminders were sent over the five months the survey was in the field. Despite efforts to encourage greater participation, the total number of responses was lower than desired. The human resources organization yielded an 8.6 percent response rate, despite reporting an approximately 10 percent response rate as typical. 
In an attempt to gain sufficient responses, a local networking organization for nonprofit professionals was contacted and agreed to allow the survey to be sent through their listserv. The contact for that organization indicated there were approximately 3000 addresses in that listserv. Unfortunately, nothing more precise was available. That organization did not supply any supporting or encouraging email or any demographic information. The survey was sent one time to that listserv.

\section{Sample}

The responses constituted a convenience sample of nonprofit paid staff members. They held one of three organizational staffing levels: line staff, mid-level manager or senior leader. The sample of staff members represented organizations from every category of the NTEE major group (12) from the National Taxonomy of Exempt Entities (NTEE) (National Center for Charitable Statistics, 2013). See Table 5 for organizational categories by respondents and the San Diego sector.

\section{Respondents}

Survey respondents included 402 individuals affiliated with the San Diego nonprofit human resources support organization and 69 from the local nonprofit professional networking organization. Two hundred and ninety-eight respondents indicated they had worked for an abusive supervisor and 173 responded they had not. This met the requirement of 131 responses for the linear regression analysis to evaluate the relationship between toxic supervision and $\mathrm{OCB}$, but not the 522 responses needed for the logistic regression to understand the possible influence commitment may have had on the toxicity and turnover relationship. 
The demographic variables collected included gender, age, race/ethnicity, age at time of toxic experience, level in organization during experience, category or type of nonprofit organization, years worked for the toxic supervisor, and highest education attained during the experience. Of the 471 respondents, $89(19 \%)$ were male, $363(77 \%)$ female, and $19(4 \%)$ declined to answer. Seventy three percent (328) were white and 13 percent (56) Hispanic. All other race/ethnic groups totaled 18 percent (87). Two hundred and ninety eight (63\%) responded they had worked for a toxic supervisor. The remaining demographic variables pertain only to those who responded they had worked for a toxic supervisor.

Of the 273 who responded to the highest education attained question, the majority had attended college with 32 percent reporting holding advanced degrees, 44 percent baccalaureate degrees, and 13 percent attending some college. The average age at the time the respondent worked for a toxic supervisor was 38 years. Respondents who indicated the position level they held during the experience were fairly evenly distributed with slightly higher mid-level managers: Line Staff 87 (32\%), Mid-managers 107 (39\%), and Senior Leaders $80(29 \%)$. Comparing the response rate to the total HR agency clients of each level in the organization, Line Staff represented 27 percent, Mid-level Manager 27 percent, and Senior Leaders 16 percent of the HR agency's clients, with the remainder not holding one of these position types.

The type of organizations the respondents worked in was compared to the distribution of nonprofit categories found in San Diego County. A Caster Family Center report showing San Diego nonprofit category numbers (Hitchcock, Deitrick, Cesarini, McDougal, Roberts \& Zinser, 2010) was used for comparison. As can be seen in Table 
6, the survey respondents represented a higher percentage of Arts and Culture organizations ( $15 \%$ versus $10 \%)$, Health organizations (19\% versus $7 \%$ ), and Human Services organizations ( $32 \%$ versus $23 \%$ ), than were found in the San Diego nonprofit sector, as a whole (See Table 5).

Table 5

San Diego Sector Comparison with Respondents' Organizations

\begin{tabular}{lcl}
\hline Nonprofit Organizational Type & $\begin{array}{l}\text { Percentage of Organization } \\
\text { Type in San Diego Sector } \\
2010\end{array}$ & $\begin{array}{l}\text { Percentage of } \\
\text { Organization Type by } \\
\text { Respondents }\end{array}$ \\
\hline Arts \& Culture & 10 & 15 \\
Education & 16 & 9 \\
Higher Education & 0.4 & 6 \\
Environmental/Animals & 4 & 19 \\
Health & 8 & 1 \\
Medical Research & 0 & 32 \\
Human Services & 23 & 1 \\
International & 2 & 10 \\
Public/Societal Benefit & 18 & 2 \\
Religion & 20 & 2 \\
Mutual Member Benefit & 0.1 & 2 \\
\hline
\end{tabular}

Additionally, the HR organization that distributed the survey provided a breakdown of their constituents by their level in the organization and type of organization. These were the only demographics available from the distributing agencies, and they are presented as a point of comparison to the sample for these particular demographics. 
Arts and Culture, and Health organizations were overrepresented in the sample compared to the Human Services organization's client base for Line Staff. Arts and Culture organizational employees were also more often Mid-managers in the sample, while Mutual/Member Benefit organizations were hardly represented in the sample at all. See Table 6.

Table 6

Comparison of Staff Level and Type of Organization by Agency and Sample

\begin{tabular}{|c|c|c|c|c|c|c|}
\hline & \multicolumn{2}{|c|}{ Line Staff } & \multicolumn{2}{|c|}{ Mid-manager } & \multicolumn{2}{|c|}{ Senior Leader } \\
\hline $\begin{array}{l}\text { Organization } \\
\text { Type }\end{array}$ & Agency & Sample & Agency & Sample & Agency & Sample \\
\hline Arts \& Culture & 7 & 13 & 6 & 20 & 11 & 15 \\
\hline Education & 6 & 5 & 6 & 11 & 12 & 10 \\
\hline Higher Education & 2 & 3 & 1 & 1 & 2 & 3 \\
\hline $\begin{array}{l}\text { Environmental/ } \\
\text { Animals }\end{array}$ & 5 & 5 & 5 & 7 & 5 & 7 \\
\hline Health & 19 & 32 & 15 & 9 & 10 & 13 \\
\hline Medical Research & 0 & 3 & 0 & 0 & 0 & 1 \\
\hline Human Services & 30 & 25 & 33 & 33 & 35 & 41 \\
\hline International & 0 & 0 & 0 & 2 & 0 & 1 \\
\hline $\begin{array}{l}\text { Public/Societal/ } \\
\text { Benefit }\end{array}$ & 3 & 9 & 3 & 11 & 5 & 6 \\
\hline Religion & 3 & 1 & 4 & 2 & 4 & 1 \\
\hline $\begin{array}{l}\text { Mutual/Member } \\
\text { Benefit }\end{array}$ & 27 & 3 & 27 & 2 & 16 & 1 \\
\hline Total & 100 & 100 & 10 & 100 & 100 & 100 \\
\hline
\end{tabular}

\section{Challenges to Sampling}

The primary challenge to completing this study was access to a population of nonprofit paid staff members sufficiently large enough to yield the desired level of 
statistical significance. While there are many organizations in the San Diego nonprofit sector that maintain listservs of their constituent or client organizations' members, none, however, are necessarily representative of the local sector, or available to outside researchers without benefit of an existing relationship. Another challenge was that the organizations that agreed to allow access to their member lists also send other surveys throughout the year raising the very real possibility of survey fatigue. Despite efforts to encourage greater participation, the total number of responses was lower than desired.

\section{Data Collection and Preparation}

After obtaining IRB approval, surveys were distributed electronically through emails with a link to a survey in the software Qualtrics housed on the University of San Diego servers. The emails were sent by one local human resources agency to its listserv. The other was sent to a networking organization's list by the researcher through a process available to members. Membership is free to anyone interested. The researcher completed the membership form and uploaded the survey with the IRB approved accompanying email. Email addresses were not available to the researcher and the organizations did not track which email addresses completed the survey. The data from 471 responses to the questionnaire were migrated into SPSS from Qualtrics.

\section{Coding of Quantitative Data and Scale Scores}

All cases were examined for data entry and clerical errors; when errors were found they were corrected. Descriptive statistics were then reviewed for all variables. All questionnaire items were explored for normality and equality of variance, as well as reliability. All scale variables were slightly negatively skewed. Visual inspection showed relatively normal data and no transformations were conducted. Cronbach's alpha 
reliability coefficients were greater than the normally accepted .7 (Santos, 1999) for all three measures used in this study.

The 25 items considered appropriate for this study from the Destructive Leadership Questionnaire (DLQ) (Shaw, Erickson \& Harvey, 2011) were scored with a 7-point Likert-type response category ranging from 1- Strongly Disagree to 6-Strongly Agree and 7- I Don't Know. The I Don't Know response was coded 777 in SPSS. The Cronbach's alpha reliability coefficient for the toxic supervision scale from this questionnaire was .88 . There were 179 valid responses with a mean response of 111 , median response of 113 and variance of 575 . The skewness value was -0.52 and Kurtosis value was 0.118 . Visual inspection supported the normality of the scale data. See Figure 3. 


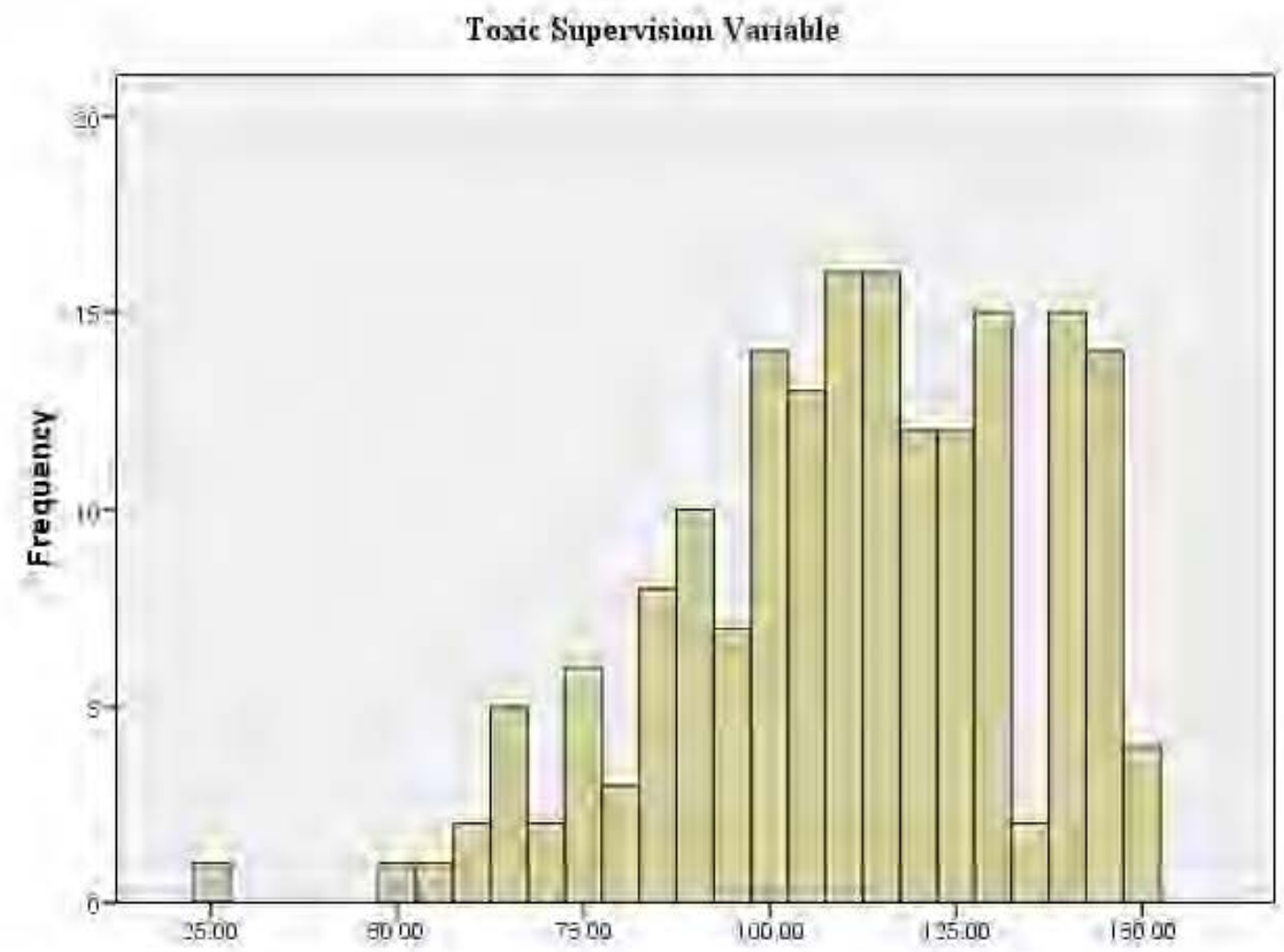

Figure 3. Toxic Supervision Variable Data Histogram from SPSS Output.

The Organizational Citizenship Behavior Measure (Podsalsoff, Ahearne \& Mackenzic, $1997 \mathrm{j}$ is a fourteen item scale that uses a 7 point Likert-type response category ranging from 1-Strongly Disagree to 7-Strongly Agree. Three items were reverse coded in the survey and recoded in SPSS. The scale in this study had a Cronbach's Alpha reliability coefficient of .85 . There were 240 valid responses with a mean of 61 , median response of 61 and variance of 120 . The skewness value was $-0,125$ and Kurtosis value was $-0,57$. Visual inspection supported the normality of the scale data. See Figure 4. 
Organuzational Citzzenslip Beharion Vaivahle

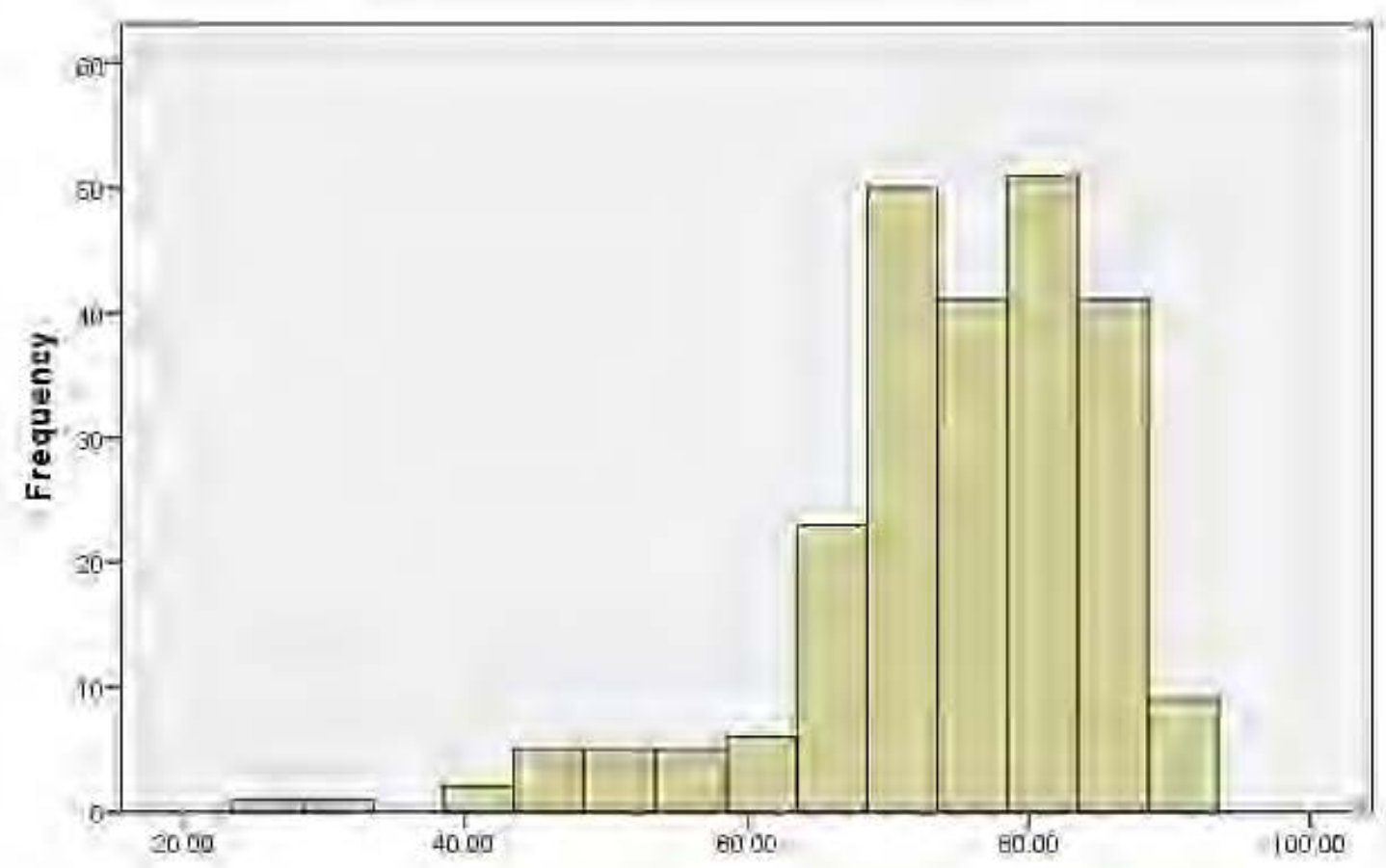

Figure 4. Organzational Citizenship Behanor Varable Data Histogram from SPSS ontout.

The Measurement of Organizational Commitment (Mowday, Steers \& Porter, 1979) is also a fourteen item scale that uses a 7 point Likert-type response category rarging from 1-Strongly Disagree to 7 -Strongly Agree. Six items were reverse eoded and recoded in SPSS. The seale in this study had a Cronbach's alpha reliability coefficient of .39. There were 238 valid responses with a mean response of 75 , median of 76 and variance of 331 . The skewness value was -1.36 and Kurtosis value was 2.82 . Visual inspection supported the normality of the seale data. See Figure 5. 


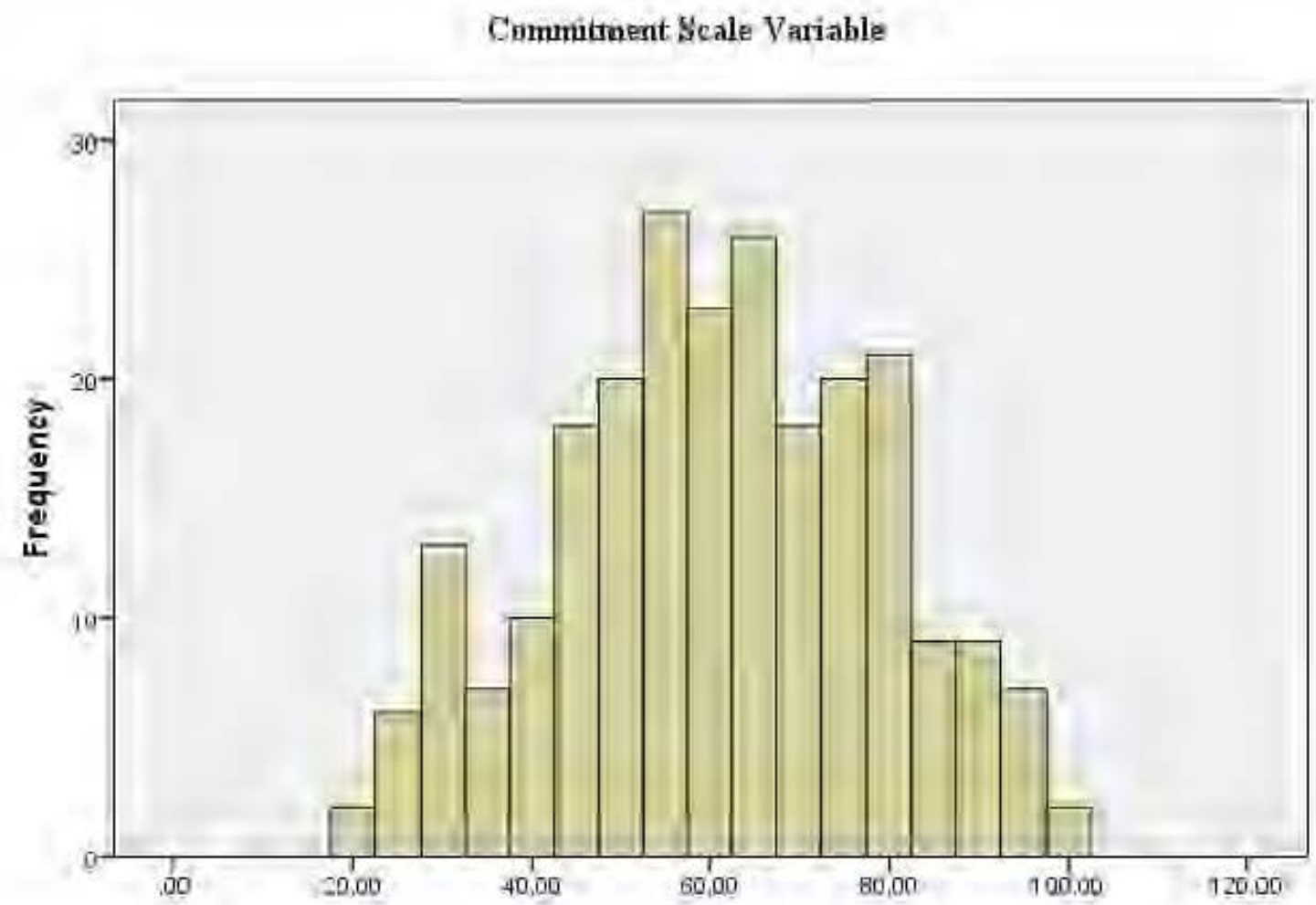

Figure 5. Commitment Vargable Dato Histogrom fram SPSS Output.

\section{Researdh Questions}

Four research questions were anal yzed. Deseriptive statistics werensed for research question 1. Regression and reliability analyses were used for research questions 2. and 3. Finally, content analysis was used to code and eategorize the open ended responses of why the individual remained in spite of toxic leadership. The following explains the analysis in depth.

\section{Research Question 1}

To what extent does toxic leader behavior exist in San Diego nonprofits? 
This question was analyzed using the responses from the $63 \%(298)$ of the total respondents who indicated they had worked for a toxic supervisor. Descriptive statistics were calculated for the demographic variables provided by this group of respondents. Additionally, these respondents responded to 25 items from the Destructive Leadership Questionnaire (DLQ) (Shaw, Erickson \& Harvey, 2011) concerning type and severity of the toxicity they experienced. These items comprised the toxic supervision variable used for further analysis. It was evaluated using frequencies, mean, median and quartiles. Because Shaw, Erickson and Harvey reported their findings from their initial study using the highest and lowest means for the DLQ's items, the means for each of the 25 items used in this study were also calculated.

\section{Demographics of Respondents Experiencing Toxicity}

With respect to the demographic variables, nonprofit employees were found to be more often white, female, and with higher levels of educational attainment than their forprofit and public sector counterparts (Leete, 2006). As shown in Table 7, while there were only $89(19 \%)$ male respondents overall, $49 \%$ (44) of them indicated they had worked for a toxic supervisor. Female respondents represented $77 \%$ (363) of the total respondents with $70 \%(253)$ of them experiencing toxic supervision, revealing that in this sample, women experienced toxicity at a higher rate than men. 
Table 7

Total Gender and Gender Experiencing Toxic Supervision

\begin{tabular}{lclll}
\hline Gender & $\begin{array}{l}\text { Total } \\
\text { Respondents }\end{array}$ & $\begin{array}{l}\text { Percentage of } \\
\text { Total } \\
\text { Respondents }\end{array}$ & $\begin{array}{l}\text { Respondents } \\
\text { Who Worked } \\
\text { for Toxic } \\
\text { Supervisor }\end{array}$ & $\begin{array}{l}\text { Percentage of } \\
\text { Respondents } \\
\text { Who Worked } \\
\text { for Toxic } \\
\text { Supervisor }\end{array}$ \\
\hline Male & 89 & 19 & 44 & 49 \\
Female & 363 & 77 & 253 & 70 \\
Missing & 19 & 4 & 1 & - \\
Total & 471 & 100 & 298 & 63 \\
\hline
\end{tabular}

Table 8 shows respondents by race/ethnicity as well as the percentage of those who experienced toxic supervision by race and ethnicity. While White respondents were the majority by far at $73 \%$, they experienced toxicity at a lower rate $(66 \%)$ relative to their total representation. Hispanic respondents were the next largest category with $13 \%$ of the total sample. However, $59 \%$ of the Hispanic respondents experienced toxicity. The small number of non-white respondents may explain some of the much larger percentages experiencing toxicity, but does suggest a possible line of future inquiry. 
Table 8

Respondents Who Worked for a Toxic Supervisor by Race/Ethnic Group

\begin{tabular}{lcclll}
\hline Category & $\begin{array}{l}\text { Total } \\
\text { Sample }\end{array}$ & $\begin{array}{l}\text { Percentage Total } \\
\text { Sample }\end{array}$ & $\begin{array}{l}\text { Worked for } \\
\text { Toxic } \\
\text { Supervisor }\end{array}$ & $\begin{array}{l}\text { Percentage Who } \\
\text { Worked for } \\
\text { Toxic } \\
\text { Supervisor } \\
\text { Within Group }\end{array}$ & $\begin{array}{l}\text { Percentage } \\
\text { Who Worked } \\
\text { for Toxic } \\
\text { Supervisor } \\
\text { by Total All } \\
\text { Groups }\end{array}$ \\
\hline White & 328 & 73 & 217 & 66 & 48 \\
$\begin{array}{l}\text { African } \\
\text { American }\end{array}$ & 8 & 2 & 5 & 63 & 1 \\
$\begin{array}{l}\text { Hispanic } \\
\text { Asian }\end{array}$ & 56 & 13 & 33 & 59 & 7 \\
Hawaiian & 8 & 5 & 17 & 71 & 4 \\
Other & 24 & 2 & 4 & 50 & 1 \\
Missing & 23 & 5 & 17 & 71 & - \\
Total & 471 & 100 & 5 & - & - \\
\hline
\end{tabular}

The following table provides educational attainment data for the 298 respondents who indicated they had worked for a toxic supervisor. As can be seen in Table 9, the sample in this study is heavily college educated with $44 \%$ (131) holding a baccalaureate degree and 32\% (96) holding an advanced degree. These findings are consistent with previous research that found nonprofit employees are more highly educated than their peers in other sectors (Leete, 2006). 
Table 9

Highest Education Attainment of Respondents Who Worked for a Toxic Supervisor

\begin{tabular}{lcc}
\hline Education Level & Total Respondents & $\begin{array}{l}\text { Percentage Total } \\
\text { Respondents }\end{array}$ \\
\hline Some High School & 0 & 0 \\
High School Graduate & 4 & 1 \\
Some College & 38 & 13 \\
Bachelor's Degree & 131 & 44 \\
Advanced Degree & 96 & 32 \\
Certificate & 3 & 1 \\
Missing & 26 & 9 \\
Total & 298 & 100 \\
\hline
\end{tabular}

The position level the individual held in the organization while experiencing toxic leadership was also analyzed. Table 10 shows the largest group experiencing toxicity in the sample was mid-level managers at $36 \%$. However, while senior leaders experienced toxicity at a lower rate than either of the other two categories, they did only slightly, with $27 \%$ of senior leaders reporting that they experienced toxicity, compared to $29 \%$ of line staff and $36 \%$ of mid-managers. This suggests that toxic supervision is an issue at all levels of the organization, but greatest at the mid-manager level. 
Table 10

Position Held While Working for a Toxic Supervisor

\begin{tabular}{lcl}
\hline & $\begin{array}{l}\text { Total Respondents by Position } \\
\text { Level }\end{array}$ & $\begin{array}{l}\text { Percentage of } \\
\text { Respondents Working for } \\
\text { Toxic Supervisor by } \\
\text { Position Level }\end{array}$ \\
\hline Line Staff & 87 & 29 \\
Mid-Manager & 107 & 36 \\
Senior Leader & 80 & 27 \\
Missing & 24 & 8 \\
Total & 298 & 100 \\
\hline
\end{tabular}

The final demographic variable analyzed was the category of nonprofit organization in which the respondents worked. As discussed previously, there are 26 categories of nonprofit organizations often grouped into larger categories for analysis (See Table 5). This was also the variable besides the position level in the organization that the HR agency provided. Therefore, Table 11 shows a comparison of the type of organization by category between respondents, the agency's clients and the San Diego sector as reported in 2010 (the latest report breaking down San Diego nonprofit organizations by category).

Table 11 shows that human service organizations employed the largest percentage of all three groups: respondents (29\%), the HR agency clients (32\%) and the San Diego sector $(23 \%)$. The health organization category was the next largest type represented by $17 \%$ of the respondents, $16 \%$ of the agency clients and only $8 \%$ of the San Diego sector as a whole. This variation was attributable to the types of client organizations affiliated with the HR agency, but did not suggest whether or not certain types of nonprofit 
organizations are more vulnerable to toxicity than others, indicating further inquiry is needed.

Table 11

Comparison of San Diego Sector Organization Categories with Total Agency Clients and Respondents Working for a Toxic Supervisor

\begin{tabular}{|c|c|c|c|}
\hline $\begin{array}{l}\text { Nonprofit Organization } \\
\text { Group Category }\end{array}$ & $\begin{array}{l}\text { Percentage in } \\
\text { Sample }\end{array}$ & $\begin{array}{l}\text { Percentage in } \\
\text { Agency }\end{array}$ & $\begin{array}{l}\text { Percentage in } \\
\text { San Diego } \\
\text { Sector }(2010)\end{array}$ \\
\hline Arts & 14 & 7 & 10 \\
\hline Education & 9 & 7 & 16 \\
\hline Higher Education & 2 & 2 & $0^{*}$ \\
\hline Environment/Animals & 6 & 5 & 4 \\
\hline Health & 17 & 16 & 8 \\
\hline Medical Research & 1 & 0 & $0 *$ \\
\hline Human Services & 29 & 32 & 23 \\
\hline International & 1 & 0 & 2 \\
\hline Public/Societal Benefit & 9 & 3 & 18 \\
\hline Religious & 2 & 3 & 20 \\
\hline Mutual/Member Benefit & 2 & 25 & $0.1 *$ \\
\hline Missing & 8 & - & - \\
\hline Total & 100 & 100 & 100 \\
\hline
\end{tabular}

\section{Destructive Leader Questionnaire (DLQ) Items}

The 25 items from the Destructive Leadership Questionnaire (DLQ) (Shaw, Erickson \& Harvey, 2011) were analyzed as well as the scale variable Toxic Supervision that was derived from the 25 items to determine the level of toxicity experienced by the 
respondents. The item means ranged from the lowest, 3.48, to the highest, 5.02. Table 12 depicts the items used for the toxic supervision scale variable from the DLQ along with the subscales from which the items were taken, the total responses for each item, and their means. The items dealing with brutal and bullying behavior, as well as inconsiderate and tyrannical behavior had the highest means. The toxic supervision scale variable had a mean of 111 and median of 113 with no true outliers. Overall, respondents concerns with toxic supervision in bullying were more pronounced than issues of ethics and emotionalism.

Table 12

Toxic Supervision Scale Variable Items, Response Totals and Means

\begin{tabular}{llll}
\hline Item DLQ Subscale & Item Question & $\begin{array}{l}\text { Total } \\
\text { Responses }\end{array}$ & Mean \\
\hline $\begin{array}{lll}\text { Acting in a Brutal Bullying } \\
\text { Manner }\end{array}$ & $\begin{array}{l}\text { My boss enjoys making } \\
\text { people suffer }\end{array}$ & 237 & 3.48 \\
& & &
\end{tabular}

Acting in an Insular Manner My boss does not care about 231 Relative to Other Groups in things happening in other the Organization units

Lying and Other Unethical My boss rarely acts with a 252 Behavior high level of integrity

An Inconsiderate Tyrant

My boss could best be 256 described as mean

An Inconsiderate Tyrant

My boss is a tyrant

252

Acting in an Insular Manner

My boss demonstrates no 250

Relative to Other Groups in the Organization concern for anyone outside his/her own unit 


\begin{tabular}{|c|c|c|c|}
\hline Item Subscale & Item Question & $\begin{array}{l}\text { Total } \\
\text { Responses }\end{array}$ & Mean \\
\hline $\begin{array}{l}\text { Overly Emotional With } \\
\text { Negative Psychological } \\
\text { Characteristic }\end{array}$ & $\begin{array}{l}\text { My boss often gets } \\
\text { emotional }\end{array}$ & 255 & 4.06 \\
\hline $\begin{array}{l}\text { Lying and Other Unethical } \\
\text { Behavior }\end{array}$ & $\begin{array}{l}\text { My boss often acts in an } \\
\text { unethical manner }\end{array}$ & 250 & 4.29 \\
\hline $\begin{array}{l}\text { Acting in a Brutal Bullying } \\
\text { Manner }\end{array}$ & $\begin{array}{l}\text { Anyone who challenges my } \\
\text { boss is dealt with brutally }\end{array}$ & 254 & 4.34 \\
\hline $\begin{array}{l}\text { Acting in a Brutal Bullying } \\
\text { Manner }\end{array}$ & $\begin{array}{l}\text { I have often seen my boss } \\
\text { bully another employee }\end{array}$ & 253 & 4.36 \\
\hline $\begin{array}{l}\text { Acting in a Brutal Bullying } \\
\text { Manner }\end{array}$ & $\begin{array}{l}\text { My boss places brutal } \\
\text { pressure on subordinates }\end{array}$ & 255 & 4.39 \\
\hline $\begin{array}{l}\text { Overly Emotional With } \\
\text { Negative Psychological } \\
\text { Characteristic }\end{array}$ & My boss lacks self-control & 256 & 4.44 \\
\hline $\begin{array}{l}\text { Lying and Other Unethical } \\
\text { Behavior }\end{array}$ & $\begin{array}{l}\text { My boss blames others for } \\
\text { his/her own mistakes }\end{array}$ & 249 & 4.49 \\
\hline An Inconsiderate Tyrant & $\begin{array}{l}\text { My boss is pig headed (i.e. } \\
\text { extremely stubborn) }\end{array}$ & 255 & 4.50 \\
\hline $\begin{array}{l}\text { Acting in a Brutal Bullying } \\
\text { Manner }\end{array}$ & $\begin{array}{l}\text { My boss rarely shows a high } \\
\text { level of respect for others }\end{array}$ & 255 & 4.58 \\
\hline $\begin{array}{l}\text { Lying and Other Unethical } \\
\text { Behavior }\end{array}$ & $\begin{array}{l}\text { My boss often says one } \\
\text { thing while doing exactly } \\
\text { the opposite }\end{array}$ & 252 & 4.65 \\
\hline $\begin{array}{l}\text { Lying and Other Unethical } \\
\text { Behavior }\end{array}$ & $\begin{array}{l}\text { My boss often takes credit } \\
\text { for the work that others } \\
\text { have done }\end{array}$ & 252 & 4.72 \\
\hline $\begin{array}{l}\text { Playing Favorites and Other } \\
\text { Divisive Behavior }\end{array}$ & $\begin{array}{l}\text { My boss tends to show } \\
\text { excessive favoritism }\end{array}$ & 248 & 4.73 \\
\hline
\end{tabular}




\begin{tabular}{llll}
\hline Item Subscale & Item Question & $\begin{array}{l}\text { Total } \\
\text { Responses }\end{array}$ & Mean \\
\hline An Inconsiderate Tyrant & $\begin{array}{l}\text { My boss is an inconsiderate } \\
\text { person }\end{array}$ & 255 & 4.77 \\
Acting in a Brutal Bullying & $\begin{array}{l}\text { My boss sees every } \\
\text { negotiation issue as a } \\
\text { win/lose conflict }\end{array}$ & 242 & 4.80 \\
$\begin{array}{llll}\text { Playing Favorites and Other } \\
\text { Divisive Behavior }\end{array}$ & $\begin{array}{l}\text { My boss has personal } \\
\text { favorites }\end{array}$ & 251 & 4.96 \\
An Inconsiderate Tyrant & My boss is arrogant & 256 & 4.97 \\
An Inconsiderate Tyrant & My boss is self-centered & 256 & 5.01 \\
$\begin{array}{l}\text { Acting in a Brutal Bullying } \\
\text { Manner }\end{array}$ & My boss holds grudges & 241 & 5.02 \\
\hline
\end{tabular}

\section{Summary Research Question 1}

Two hundred and ninety-eight (63\%) respondents experienced toxicity. While this sample cannot be generalized to the greater San Diego sector, the sample does have some representative characteristics of nonprofit employees, such as their race, gender and educational level. In other words, they tended to be white women with higher levels of education. If the desire to respond to the questionnaire itself is any indication of toxicity, respondents from arts organizations responded to the survey at twice the rate that they were represented in the agency's population. At the same time, mutual $/$ member benefit organizations were one of the largest client groups of the agency and were not part of the response group at all. There may be many other reasons for this such as time available to take the survey, fear of confidentiality being broached, or perhaps some other reason, but this certainly suggests further study is needed into the level of toxicity with respect to different organizational types. 
The level of toxicity as represented by the item means was compared specifically because the initial study of the DLQ by Shaw, Erickson and Harvey (2011) reported their highest and lowest item means. However, since this dissertation used only respondents who indicated they had worked for a toxic supervisor, the highest and lowest item means were higher than those reported in the initial study that included all participants whether or not they had worked for a toxic boss. Therefore, while there were higher levels of toxicity reported by the highest and lowest means of the 25 items used in this study, it is not a clear indicator of higher levels in this sample. However, these results did indicate that toxic leadership by an immediate supervisor or other organizational leader does exist in at least some places in the San Diego nonprofit sector.

\section{Research Question 2}

To what extent does toxic leader behavior explain variation in both organizational citizenship behavior and turnover behavior in San Diego nonprofits?

This question was analyzed using bivariate correlations, linear, and logistic regression. Specifically, the outcome variable organizational citizenship behavior (OCB) was modeled as a continuous variable and was evaluated with multiple linear regression. The outcome variable turnover was measured as dichotomous and was evaluated with logistic regression.

\section{Organizational Citizenship Behavior (OCB)}

Bivariate correlations were used for an initial identification of possible predictor variables. Stepwise regression was then used to identify predictor variables from this initial set that might have a significant relationship to the outcome variables. Pearson product-moment correlations of the toxic supervision, $\mathrm{OCB}$, and all demographic 
variables yielded only one significantly correlated variable, high school graduate, $p$ value $=.01, r=.16$. However, only 4 responses were in that category so the variable was not used. In addition, there were seven other variables with insufficient responses to include in the model: International, Medical Research, Religious, Some High School, High School Graduate, Certificated and Some College. As such, each stepwise model included the following demographic variables: African American, Hispanic, Asian, Hawaiian, Other Race/Ethnicity, Bachelor's Degree, Advanced Degree, Arts, Education, Higher Education, Environment/Animals, Health, Human Services, Public/Societal Benefit, Mutual/Member Benefit, Line Staff, Mid-Manager, Senior Leader, and Male.

A stepwise regression model including the above mentioned demographic variables and the predictor variable, toxic supervision, were regressed against the outcome variable, $\mathrm{OCB}$, and none of the independent variables were found to be significant. However, because the literature suggested that certain variables might be correlated, and assuming that nonprofit employees respond as employees in other sectors have been found to behave, the scale variables OCB and toxic supervision were recoded into their subscales for additional analysis.

Three separate models were evaluated for each of the three OCB subscales (helping behavior, sportsmanship and civic virtue). Each model included the six DLQ subscales used for the toxic supervision variable and the earlier described demographic variables. Of the 26 subscales in the DLQ, this study's toxic supervision scale variable contained questions from six of the 26 subscales of the DLQ that were most related to the definition of toxicity used in this study. Table 13 reports both OCB and toxic supervision 
scale and subscale reliability scores, all of which were at or above the .7 level (Santos, 1999).

Table 13

Cronbach's Alpha Values for Toxic Supervision, OCB Scale and Subscale Variables

\begin{tabular}{|c|c|c|}
\hline Scale Variable & Subscale Variable & $\alpha$ \\
\hline \multirow[t]{4}{*}{$\begin{array}{l}\text { Organizational } \\
\text { Citizenship Behavior } \\
(\text { OCB })\end{array}$} & & .85 \\
\hline & Helping Behavior & .90 \\
\hline & Civic Virtue & .85 \\
\hline & Sportsmanship & .79 \\
\hline \multirow[t]{7}{*}{ Toxic Supervision } & & .95 \\
\hline & Acting in a brutal bullying manner & .88 \\
\hline & Lying and other unethical behavior & .84 \\
\hline & Playing favorites and other divisive behavior & .85 \\
\hline & $\begin{array}{l}\text { Acting in an insular manner relative to other } \\
\text { groups in the organization }\end{array}$ & .81 \\
\hline & $\begin{array}{l}\text { Overly emotional with negative } \\
\text { psychological characteristics }\end{array}$ & .67 \\
\hline & An inconsistent tyrant & .85 \\
\hline
\end{tabular}

Stepwise regression was performed for the OCB subscale variables on the demographic variables, the toxic supervision scale variable, and its six DLQ subscale variables used to create the toxic supervision scale variable. Of the eight models evaluated, five yielded at least one significant predictor (See Table 14 for the significant predictor variable models). While these models were all significant, they had nearly no 
predictive capacity as shown by the R-square values that indicated the models explained only three to six percent of the variation in the outcome variable.

Table 14

Significant Models for the Outcome Variable OCB, OCB Subscales, and Predictors Toxic Supervision and Toxic Subscales

\begin{tabular}{|c|c|c|c|c|c|c|c|c|}
\hline Model & Outcome & Predictors & $\mathrm{F}$ & Sig & $\mathrm{R}^{2}$ & $\mathrm{t}$ & Sig & B \\
\hline \multirow[t]{3}{*}{1} & OCB & Demographics & 5.78 & .02 & .04 & & & \\
\hline & & Toxic Subscales & & & & & & \\
\hline & & Significant Predictor: & Lying/Unethical & & & 2.41 & .02 & .34 \\
\hline \multirow[t]{3}{*}{2} & Civic Virtue & Demographics & 5.0 & .03 & .03 & & & \\
\hline & & Toxic Subscales & & & & & & \\
\hline & & Significant Predictor: & Lying/Unethical & & & 2.23 & .03 & .03 \\
\hline \multirow[t]{3}{*}{3} & Civic Virtue & Demographics & 5.37 & .02 & .03 & & & \\
\hline & & Toxic Subscales & & & & & & \\
\hline & & Significant Predictor: & Brutal/Bullying & & & 2.32 & .02 & .08 \\
\hline \multirow[t]{3}{*}{4} & Sportsmanship & Demographics & 4.33 & .04 & .03 & & & \\
\hline & & Toxic Subscales & & & & & & \\
\hline & & Significant Predictor: & Arts Organization & & & -2.08 & .04 & -1.95 \\
\hline \multirow[t]{4}{*}{5} & Helping & Demographics & 5.41 & .04 & .03 & & & \\
\hline & & Toxic Subscales & & & & & & \\
\hline & & Significant Predictor: & Lying/Unethical & & & 3.29 & .001 & .35 \\
\hline & & & Insular & & & -2.01 & .05 & -.47 \\
\hline
\end{tabular}

Upon inspection, two additional issues were noted. First, the direction of the relationship was not what has been reported in the literature; and, second, the coefficients were so small as to be unimportant. Furthermore, the literature consistently reports a negative relationship between toxicity and OCB. However, in all cases except two (the demographic predictor, arts organization, on the OCB subscale, sportsmanship, and the toxic supervision subscale, acting in an insular manner relative to other groups in the organization, on the OCB subscale, helping behavior) the direction of the relationship was positive, and the coefficient was less than 0.50 . Even for the models that conformed 
to the expected direction, the effect size was extremely small. One explanation for this is that the sample may have been too narrowly constrained from the beginning. The survey instrument included a sorting question. Those respondents who indicated that they did not believe they had worked for an abusive supervisor did not respond to the toxic supervision items. Doing this may have too greatly limited the variation in the responses which may account for the extremely low explanatory capacity of the models and the miniscule effect size. This may also account for the lack of significance in the turnover logistic regression models.

\section{Turnover}

Logistic regression was used to evaluate the relationships between the dichotomous dependent variable, turnover, and the same predictor variables that were considered for OCB. These variables included toxic supervision and the subscales comprising toxic supervision. Neither the model with the toxic supervision scale variable nor the model with the toxic subscale variables was significant. This too is not supported by the literature, where turnover is consistently found to increase as toxicity increases. While this may also be a result of the too tightly constrained sample that, in the case of turnover resulted in a lack of significance, this lack of significance may have other reasons.

One of these reasons may have been that the sample was too small for the logistical regression required for the dichotomous turnover outcome variable since power analysis indicated that 522 responses were necessary and only 298 were obtained. While there are statistical methods like bootstrapping designed to overcome these kinds of issues, bootstrapping is based on the assumption that all possible responses are 
represented in the sample (Meyers, Gamst \& Guarino, 2006, p. 222). If the sample was overly narrow, this would not be the case. Therefore, the lack of improvement in significance after bootstrapping may have reflected the need for improved sampling because all responses had not been obtained, resulting in too little variation for the analysis.

Finally, the turnover and toxic supervision relationship may not be significant as a result of other significant variables that were not included in this study. Some of these may have been uncovered through the open ended question responses addressed in Research Question 4.

\section{Summary Research Question 2}

This analysis evaluated the relationships between toxic supervision, and OCB and turnover. While there was no significant relationship between turnover and toxicity in this sample, OCB was significantly related to one of the toxic subscales, lying and other unethical behavior. Additionally, each of the OCB subscale models indicated that there was a relationship with at least one of the toxic subscales (See Table 13). However, these relationships were quite weak, the direction of the relationships was not supported by the literature, and the models' explanatory power was so small as to be unimportant. In light of this, another possibility was considered.

Because the respondents only answered the toxic supervision items if they indicated that they believed they had worked for a toxic supervisor, there may have been too little variation in the sample and the finding may have actually been an example of a Type I error. In addition to this issue for OCB, the sample was determined to be too 
small for the logistical regression required for the dichotomous turnover outcome variable.

Since previous research from the private and public sectors revealed that turnover increases and OCB decreases in the face of toxicity, the internal sampling issues that have been discussed may have impacted the analysis. Furthermore, with respect to turnover, some qualitative findings addressed in the open ended question may offer other possible influencers acting on those who stayed in spite of toxicity. These are addressed later in Research Question 4.

\section{Research Question 3}

Does level of commitment significantly mediate and/or moderate the effect of toxic leadership on both organizational citizenship behavior and turnover behavior in San Diego nonprofits?

Moderator and mediator variables account for many differences in people's behaviors (Barons and Kenny, 1986). According to Baron and Kenny (1986) these differences are influenced in unique and specific ways depending on which type of variable is exerting that effect. However, moderation and mediation are often used interchangeably resulting in confusion for both readers and analysts. As a specification variable used to determine the type and strength of the relationship between the dependent (outcome) variable and independent (predictor) variable, a moderator is classified as being related to the outcome variable and interacting with the predictor variable (Sharma, Durand \& Gur-Arie, 1981). Mediating variables, however, explain how and why the outcome and predictor variables are related, suggesting underlying processes across behaviors (McKinnon, 2009). 
Commitment was included in this study to determine if it moderated or mediated the relationship between toxic supervision, and both OCB and turnover since nonprofit paid staff members are thought to endure less than optimal working conditions because they are committed to the cause for which they work (Handy \& Katz, 1989).

\section{Moderation}

There are three relationships used to test for moderation in the Baron and Kenny method. The evaluation of the moderating effect of commitment on the relationship between the outcome variable (turnover or $\mathrm{OCB}$ ) and the predictor variable, toxic supervision, consists of the effect of the predictor variable on the outcome variable, the effect of the moderator variable on the outcome variable, and the effect of the interaction of the predictor and the moderator, together, on the outcome variable (Baron \& Kenny, 1986, p. 176). To control for commitment and toxicity, a fourth model was included to understand how the interaction term affects both the predictor and moderator. Baron and Kenny also suggest that while the interaction of the predictor and moderator variables should be significantly correlated to the outcome variable, the moderator and predictor variables separately should not be significantly correlated to the outcome variable.

Organizational Citizenship Behavior (OCB). To test for moderation, a precondition is that the interaction variable (toxic supervision and commitment) needs to be correlated to $\mathrm{OCB}$, and the toxic supervision and commitment variables uncorrelated individually with OCB.

The interaction term was significantly correlated to the outcome variable $\mathrm{OCB}, \mathrm{r}$ $(156)=.34, p=.000$, while the predictor variable, toxic supervision, was not significantly correlated to OCB, thus supporting moderation. However, the moderator 
variable, commitment, was significantly correlated with the outcome variable, OCB, $r$ $(227)=.33, p=.000$, violating the requirements for moderation. Therefore, this first step in moderation indicated that commitment did not moderate the relationship between toxic supervision and OCB.

In an effort to completely evaluate the moderation issue, the regressions were performed despite the correlations not conforming to the requirements in this model. The four models involved regressing: toxic supervision on $\mathrm{OCB}$; commitment on $\mathrm{OCB}$; the interaction variable (toxic supervision and commitment) on $\mathrm{OCB}$; and the interaction term, predictor, and moderator on OCB (See Table 15 for models' results). The regression results were varied and inconclusive. As can be seen in Table 15, the Rsquare improves slightly between models 3 and 4, however, model 1 was not significant and the coefficient values were so small as to be unimportant. While this may be another result of the sample being too tightly constrained, there was no conclusive evidence that commitment moderated the effects of toxicity on OCB. 
Table 15

Results of the Moderation Regressions for the OCB Dependent Variable

\begin{tabular}{|c|c|c|c|c|c|c|}
\hline Model & $\mathrm{F}$ & Sig & $\mathrm{R}^{2}$ & $\mathrm{t}$ & Sig & $\mathrm{B}$ \\
\hline Toxic supervision & 3.46 & .07 & .02 & 1.86 & .07 & .07 \\
\hline Commitment & 26.88 & .000 & .11 & 5.19 & .000 & .20 \\
\hline Interaction Term & 20.52 & .000 & .12 & 4.53 & .000 & .001 \\
\hline Full Model & 9.17 & .000 & .15 & & & \\
\hline Toxic Superv. & & & & 2.31 & .02 & .22 \\
\hline Commitment & & & & 2.53 & .01 & .44 \\
\hline $\begin{array}{l}\text { Interaction } \\
\text { Term }\end{array}$ & & & & -1.44 & .15 & -.002 \\
\hline
\end{tabular}

Turnover. To test for moderation with the turnover outcome variable, a precondition was that the interaction variable (toxic supervision and commitment) needed to be significantly correlated to turnover. It was not. Additionally, only the logistic regression models including toxic supervision and commitment separately were significant. These results indicated that commitment did not moderate the relationship between toxic supervision and turnover, either.

\section{Mediation}

The method used to determine mediation was derived from Axman (2009, p. 173) and Baron and Kenny (1986, p. 1177). Mediation explains the psychological aspect of a person's actions related to external events. The process to determine mediation includes evaluating the significance of correlations between the mediator and predictor variable, and three regression steps to understand if the mediating variable has an effect on the outcome variable. The first step regresses the mediator on the predictor. The second step 
regresses the outcome variable (turnover or $\mathrm{OCB}$ ) on the predictor variable, and the third step regresses the outcome variable on both the mediator and predictor variables.

Therefore, to first determine if commitment mediates toxic supervision's effect on turnover and $\mathrm{OCB}$, the commitment and toxic supervision variables need to be significantly correlated. Additionally, upon inspection, coefficients and errors need to indicate that there is an appropriate directional change (Baron \& Kenny, 1986, p. 1177). In other words, the effect of the mediator should produce a smaller coefficient for toxic supervision in the third step equation that includes both commitment and toxicity. Inspection of coefficients and errors can be used because this is a simple model with one predictor and one mediator (Baron \& Kenny, 1986). In this analysis, the mediator (commitment) and predictor (toxic supervision) were significantly correlated, $\mathrm{r}(164)=$ $.190, p=.014$ indicating that it was appropriate to run the regressions.

Organizational Citizenship Behavior (OCB). Because the correlational requirement was met, the three previously discussed regressions were run. While the mediator on predictor model was significant, the outcome on predictor model was not, making it impossible to determine if the unstandardized coefficient decreased when commitment was added to the model. Therefore, commitment was not found to mediate the relationship between toxic supervision and OCB.

Turnover. Again, since the toxic supervision and commitment variables were significantly correlated, the three regressions were run. In this instance, all three logistic regression models were significant. However, the toxic supervision predictor variable was not significantly different from zero in the full model, indicating a change, but the R- 
squares and coefficients were so small that the results were still inconclusive, as they had been for OCB.

\section{Summary Research Question 3}

There was no conclusive moderating or mediating effect of commitment on either $\mathrm{OCB}$ or turnover found. As noted above, this may have been a result of the sample being too narrowly constrained. Only those respondents who indicated that they believed they had worked for a toxic or abusive supervisor completed the toxic supervisor variable items, likely limiting the variation too much to discover any inferential findings. Furthermore, other measurement errors and incorrect assumptions about the influencer variables may also have impacted the analysis. Specifically, the assumption in this study was that commitment was the influencer variable on toxic supervision. This may not be the case.

Baron and Kenny (1986), caution that because of the very nature of mediators being an internal, psychological variable, measurement error can result in an underestimation of the effect of the mediator and an overestimation of the effect of the predictor variable (p. 1177). They also warn that there may be an incorrect assumption about which variable is the predictor and which is the mediator in the model (p. 1177). Therefore, while commitment did not conclusively moderate or mediate either relationship, there may be other as yet unidentified variables operating on the relationship. Some of these other factors may have been discovered in the qualitative question responses. 


\section{Research Question 4}

What reasons do individuals give for remaining with a nonprofit organization despite toxic leadership in San Diego nonprofits?

The fourth and final research question was an open-ended qualitative question to address reasons why people who worked for a toxic supervisor remained after considering leaving. Coding and category development was accomplished using the manual method of data analysis.

\section{Data Collection}

Respondents who indicated that they had worked for an abusive supervisor were asked a dichotomous (yes/no) question if they had considered leaving the organization because of the toxic supervisor. If they responded they had, they were asked if they did leave. If they responded that they had not left, they were then asked to explain why in as much detail as possible in a single open ended question. Of the 298 respondents who indicated they had worked for a toxic supervisor, 182 considered leaving but stayed in spite of it. Of these individuals who stayed, 175 gave an explanation as to why they did.

\section{Data Preparation}

The researcher copied the list of responses into an excel document. Responses were reviewed for all possible codes. Each separate code was copied to its own cell to facilitate recording frequencies of each, as well as ease of reassigning the coded data to different family networks or categories. 


\section{Analysis}

Manifest and latent content analysis were used to explore themes. The manifest descriptions of the content resulted in reported frequencies, while the latent descriptions also described underlying meanings represented in conceptual mapping (Hsieh \& Shannon, 2005). Open coding determined frequencies of response ideas and was used to explore family networks or categories. Because this analysis addressed research question four that specifically looked at the reasons that people stayed in spite of working for a toxic supervisor or other organizational leader, the Framework Approach was used. The software Atlas.ti was used to map the thematic relationships between the codes and the categories.

The Framework Approach analyzes qualitative data within a context of a particular issue (usually in a policy context), in this case explaining staying after considering quitting (Pope, Ziebland \& Mays, 2000). It employs multiple steps but is also flexible for the needs of the research (Srivastava \& Thomson, 2009). As with all qualitative analysis, familiarization with the data was the first step. The second step involved identification of the thematic framework, or using the a priori themes, while searching for other possible themes from the data. The data was then coded, charted, mapped and interpreted (Srivastava \& Thomson, 2009, p. 4).

\section{Quality and Integrity}

Discussion regarding the rigor of qualitative research is ongoing. While some qualitative researchers reject the notions of reliability and validity used in quantitative research, the need for researchers and the consumers of their research to have confidence in the methods and analysis is still needed (Morse, Barrett, Mayan, Olson \& Spiers, 
2002). Lincoln and Guba developed four constructs around trustworthiness of qualitative research to address these issues (Shenton, 2004). They are: credibility, transferability, dependability and confirmability (p. 64).

Credibility, one of the most important aspects of trustworthiness, considers how congruent the findings are with reality (p.64). Transferability is concerned with the applicability of the findings to other situations (p. 69). Dependability refers to replicability of the research, looking for some confidence that if the study was redone with the same respondents, similar results would be had (p. 71). Finally, confirmability addresses the possible biases of the researcher to ensure they do not influence the findings.

The qualitative question in this concurrent mixed methods design had a single specific purpose- to identify categories of reasons why those who considered leaving because of the toxic leader but did not. To develop these codes and categories, the data was reviewed by multiple people; therefore, dependability and confirmability were addressed by the data review process.

The data, codes and categories were reviewed with at least one other colleague and a committee member to ensure appropriateness of the category and assignment of codes to those categories. The data was maintained so that the original written responses were kept beside the codes and categories that were developed. This provided easy access and an opportunity to calculate frequencies. The written responses and codes were unattached to any identifying markers and were broken up into phrases so as not to be connected to the original response or identifiable in any other way to the respondents. Because these responses were a few sentences or phrases, there was little or no context 
discernible. Therefore, there was little concern that separating the response items into component single expressions, or components, would affect understanding. On the other hand, the possibility of incorrect reinterpretation of the phrases was avoided by not using single word lists. Credibility was addressed by including other research that addressed the findings, while transferability was examined by using the qualitative findings to help explain the quantitative findings in this study.

\section{Categories and Themes}

The a priori categories discovered in the qualitative data were commitment and OCB. Additionally, seven other categories emerged. While five were manifest categories, resilience emerged as another latent variable with the a priori categories. The categories and their codes and frequencies are noted with representative quotations from the survey responses throughout the discussion that follows. Additionally, the codes and their frequencies can be found in Appendix C.

Manifest categories. The following section describes the categories developed from words and phrases that suggest the straightforward meaning of the words. While these categories may represent important influencer variables, any underlying themes cannot be gleaned in this type of analysis. Analysis of the responses determined five of this category type. Table 16 displays the manifest categories, frequencies, and the accompanying codes. 
Table 16

Manifest Categories, Frequencies and Codes

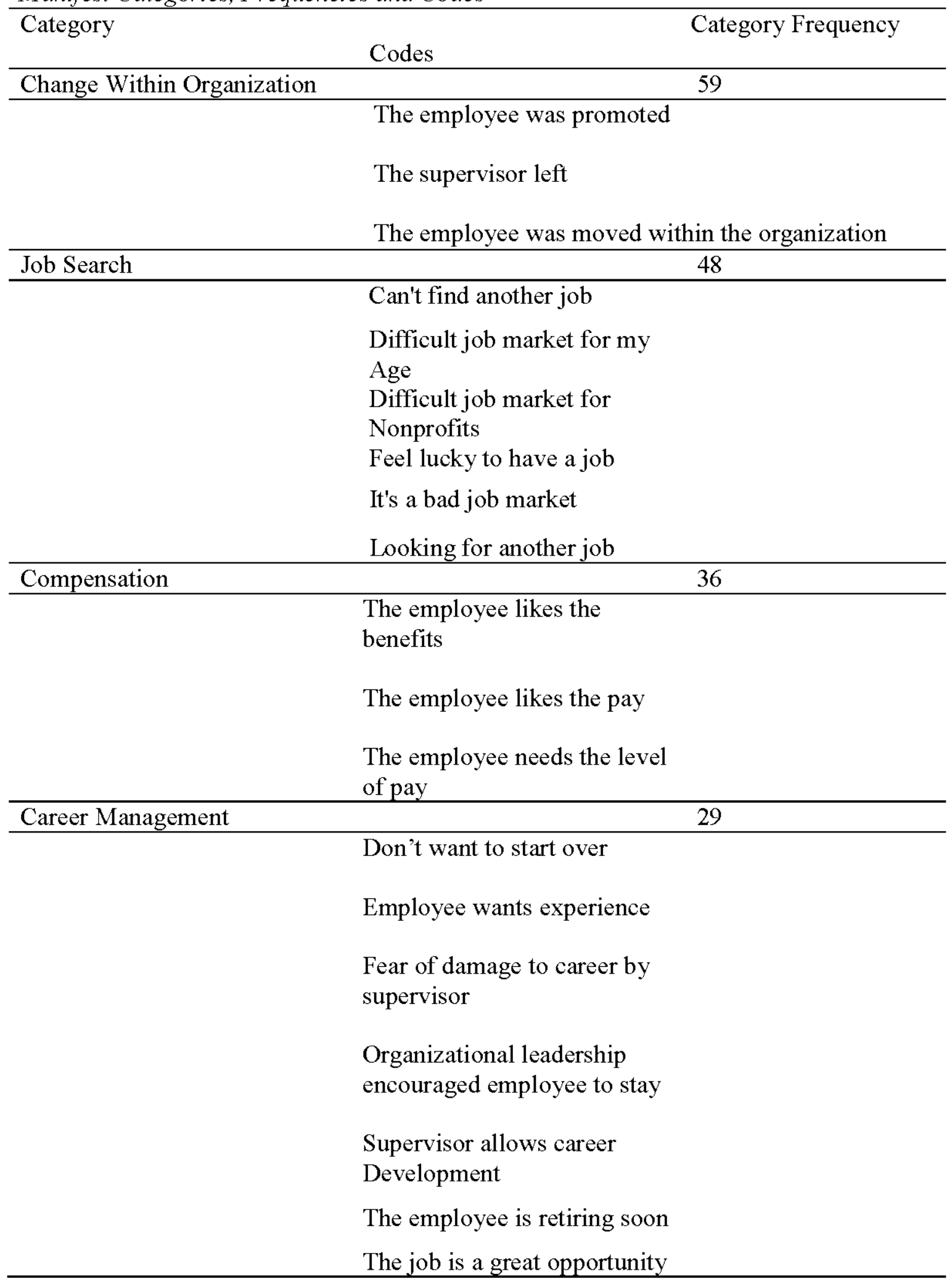




\begin{tabular}{lll}
\hline Category & Codes & Category Frequency \\
\hline Likes Work & & 23 \\
\hline & Employee likes the field \\
& Employee likes the work \\
\hline
\end{tabular}

Change within the organization. Change within the organization had only two coded components and was the largest category frequency (59). In the first code, the individual was moved away from the abusive leader. In the second, the toxic supervisor left the organization. In some cases, the leader or supervisor was fired, but often it was represented simply as the person left. Twice as often the supervisor left the organization, either fired or chose to leave, (40 comments), as the staff member was moved (19 comments), indicated by "The supervisor took a job at another nonprofit, so I remained at the organization." In six instances, the staff member reported being promoted with the move. For example, the comments were similar to "The boss moved on and I was promoted to another role." None of these comments suggested that the promotion was connected to the abuse.

Job search. The job search category included five codes that delved further into how the individual felt about the possibility of existing opportunities. Only one code was not representative of a discouraged seeker or someone fearing limited opportunities. The negative toned codes expressed concerns with the economy such as feel lucky to have a job and it's a bad job market.

Table 17 represents those who indicated they were in search of other employment. Of the 48 responses, $44 \%$ ( 21 comments) indicated that the individual was still in search of other employment. These individuals simply had not become discouraged seekers yet. 
The majority, however, 56\% (27 comments) suggested a long period of looking or a failure to find other employment. Often, comments included references to the difficult economy or the 2008 economic downturn.

Table 17

Job Search Category Illustrative Comments

Representative Quotations

"I applied to many jobs while I worked for this person but couldn't find one."

"I have been looking for other job opportunities for some months now because after six years of being under his leadership, I really can't handle it anymore."

"I have only stayed because I am currently in the process of looking for a new job, but she is the direct reason as to why I no longer want to work here."

"I am only with the organization while I am in the process of finding another job."

"There are little opportunities in the current job market."

"Recession hit, lack of jobs, purchased new home so had to keep present level of employment."

"I need the job, downturn in the economy means fewer jobs in my sector, in general there are not many opportunities in my chosen career field to move from institution to institution, i am limited to where I can go."

"Terrible job market for nonprofits in San Diego is big reason why I have chosen to stay."

Compensation. The compensation category had a frequency response of 36 and also had two response codes, as shown in Table 18. One code represented an expression of responsibility as the family bread winner, while the other expressed the desire to maintain the level of pay or benefits they had without explaining why. These responses focused on salary and benefits. In some cases, the individuals remarked that the organization offered a higher level of pay and benefits than is typical in nonprofit 
organizations suggesting that there may be an underlying belief that working in the sector brings low pay and benefits. This could be an interesting interview topic for future research. The compensation category was intentionally limited to comments solely about pay and benefits.

Table 18

Compensation Category Illustrative Comments

Representative Quotations

"I have a family to support and times are tough as it is difficult to find adequate employment."

"It is a full time job in my field with benefits, which cannot be said of a lot of other jobs in my field in San Diego."

"Concern that I could not find another position with the same level of pay, responsibility and seniority that I had at the organization with the abusive supervisor." "After 20 years, my paycheck is high enough that starting over somewhere else would be a financial hit."

"I have a single family income and would require a job that would provide a similar salary."

Career management. The category, career management, expressed sentiments of wanting the experience the job offered or the career enhancement the supervisor afforded the employee. It also demonstrated fear that the supervisor would undermine the employee's career if he or she left. This category represented a career focus that overrode any negative aspect of the situation. While some looked to the future expressing consideration for what they could gain, others expressed that keeping what they had gained in the career was more important than leaving. 
Another code that was considered for career management involved those who were promoted away from the toxic supervisor within the organization. These were included with the larger category of change within organization because there was no indication that the individual had considered their career, only that the move had included a promotion.

While this category had some of the most varied types of comments, it also had one of the smaller frequencies, 29. As can be seen in Table 19, they ranged from long term goals to fear of damage to the career by a vindictive boss. Additionally, there was a code that dealt with those who put up with the abuse because of the career development and community connections the abusive supervisor afforded the employee.

Table 19

Career Management Category Illustrative Comments

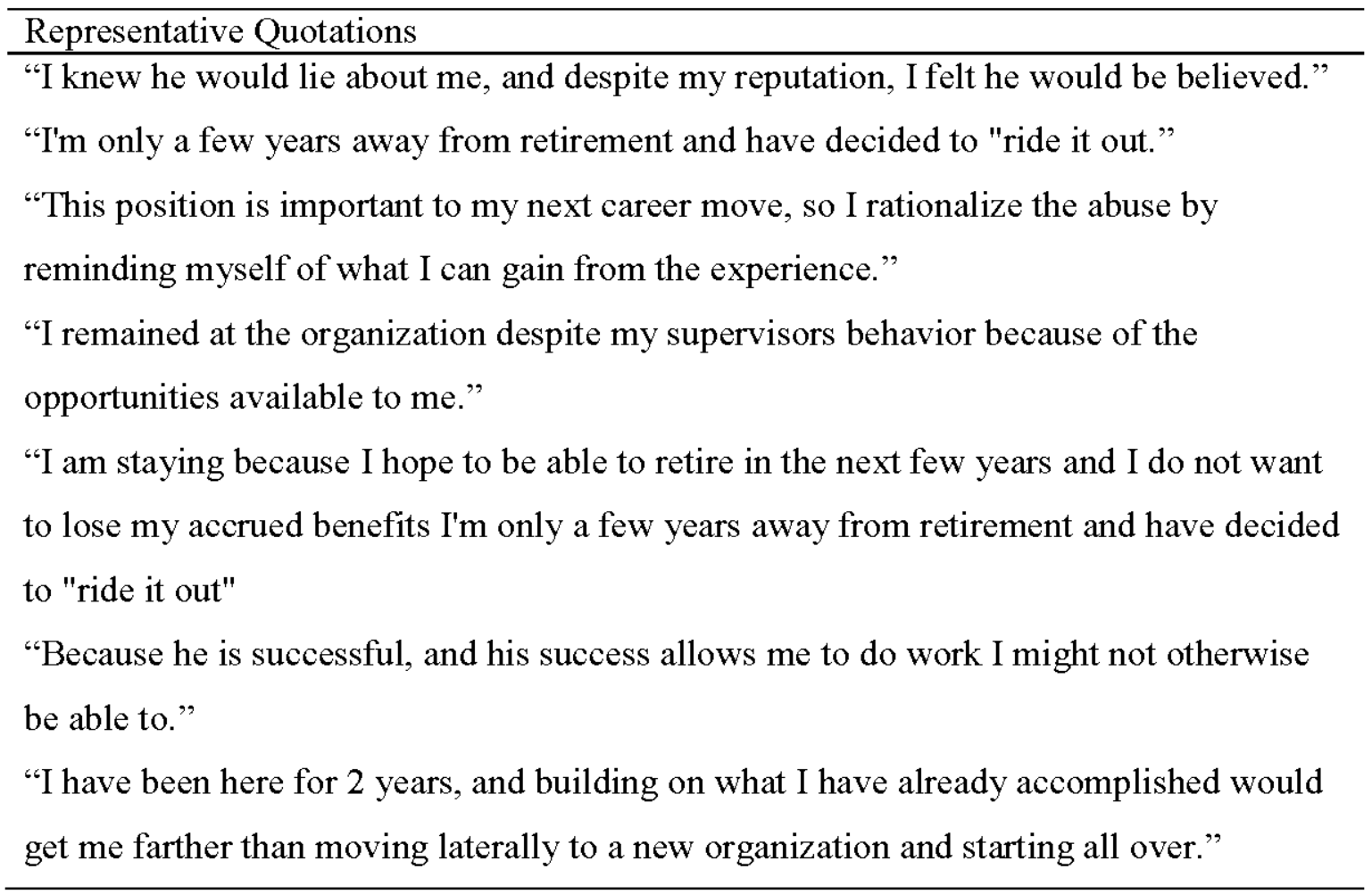


Representative Quotations

"I wanted to gain further experience in my position and I did not think I would be able to find an equivalent position elsewhere."

"Lack of relevant work experience and new to the work force; needed to stay for longevity reasons to gain enough experience before looking for other work."

Likes Work. The last manifest category had response types that the individual indicated they liked the job. Of the 23 comments, two codes emerged. Comments for one code expressed that the individual liked the field. "I loved my job and what I was doing it was that simple." The other type of comments expressed an idea that the person liked the actual work process. "I was able to do my job effectively and with quite a bit of independence." Since these codes did not indicate any deeper meaning or feelings and only expressed enjoying the work and the process, these responses were not included in the commitment category.

The manifest categories represented both temporal and practical content. Some respondents were thinking far ahead considering what the long-term benefits to their career might be, while others expressed ideas that appeared more in the present such as that they enjoyed the job or had immediate family financial needs to consider. The next group of categories represented those responses that may be part of a larger or deeper theme. There are four of these latent categories

Latent categories. Latent categories represent underlying themes and meanings of the coded words and phrases (Hsieh \& Shannon, 2005). Four latent categories were discovered during coding, $\mathrm{OCB}$, commitment, resilience, and the antithesis category to resilience, lost confidence. Table 20 offers the latent categories' frequencies and codes. 
Table 20

Latent Category Frequencies and Codes

\begin{tabular}{|c|c|c|}
\hline Category & Codes & Category Frequency \\
\hline \multirow[t]{6}{*}{ Resilience } & & 52 \\
\hline & Not directed at me & \\
\hline & Personal responsibility & \\
\hline & Situation got better & \\
\hline & $\begin{array}{l}\text { Sought help from organizational } \\
\text { leadership }\end{array}$ & \\
\hline & $\begin{array}{l}\text { Employee believed it would work } \\
\text { itself out }\end{array}$ & \\
\hline \multirow[t]{4}{*}{ Commitment } & & 45 \\
\hline & $\begin{array}{l}\text { The employee is committed to the } \\
\text { mission }\end{array}$ & \\
\hline & $\begin{array}{l}\text { The employee is passionate about } \\
\text { the mission }\end{array}$ & \\
\hline & $\begin{array}{l}\text { The employee loves the mission } \\
\text { and clients }\end{array}$ & \\
\hline \multirow{5}{*}{$\begin{array}{l}\text { Organizational } \\
\text { Citizenship } \\
\text { Behavior } \\
\end{array}$} & & \\
\hline & & 25 \\
\hline & Employees banded together & \\
\hline & Employee likes colleagues & \\
\hline & $\begin{array}{l}\text { Employee wants to protect } \\
\text { colleagues }\end{array}$ & \\
\hline \multirow[t]{2}{*}{$\begin{array}{l}\text { Lost } \\
\text { Confidence }\end{array}$} & & 4 \\
\hline & $\begin{array}{l}\text { Employee has lost confidence in } \\
\text { self }\end{array}$ & \\
\hline
\end{tabular}


Resilience and Lost Confidence. The Lost Confidence and Resilience categories are discussed together here because they may represent two extremes on a continuum. For example, people who expressed ideas that indicated they may be resilient may have gained this capacity from both their personal experiences and their genetic predisposition. The same may be said for those who expressed losing confidence or feeling beaten down. They may have not gained resilient capacities nor had a genetic predisposition to resilient behavior, since resilience is the ability to succeed in spite of adversity (Resnick, 2011). Importantly, it is both a process and state of being that can be modified over time (Luther, Cicchetti \& Becker, 2000). Some research has identified changes in the brain that create a propensity to be resilient, or not, particularly in the face of long term stress (Tsankova, Renthal, Kumar \& Nestler, 2007). Resilience also relates to the systems in which one lives and the resources available often referred to as the ecological model (Ungar, 2011).

There were 52 responses that might be considered resilience and only four that were not but the four were so intense that they required their own code. These indicators suggest some people may have had the internal and external resources and capacity to cope with certain levels of abusive behavior. Additionally, a lack of resilience may explain why some people indicated they were or nearly were incapacitated by the same kind of situation. Table 21 shows the varied comments in this category. Some remarked about a long-term engagement with the abuser in an effort to modify the behavior. Others suggested that the impact of the abuse was limited, further suggesting resilience. Those four who had lost their confidence either alluded to or openly admitted internalizing the negativity directed at them. 
Table 21

Resilience and Lost Confidence Categories Illustrative Comments

\section{Representative Quotations}

\section{Resilience}

"In general, his behavior had a limited effect on me but it did affect the entire organization."

"I had worked (hard) for this organization for over five years and felt I was not going to let someone bully me out of a job."

"I also protect myself quite well from my supervisor by not engaging in the arguments or power struggles."

"I also feel this is a temporary situation that will work itself out eventually."

"It took over a year of firmly refusing to engage in battles, but insisting on respectful behavior."

\section{Lost Confidence}

"The pattern of abuse was so pervasive that I had internalized her negative view of me so I thought that I was in a hopeless situation, powerless to get out, and worthless to any other organization."

Commitment. Commitment is the attitude that causes one to continue working in an organization regardless of the type of environment, and may be attributed to the type of mission or work of the organization (Blau and Boal, 1987; Handy \& Katz, 1998). It is associated with people giving greater effort to work activities without external incentives or threats (Goulet \& Frank, 2013). Of the 45 responses, some respondents used the term commitment or committed to the cause, the mission or the clients served. Others expressed love or passion for the mission or the clients. These emotions have been noted as part of nonprofit employees' views about why they do difficult and often poorly 
compensated work (Handy \& Katz, 1998). The quotations shown in Table 22 suggest a deeper feeling than those represented in the Likes job category.

Table 22

Commitment Category Illustrative Comments

Representative Quotations

"I have a strong commitment to the mission of the organization and I knew that I would outlast her board tenure."

"I love serving the clients."

"I passionately believe in my organization's mission and vision"

"Love the non-profit I work for and figured I would be dealing with similar issues at other jobs."

"I also stayed because I feel strongly that the job I do is important and I am committed to making a difference in the lives of the children and families we work with." "Because I believe very strongly in the mission of the nonprofit organization."

Organizational citizenship behavior (OCB). Organizational citizenship behaviors are those actions of one employee to another or one group to another that can enhance the long-term productivity of the organization but are not part of the individual's job requirements in any way. This is a key element of OCB -- that the behavior is not a technical or contractual performance requirement (Organ, 1997). Specifically, OCB is behavior that helps out coworkers, is courteous, and gives a good impression of the organization to outsiders (Zellars, Tepper \& Duffy, 2002). In essence, these behaviors are collaborative, helpful and supportive.

The OCB category was expressed by 25 comments in three distinct codes. These codes revolved around descriptions of supporting colleagues that might involve the peacemaker subscale of Organ's OCB model (Podsakoff, MacKenzie, Paine \& Bachrach, 
2000). The individuals indicated wanting to protect their other colleagues. Respondents noted that the employees banded together to support one another against the toxic leader, suggesting in some cases that their deep relationships help them accomplish their work. As can be seen in Table 23, the responses tended to revolve around ideas of unity and job accomplishment.

Table 23

Organizational Citizenship Behavior Category Illustrative Comments

Representative Quotations

"Some of us have chosen to band together and ride her out."

"I really enjoy working with every other person in my organization"

"I believe I mitigate some of the executive director's difficult and abusive actions."

"I also love the rest of my co-workers and feel we have a good relationship, get stuff done, and collaborate despite the difficult boss."

"I remain with the organization because I enjoy the culture, staff and environment here in spite of my supervisor."

"I fear that if I leave, the next level would too."

\section{Summary Research Question 4}

The five manifest and four latent categories discovered in the responses offer only a cursory look at the reasons people stayed in spite of toxic leadership. Further amplification of the relationship between these potentially important influencers on staff members' decisions to stay or leave is necessary to better understand why they stay, as well as how they interact with their colleagues and perform their duties. These responses, however, suggest that there may be more, complex and difficult relationships amongst staff members, leaders and colleagues that need further exploration. 
The five manifest categories suggested concerns with the economy (familial responsibility), difficulty finding another job and personal interests that outweighed the toxicity such as career management concerns and just liking the job itself. The latent categories, resilience, $\mathrm{OCB}$, commitment and lost confidence, may relate to the manifest categories but more complete follow up is required to fully understand the connections between these categories and the nuances within them.

\section{Summary of Results}

Toxic leadership was found to exist in this sample of San Diego nonprofit organizations. Despite the sample being too tightly constrained at the beginning of the study, the findings regarding the relationship between toxicity, and OCB and turnover indicated that there was no relationship. However, a less constrained sampling method may be needed to determine conclusively if there is or is not a relationship. This may also be the case for the mediating or moderating influence of commitment on both OCB and turnover. Baron and Kenny (1986) support this possibility in their discussion of the complexity of social science variables, especially, that the internal psychological nature of mediators can result in an underestimation of the effect of the mediator and an overestimation of the effect of the predictor. Therefore, there may be variables that are operating on the respondents that are not included in the model, some of which may have been discovered in the qualitative question responses with variables that include issues of compensation, a difficult economy, professional development, personal relationships, commitment and resilience. Further, OCB was found as a possible influencer variable that may be an additional explanation why there were inconclusive findings as an outcome variable. 
The relationships between leader and follower and between fellow colleagues are complex. There are also a myriad of influences on the decision to remain or leave an organization. It is not surprising that toxicity exists in nonprofit organizations as it exists in organizations in both the for-profit and government sectors, however, the employee response to that toxicity is a complex interaction that calls for analysis that includes as much of that complexity as possible to fully understand its depth and breadth. In this way, researchers and practitioners can begin to understand the true impact toxicity has on the nonprofit organization. 
Chapter 5: Discussion

This study found that toxic supervision exists in the sample of nonprofit organizations. In this final chapter, the research is summarized including the problem and purpose statements and a review of the methodology. Findings are offered with some possible explanations that were discovered in the literature that may address certain aspects of the results. Finally, limitations of this study are discussed and some suggestions for future research are provided.

\section{Statement of the Problem}

The nonprofit sector in San Diego County provides important services to residents, often the most vulnerable, who might otherwise be without them. In times of shrinking resources, nonprofit organizations need to be innovative and creative in how they continue to deliver those services. Although toxic leader behaviors have been shown to undermine organizational success in for-profits and public organizations, it is not well documented how, or even if, toxicity is related to nonprofit professionals and their organizations' success (Conger, 1990; Ashforth, 1994; Whicker, 1996; Kellerman, 2004; Reed, 2004; Hogan \& Kaiser, 2005; Lipman-Blumen, 2005; Einarsen, Aasland \& Skogstad, 2007; DeAngelis, 2009; Reed \& Olsen, 2010). Specifically, there is no empirical evidence of the effect toxic leader behaviors have on nonprofit paid staff members' OCB and turnover behavior; nor, is there evidence of the influence employees' commitment to the organization's mission may have on those relationships.

\section{Purpose of the Study}

The objective of this study was to explore the constructs of toxic leader behavior and its effect on the individual's OCB and intent to stay in the nonprofit organization 
despite experiencing toxic leadership. Its objective included an understanding of the influence of commitment on those effects. Finally, it was intended to identify reasons individuals stayed in an organization despite experiencing toxicity from their leaders. Questions that addressed this objective were:

1. To what extent does toxic leader behavior exist in San Diego nonprofits?

2. To what extent does toxic leader behavior explain variation in both organizational citizenship behavior and turnover behavior in San Diego nonprofits?

3. Does level of commitment significantly mediate and/or moderate the effect of toxic leadership on both organizational citizenship behavior and turnover behavior in San Diego nonprofits?

4. What reasons do individuals give for remaining with a nonprofit organization despite toxic leadership in San Diego nonprofits?

\section{Review of the Methodology}

To accomplish the aims of this study, a concurrent cross-sectional mixed methods design was used. Data was collected via an electronic survey developed in the software Qualtrics and stored on university servers. The data included 63 survey items to collect data on the respondents' experiences with toxic leadership and their reaction to it as measured through OCB, commitment and turnover. An open ended question was used to collect data on the reasons the individual stayed in the organization despite experiencing toxicity. The sample primarily consisted of San Diego nonprofit paid staff members whose organizations use a large San Diego human resources firm that provides personnel and training services. Additionally, a small group of respondents were affiliated with a 
San Diego nonprofit professional networking group. The data was then analyzed using both descriptive and inferential techniques as well as content analysis.

\section{Findings}

The primary finding was that toxic leader behavior was found in the sample of San Diego nonprofit organizations. Unfortunately, the results of the analyses of the relationships between toxic leadership, and $\mathrm{OCB}$ and turnover, as well as the influence of commitment on those relationships were inconclusive. However, respondents offered other influencer variables for the reasons nonprofit employees remain in the organization in spite of toxic supervision. Particularly, the outcome variable OCB was found in the qualitative results of other influencer variables on turnover suggesting that it may not be an outcome variable at all. The following discusses these findings by research question.

\section{Research Question 1}

To what extent does toxic leader behavior exist in San Diego nonprofits?

The fundamental purpose of this study was to determine if toxic leadership could be found in San Diego nonprofit organizations. It was. Two hundred and ninety-eight $(63 \%)$ respondents experienced some level of toxicity. The respondents had representative demographic characteristics of nonprofit employees found in previous research. They were white $(73 \%)$ women $(77 \%)$ with higher levels of educational attainment (88\%) than their counterparts in the for-profit and public sectors. On the other hand, the sample's types of organization differed from the agency's client organizations.

For example, arts and culture employees responded at twice the rate of the agency's clients. Moreover, mutual and member benefit organizations were not represented in the sample at all but were one of the largest groups of agency client 
organizations. This may suggest a need for further inquiry into the relationship between toxic leader behavior and certain types of organizations.

The toxic supervision variable items were taken from the Destructive Leader Questionnaire (DLQ) that Shaw, Erickson and Harvey (2011) developed based on Kellerman's (2005) models of destructive leaders. Their sample was derived from respondents from advertisements on over 600 international professional websites and newspapers, at their university, on their local and national television stations, and with the cooperation of several human resource directors with whom they were acquainted (2011, p. 577). This resulted in item responses ranging from 501 to 691 respondents. Their respondents were from 30 nationalities, over half Australian (53.9\%) and nearly a quarter (22.9\%) American (p. 578), and represented all sectors. The average age was 43.8 years, with a range from 19 years to 76 years (p. 577), and 92.3 percent held university degrees (p. 578). Shaw and his colleagues ran descriptive statistics on each of the 123 items in the instrument but reported only the highest and lowest mean scores, 2.12 to 3.99 (p.578). In comparison, this study used a convenience sample solicited from staff members whose organizations were affiliated with a local human resources agency, and from members of a nonprofit professionals' networking organization that yielded 471 total responses.

Seventy-six percent of this study's respondents held university degrees and their average age at the time the toxic experience they were reporting was 38 years. They responded to 25 of the 123 items of the DLQ considered appropriate to this study's definition of toxicity. The highest and lowest item means in this study were 3.48 and 5.02 respectively, higher than those reported by Shaw, Erickson and Harvey. This is 
likely due to the sorting process described above having only those who believed they had worked for a toxic leader respond and not that San Diego nonprofit organizations experience considerably higher levels of toxicity. However, this study was able to show that San Diego nonprofit employees do experience toxic leadership in different types of organizations, at all levels in the organization and educational attainment. The study provided a baseline for comparison by other researchers.

\section{Research Question 2}

To what extent does toxic leader behavior explain variation in both organizational citizenship behavior and turnover behavior in San Diego nonprofits?

This analysis evaluated the relationships between toxic supervision, and OCB and turnover. While there was no significant relationship between turnover and toxicity in this sample, OCB and its three subscales (civic virtue, helping behaviors and sportsmanship) did have a significant relationship with one or more of the toxic DLQ subscales used for the toxic supervision variable (acting in an insular manner relative to other groups in the organization, acting in a brutal or bullying manner, and lying and other unethical behavior) and a demographic variable (arts organizations) (See Table 14). However, these relationships were weak, the direction of the relationships was not supported by the literature and the models' explanatory capacities were so small as to be unimportant. In light of this, other possibilities were considered.

The design of the study most likely caused these results because the respondents only accessed the toxic leader items if they indicated they believed they had worked for an abusive supervisor. This may have produced a too narrowly constrained sample that did not include the greater response variation of all respondents that impacted all or some 
of the relationship evaluations. However, there may be some indication that other issues also impacted the results. How these may have affected the turnover and OCB relationships with toxic supervision is discussed briefly below.

Turnover. The dichotomous outcome variable turnover was unexpectedly negatively correlated to the toxic supervision predictor variable (TS) (TS, r(177) $=$ $-0.147, p=.05)$, a finding that is unsupported in the literature. Logistic regression was used to evaluate the relationships between the dichotomous dependent variable, turnover, and the toxic leadership predictor variable and its subscale variables. Neither the model with the toxic supervision scale variable nor the models with the subscale variables were significant.

Power analysis indicated that 522 responses were necessary for a logistic regression analysis. Only 298 were obtained. While there are statistical methods like bootstrapping designed to overcome these kinds of issues, insufficient variation in the sample in the first place negated the use of this technique. The literature, however, reflects that turnover increases as toxicity increases. The negative correlation found in this study's analysis and the lack of model significance may be a result of the sampling method used. However, for the most part, these findings were inconclusive. Like the turnover relationship, the toxic supervision and OCB relationship also had inconclusive and unsupported findings that may be related to the sampling method. They may, however, also have other influences working on the relationships that will be touched on in the next section.

Organizational Citizenship Behavior (OCB). Organizational Citizenship Behavior (OCB) was not significantly correlated to the toxic supervision variable. In an 
effort to completely understand the relationship, stepwise regression was used with models including the outcome variable OCB, its subscales, the demographic variables, the toxic supervision scale variable and its subscale variables.

As can be seen in Table 14, the two toxic subscale variables, lying and other unethical behavior and acting in a brutal or bullying manner, were significant with two subscales of OCB (civic virtue and helping behaviors). However, the model's explanatory capacity and the coefficient effect sizes were so small as to be unimportant. As was discussed in the above section about the turnover outcome variable, this may be a result of the sampling method used. In an effort to more thoroughly explore these results, an investigation into additional literature yielded some other possibilities for them.

For example, Meyers, Gamst and Guarino (2006) suggest that a low R-square in a complex social science study may indicate a need for further research rather than an inadequate variable (p. 166). An example of one of these other variables is identification with the organization.

Decoster and colleagues (2013) considered how an employee's identification with the organization might buffer the effect abusive supervision has on group cohesion (Decoster, Camps, Stouten, Vandevyvere \& Tripp, p. 626) using group cohesion as a desired organizational outcome variable (p. 624). It is an individual's perception of his or her relationship with their group and the force it creates to remain in that group. They found that higher identification with the organization buffers the effects of toxic supervision on perceived group cohesiveness (p. 630).

For nonprofit employees specifically, Handy and Katz (1998) found that nonprofit employees view the organization itself as fulfilling a social need (p. 251), suggesting that 
they see the organization and the cause or mission as one. In light of this, Decoster's and colleagues' findings may indicate that nonprofit employees, who strongly identify with their organization's mission, and therefore their organization, may respond differently to abusive supervision with respect to certain organizational outcomes. Further research and a more inclusive sampling method might shed light on this possibility.

Further support of the idea that nonprofit employees' relationship to their organizations may be different than their counterparts in other sectors is Akingbola's (2012) nested social exchange model designed to explain the exchange or relationship between employees and their organizations. He nests both the economic exchange and social exchange in a third level derived from the social objectives, values and environment of the nonprofit organization (p. 984). He posits that when the social objectives and values of the organization are similar to those of the employee, it fosters a system of built-in social exchange between employees and their organizations. This exchange is based on the actual social goals and values of that particular nonprofit.

These employees expect a work environment that actualizes their values and offers them an opportunity to contribute to the social cause (Akingbola, 2012, p. 985), and they perceive the social objectives of the organization as part of their personal objectives (p. 988). This is offered as connectedness that may exist between employees and their organizations supporting the idea of mediating or buffering negative experiences such as toxic supervision that may not be prevalent in other sectors.

While the lack of variation in this study's sample produced inconclusive results, other research such as that presented above suggests the possibility that the relationships between toxic supervision and organizational success outcome variables like turnover and 
OCB actually are different than normally found in the for-profit and public sectors.

There may also be other influencers and the influencer and predictor variables may even be juxtaposed as suggested by Meyers, Gamst and Guarino (2006). Some of these other influencers included OCB as a mediator instead of an outcome variable.

\section{Research Question 3}

Does level of commitment significantly mediate and/or moderate the effect of toxic leadership on both organizational citizenship behavior and turnover behavior in San Diego nonprofits?

There was no conclusive moderating or mediating influence by commitment on either the relationship between abusive supervision and $\mathrm{OCB}$, or abusive supervision and turnover. As noted above, this may have been a result of the sample being too narrowly constrained. However, this lack of influence may also have been impacted by incorrect assumptions about the influencer variable itself.

Baron and Kenny (1986) caution that because mediators are an internal psychological variable, measurement error can result in an underestimation of the effect of the mediator and an overestimation of the effect of the predictor variable (p. 1177). They also warn that there may be an incorrect assumption about which variable is the predictor and which is the mediator in the model (p. 1177). There may also be multiple influences acting at the same time.

In a study looking at the buffering effect of coworker support on work engagement in the presence of abusive supervision, Poon (2011) found that coworker support did not buffer the impact of abusive supervision on work engagement. However, Poon suggests that the lack of buffering may have been a result of three-way interactions 
rather than the variable having no influence (p.68). A three-way interaction occurs with more than one moderator (Preacher, Curran \& Bauer, 2006). Therefore, there may be other interaction variables that were not included in the model that affected the relationship between toxicity and the outcome variables. Furthermore, some overlap of other role perception and OCB may be involved.

Extra-role behavior, or those behaviors that are not part of their work requirements, such as OCB activities, may not be completely understood in their similarities and differences (Podsakoff, MacKenzie, Paine \& Bahrach, 2000, p. 515). In light of this, nonprofit staff may view some aspects of OCB similarly to other types of behaviors such as commitment. Since they have been found to closely identify their organization's mission with their own values (Handy \& Katz, 1998; Akingbola, 2012), they may have unidentified overlap in their concept of commitment and at least some aspects of $\mathrm{OCB}$.

Additionally, as noted by Poon (2011), moderation may be present but with interactions between multiple influencer variables. Therefore, while commitment did not influence the relationship between toxic leadership and OCB or turnover, there may be other as yet unidentified variables influencing those relationships at the same time.

However, if it is the case that there are other influencer variables, some of these may have been uncovered in the qualitative analysis involved in the final research question.

\section{Research Question 4}

What reasons do individuals give for remaining with a nonprofit organization despite toxic leadership in San Diego nonprofits? 
Content analysis was used to analyze the qualitative question. It uses an inductive approach to create meaning from qualitative data's codes and categories through patterns and themes (Patton, 2002, p.453). The manifest descriptions of the content resulted in reported frequencies, while the latent descriptions also suggested underlying meanings represented in conceptual mapping through open coding (Hsieh \& Shannon, 2005). The Framework Approach was included in the analysis process because the open-ended question had a single directed intent, specifically looking for reasons nonprofit employees stayed in an organization despite toxic leadership.

The first step of the analysis was familiarization with the data. The second step identified the thematic framework, or used the a priori themes, while searching for other possible themes. The data was then coded, charted, mapped and interpreted (Srivastava \& Thomson, 2009, p. 4). Five manifest and four latent categories were discovered in the data. These categories represent potentially important influencers on staff members' decisions to stay, their interactions with their colleagues, and their performance of their duties. Respondents' comments expressed concerns about the economy, responsibilities to their families and colleagues, career aspirations, commitment to their mission and clients, and indicated personal characteristics reflective of resilience.

The manifest categories were change within organization, job search, compensation, career management and likes work. The category frequencies ranged from 23 to 59. Table 16 shows the manifest categories, their codes and frequencies.

Those who indicated that they were motivated to stay for their careers looked at the larger picture recognizing that they could gain needed experience and opportunities to further their work and their careers if they just endured the abuse. Others reported 
fearing retribution by the toxic supervisor if the employee left the organization. Many of the responses reflected concern about the state of the economy. Some simply believed that there were few opportunities available for people in their field. Some respondents expressed worry that they could not afford to take a reduction in compensation because of their age or family situation. The only job search code that was not discouraged simply indicated that the individual was still in search of other employment and had not yet become discouraged.

A drawback to using a single open-ended question response is losing the context and deeper meaning of the response. For integrity purposes, no assumptions were made, so some manifest categories may actually be part of other latent categories, but understanding how would require further exploration. For example, the likes job category may in fact be part of the latent commitment category but the brevity of the responses prevented uncovering that much detail. The latent categories represented the two a priori variables, commitment and $\mathrm{OCB}$, and two new and related categories, resilience and lost confidence. Table 20 shows the latent categories, frequencies and associated codes.

Those respondents who suggested mutual support from colleagues may represent part of Organ's OCB subscale, peacemaker (Podsakoff, MacKenzie, Paine \& Bachrach, 2000, p.518). Again, without follow up clarification, the true meaning was difficult to ascertain. However, this suggests that OCB may not in fact be an outcome variable but an influencer that might explain the inconclusive results as an outcome variable. Less difficult to discern, the a priori variable, commitment, was well represented in the sample's responses with statements revolving around love, dedication and stated 
commitment to the organization's mission and clients. Resilience and lost confidence (considered as a lack of resilience in this study) were the final categories uncovered in the analysis.

Resilience is the ability of an individual, when faced with adversity, to create positive outcomes (Luther, Cicchetti \& Becker, 2000). Considered culturally and temporally specific (Unger, 2011), it derives from the competence literature defined as patterns of effective adaptation in one's environment (Masten \& Coatsworth, 1998, p. 206). In addition to the adaptive aspects of resilience, there is also a physical component. Epigenetics, the chemical and cellular changes in the brain that occur when it is exposed to intense and extended stress, suggest that individuals may be more or less predisposed to cope with stress depending on their genetic expression (Tsankavoa, Renthal, Kumar, \& Nestler, 2007, p. 355). The responses in the resilience category included views such as refusing to engage in combative activities and not allowing the toxic behavior to impact the individual, the same as the lost confidence responses indicated a possible lack of resilience.

The nine categories represented potentially important variables that influence leader/follower relationships in the nonprofit workforce. Underlying this analysis are multiple possible interactions that could be influencing these complex relationships that may be important to the understanding of toxic leadership's impact on nonprofit organizations' mission accomplishment.

\section{Limitations}

In order to understand the findings of this study, each aspect of it -- from the collection process to the analysis -- need to be clearly explained. Included in this 
thorough understanding, is as complete as possible a description of the potential biases and limitations so that the findings of the study can be understood in context.

Data collection using only an electronic survey has some response bias. A large group of people may not have organizational email thus being excluded from participation (Rea \& Parker, 2005). However, the focus of this study was nonprofit organizations large enough to have paid staff members, suggesting that they would have some organizational email. Therefore, those excluded for lack of email would most likely be outside of the scope of this study.

Another possible bias concerned recalling a stressful situation. There is some evidence that anxiety may influence the recall of difficult or anxiety-filled memories (Mitte, 2008). Further, social desirability response bias may cause inaccurate and inflated recall of toxic incidents and the feelings surrounding them (Nisbett \& Wilson, 1977).

There are also biases resulting from a small response group. In these cases some statistical measures may suffer from inflated Type I or Type II errors, and as a result, relationships may seem more or less significant than they really are (Meyers, Gamst \& Guarino, 2006). In this study, it is very likely that there was a narrowing of the variation in the sample because the sampling method included only those individuals who believed they had worked for a toxic leader.

Moreover, since the qualitative analysis involved the responses to a single openended question, there may also be limited understanding of the true meaning the respondents were trying to convey. Additionally, researcher bias is always a concern in qualitative research. This requires that steps are taken to verify that the findings are not filtered through the particular views and prejudices held by the researcher (Glesne, 2005). 
For example, if the researcher is also an employee in the nonprofit sector, bias could occur by focusing on positive and altruistic responses and ignoring or minimizing other types of responses. The specific measures taken to mitigate this type of bias were addressed in the analysis section.

Despite these limitations, however, this study verified that at least some nonprofit staff members spend time and energy dealing with toxic leader behaviors. It also offered additional influence variables that may be useful for future research.

\section{Implications}

While there were no definitive findings about the relationship between toxicity, and OCB and turnover, there was information found that San Diego nonprofit staff members do experience toxic leader behaviors. There were also other possibly important relationship and influencer variables offered that may support greater understanding of the sector's workforce. It also may serve to bring toxicity to the attention of sector leaders, and begin a dialogue designed to improve leadership and working conditions for nonprofit employees. This is a large workforce that supports community members of all ages providing services to some of the most in need in San Diego County in areas including health, education, and homelessness.

This study was intended to open a dialogue in the San Diego nonprofit sector around toxic leadership. With ever shrinking resources and growing community need, it is important to pursue research designed to uncover the complexities of nonprofit leadership, both abusive and positive, and its effect on staff members' ability to innovate and ensure their organizations' success. While, the relationship findings were inconclusive, the qualitative responses suggested other reasons nonprofit employees do 
not leave an organization because of a toxic supervisor implying organizations that measure success this way may have incorrect and misleading information.

Moreover, as employees who suffer under toxic leadership become leaders themselves, they may be inclined to continue the toxic methods through emulation, as suggested by Restubog, Scott and Zagenczyk (2011) referring to Bandura's social learning theory, resulting in increased and more widespread toxicity (p. 714). Without adequate leadership development, along with sector specific leader development, they will not understand the relationships necessary for effective organizational success to ensure long term success.

Complex, multi-stakeholder environments define the space in which organizations from all sectors work (Maak \& Pless, 2006). Nonprofit organizations need to understand how to relate to various stakeholders, including their own staff members, to successfully accomplish their missions. Based on available literature, the nonprofit sector seems to focus leadership on either board governance or succession planning, while the for-profit and government sectors have invested in leadership development throughout their organizations. The third sector may need to consider doing the same.

\section{Recommendations for Future Research}

The results of this study support further research into the influence of the variables identified as manipulating the relationship between toxic leader behavior and turnover. Seven other influencer variables were found from the responses in this study. Understanding these influences and how they relate to each other will create greater understanding of nonprofit employees to better support them. 
There are three recommendations for future research based on this study's findings. Additionally, there are other influence variables noted below that may enhance the understanding of toxicity's relationship to turnover and what influences nonprofit employees that were not found in this study but are in the literature.

First, redesign this study as an explanatory/sequential mixed methods study using an instrument that includes the entire DLQ and turnover as the outcome variable. Involve all possible respondents, not only those who feel they worked for a toxic leader.

Additionally, include other influencer variables to better understand the nuances of the relationship between toxicity and turnover. The concept map above is offered as a menu of sorts to consider other issues at work on the leader/follower relationship as well as those uncovered in the qualitative part of this study.

Second, it would be interesting to engage a network of organizations such as the Red Cross or United Way in which follow up interviews could be obtained for greater clarification, allowing for deeper meaning to unfold potentially capturing organizational context. This instrument could then be offered to multiple networks enabling a crosscase analysis of at least certain aspects of the findings to determine similarities and differences between them.

Third, conduct research with a broad sampling design that would collect data on the influencer variables discovered in this study and include some of the many possible additional influence variables noted in the conceptual map. By collecting this data from a large and diverse sample, the possible influencers could be evaluated by organizational mission to understand if mission affects the variable relationships, and include the exploration of possible self-selection characteristics of the respondents by mission type. 
Finally, other additional variables that influence responses to toxicity include fundamental aspects of the individual's personality that may make them more or less likely to accept abuse, including their personal history of abuse. The findings of reasons respondents remained in the organization in spite of toxicity did not have the benefit of the respondents' contexts and backgrounds. For example, there could be a relationship between resilience and $\mathrm{OCB}$, as well as respondent's individual personal traits, motivation and developmental level. Therefore, there are also other personal and individual aspects that influence the relationship between toxicity and turnover that could more thoroughly explain that relationship. Some are noted below.

Padilla, Hogan and Kaiser (2007) employing the core self-evaluations model, posited that individual traits and predispositions can make subordinates susceptible to toxic leadership. Core self-evaluations include self-esteem, generalized self-efficacy, locus of control, and nonneuroticism (Judge, Locke, Durham \& Kluger, 1998, p. 17). Furthermore, research has shown that people who have previous abuse from childhood, resulting in post-traumatic stress disorder, will have longer, and more extreme responses to stress as well as unnecessary stress responses, and that women will exhibit differences in those responses ( Bremner, et al., 2003; Wu, 2009). Additionally, while men and women have been found to discipline their subordinates the same, the perception of differences between them exists (Bellizzi \& Hasty, 2002; Eagly \& Karau, 2002; Wu, 2009). This also begs the question whether or not subordinates' perceptions and reactions to abusive leadership differ by gender and the gender of the leader. Finally, underlying at least part of individuals' reactions to others and their environments is their developmental level. These are important questions in a sector so diverse in mission. 


\section{Conclusions}

Finding toxic leader behaviors in this sample of San Diego nonprofits was not unexpected since it exists to some degree in all organizations. It was surprising however that contrary to the literature the OCB findings were effectively inconclusive. This may be related to it appearing as a possible influencer variable in the qualitative question. Furthermore, there was no relationship found between turnover and toxicity that may have resulted from errors occurring from the overly constraining sampling method used,

although, it may have been a function of nonprofit employees' unique characteristics and how they interrelate instead of methodological issues.

While commitment failed to influence toxic supervision's relationship to OCB and turnover, the other influencing factors uncovered need to be included in future research for greater clarity and understanding. There were eight other influencing variables in addition to commitment identified in this study, including the other outcome variable, OCB. See Figure 6. Some of these influencers dealt with the individuals' personal and group characteristics that may be stronger in nonprofit employees as well as issues and concerns they have with the economy. Further research is necessary to ascertain a more complete picture of the nonprofit workforce and how it is impacted by various leadership styles, including toxic leadership. 


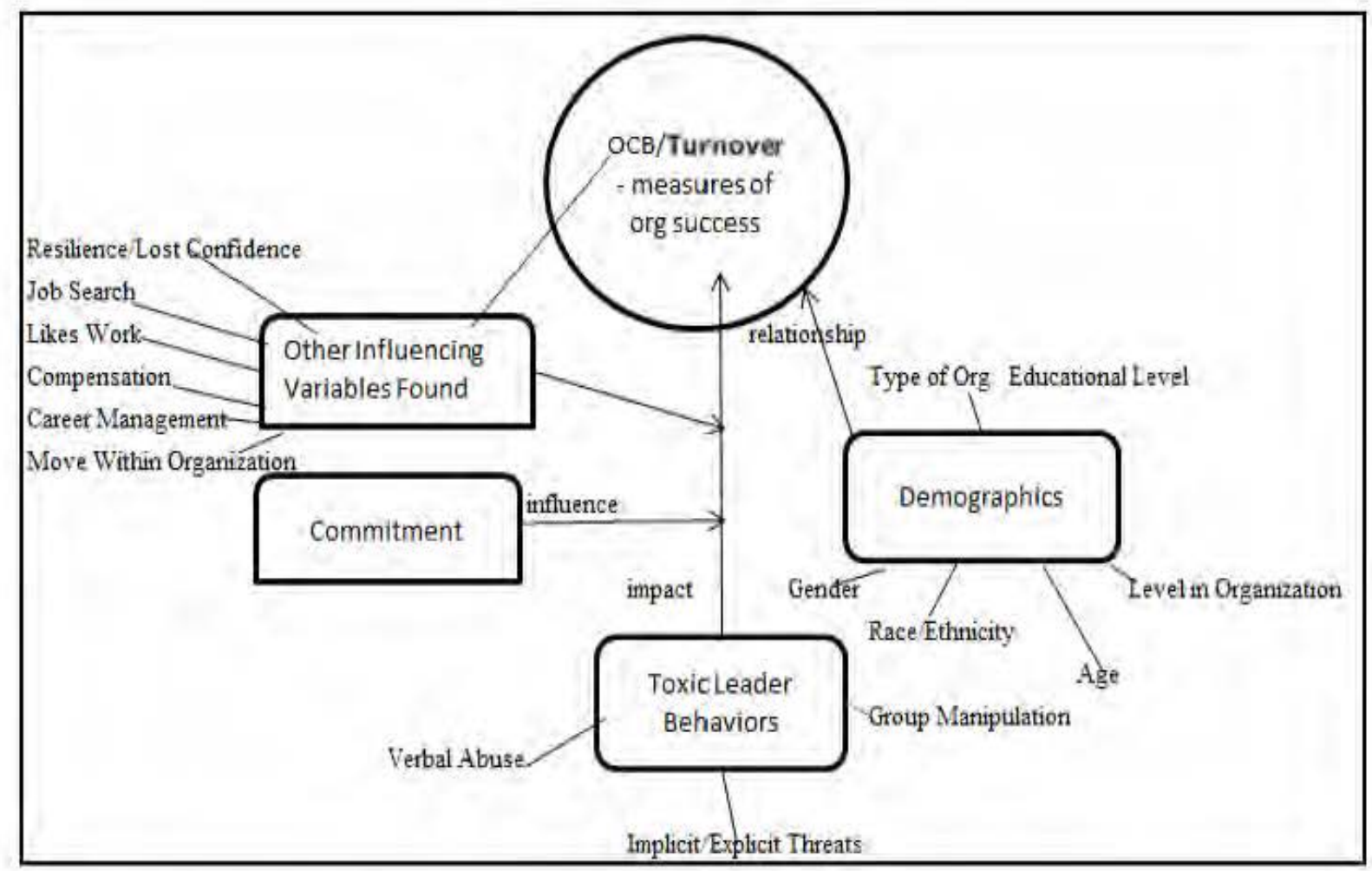

Figure 6. Revised Relationship Map. 


\section{References}

Akingbola, K. (2012). Context and nonprofit human resource management. Administration and Society, 45(8), 974-1005.

Allen, N. J. \& Meyer, J. P. (1990). The measurement and antecedents of affective, continuance and normative commitment to the organization. Journal of Occupational Psychology, 63(1), 1-18

Allen, R. D. Hitt, M. A. \& Greer, C. R. (1982). Occupational stress and perceived organizational effectiveness in formal groups: An examination of stress level and stress type. Personnel Psychology, 35(2), 359-370.

Applebaum, S. H. \& Roy-Girard, D. (2007). Toxins in the workplace: Affect on organizations and employees. Corporate Governance, 7(1), 17-28.

Ashforth, B. E. (1994). Petty tyranny in organizations. Human Relations, 17(7), 755-778.

Baron, R. M. \& Kenny, D. A. (1986). The moderator-mediator variable distinction in social psychological research: Conceptual, strategic, and statistical considerations. Journal of Personality and Social Psychology, $51(6), 1173-1182$.

Bass, B. M. \& Steidlmeier, P. (1999). Ethics, character and authentic transformational leadership behavior. Leadership Quarterly, 10(2), 181-217.

Bellizzi, J. A. \& Hasty, R. W. (2002). Supervising unethical sales force behavior: Do men and women discipline men and women subordinates uniformly? Journal of Business Ethics, 40(2), 155-166.

Berk, R. A. (1983). An introduction to sample selection bias in sociological data. American Sociological Review, 48(3), 386-398. 
Blau, G. T. \& Boal, K. B. (1987). Conceptualizing how job involvement and organizational commitment affect turnover and absenteeism. Academy of Management, 12(2), 288-300.

Boris, E. T. \& Steuerle, C. E. (2006). Scope and dimensions of the nonprofit sector. In Powell, W. W. \& Steinberg, R. (Eds.). The Nonprofit Sector: A Research Handbook, (Ed. $2^{\text {nd }}$ ). New Haven, CT: Yale University Press.

Bremner, J. D., Vythilingam, M., Vermetten, E., Adil, J., Kahn, Nazeer, A., Afzal, N., McGlashan, T., Elzinga, B., Anderson, G. M., Heninger, G., Southwick, S. M. \& Charney, D. S. (2003). Cortisol response to a cognitive stress challenge in posttraumatic stress disorder (PTSD) related to childhood abuse. The Journal of International Society of Psychoneuroendricrinology, 28(6), 733-750.

Burns, J. M. (1978). Leadership. New York, NY: Harper \& Row, Publishers, Inc.

Creswell, J. W. (2009). Research Design: Qualitative, Quantitative, and Mixed Mehtods Approaches (Ed. $3^{\text {rd }}$ ). Los Angeles, CA: Sage Publications, Inc.

Creswell, J. W. \& Clark, V. L. P. (2011). Designing and Conducting Mixed Methods Research, (Ed. $\left.2^{\text {nd }}\right)$. Thousand Oaks, CA: Sage Publishing, Inc.

Conger, J. A. (1990). The dark side of leadership. Organizational Dynamics, 19, 44-55.

Contino, D. S. (2002). How to slash costly turnover. Nursing Management, 33(2), 10-13. DeAngelis, P. M. (2009). Blindsided--Recognizing And Dealing With Passive-Aggressive Leadership In The Workplace. DeAngelis.

Decoster, S., Camps, J., Stouten, J., Vandevyvere, L. \& Tripp, T. M. (2013). Standing by your organization: The impact of organizational identification and abusive supervision on followers' perceived cohesion and endency to gossip. Journal of Business Ethics, 118, 623-634. 
Eagly, A. H. \& Karau, S. J. (2002). Role congruity theory of prejudice toward female leaders. Psychological Review, 109(3), 573-598.

Eatough, E. M., Miloslavik, S. A., Chu-Hsaing, C. \& Johnson, R. E. (2011).

Relationships of role stressors with organizational citizenship: A metaanalysis. Journal of Applied Psychology, 96(3), 619-632.

Einarsen, S. Aasland, M. S. \& Skogstad, A. (2007). Destructive leadership behavior: A definition and conceptual model. The Leadership Quarterly, 18, 207-216.

Feiock, R. C. \& Andrew, S. A. (2006). Introduction: Understanding the relationships between nonprofit organizations and local governments. The International Journal of Public Administration, 29, 759-767.

Glesne, C. (2005). Becoming Qualitative Researchers, (Ed. $\left.3^{\text {rd }}\right)$. San Francisco, CA: Pearson Education, Inc.

Gliem, J. \& Gliem, R. R. (2003). Calculating, Interpreting, and Reporting Cronbach's Alpha Reliability Coefficient for Liker-Type Scales. 2003 Midwest Research to Practice Conference in Adult, Continuing, and Community Education.

Downloaded February 15, 2015 http://www.alumniosu.org $/ \mathrm{midwest} / \mathrm{midwest} \% 20$ papers/Gliem $\% 20 \& \%$ 20Gliem--Done.pdf

Goetzel, R. Z., Hawkins, K., Ozminkowski, R. J. \& Wang, S. (2003, Jan). The health and productivity cost burden of the "Top 10 physical and mental health conditions affecting six large U.S. employers in 1999. Journal of Occupational and Environmental Medicine, 45(1), 5-14. 
Goulet, L. R. \& Frank, M. L. (2002). Organizational commitment across three sectors: Public, nonprofit and for profit. Public Personnel Management, 31(2), 201-209.

Gronbjerg, K.A. (1989). Developing a universe of nonprofit organizations: Methodological considerations. Nonprofit and Voluntary Sector Quarterly, $18(1), 63-80$.

Handy, F. \& Katz, E. (1998). The wage differential between nonprofit institutions and corporations: Getting more by paying less. Journal of Comparative Economics, 26(2), 246-261.

Harris, J. K., Kacmar, K. M. \& Zivnuska, S. (2007). An investigation of abusive supervision as a predictor of performance and the meaning of work as a moderator of the relationship. The Leadership Quarterly, 18, 252-263.

Head, G. (2003). Sustaining nonprofits during economic downturns. Nonprofit Risk, From http://nonprofitrisk.org/library/articles/strategy09002003.shtml.

Herman, R. D. \& Renz, D. O. (2008). Advancing nonprofit organizational effectiveness research and theory: Nine theses. Nonprofit Management and Leadership, $18(4), 399-415$.

Hillmer, Hillmer \& McRoberts. (2004). The real costs of turnover: Lessons from a call center. Human Resource Planning, 27, 34-41.

Hinkins \& Tracey. (2000). The costs of turnover: Putting a price on the learning curve. Cornell Hospitality Quarterly, 41(3), 14-21. 
Hitchcock, M., Deitrick, L., Cesarini, T., McDougal, L., Roberts, T. \& Zinser, J. (2010). A Spotlight on San Diego's Third Sector. Caster Family Center for Nonprofit and Philanthropic Research, University of San Diego, School of Leadership and Education Sciences. Retrieved October 27, 2013 from https:/lib.sandiego.edu/soles/documents/a s potlight_on_sandiegosthirdsector.pdf.

Hogan, R. \& Kaiser, R. B. (2005). What we know about leadership. Review of General Psychology, 9(2), 169-180.

Hsieh, H. \& Shannon, S. E. (2005). Three approaches to qualitative content analysis. Qualitative Health Research, 15, 1277-1288.

Jang, H. \& Feiock, R. C. (2007). Public and private funding reliance of nonprofit organizations: Implications for interorganizational collaboration. Public Performance and Management Review, 31(2), 174-190.

Johnson, R. B. \& Onwuegbuzie, A. J. (2004). Mixed methods research: a research paradigm whose time has come. Educational Researcher, 33(7), 14-26.

Judge, T. A., Locke, E. A., Durham, C. C. \& Kluger, A. N. (18). Dispositional effects on job and life satisfaction: The role of core evaluations. Journal of Applied Psychology, 83(1), 17-34.

Kacmar, K. M., Andrews, M. C., Van Rooy, D. L., Steilberg, R. C. \& Cerrone, S. (2006). Sure everyone can be replaced...but at what cost? Turnover as a predictor of unit- level performance. Academy of Management Journal, 49(1), 133144.

Kellerman, B. (2004). Bad Leadership: What It Is, How It Happens, Why It Matters. Boston, MA: Harvard Business School Publishing. 
Koys, D. J. (2001). The effects of employee satisfaction, organizational citizenship behavior, and turnover on organizational effectiveness: A unit-level, longitudinal study. Personnel Psychology, 54(1), 101-114.

Kusy, M. \& Holloway, E. (2009). Toxic Workplace! Managing Toxic Personalities and Their Systems of Power. San Francisco, CA: Jossey-Bass.

Larkin, R. (2013). Using outcomes to measure nonprofit success. Nonprofit Quarterly, 20(2). Retrieved March 15, 2015 from:

https://nonprofitquarterly.org/management/22549-using-outcomes-tomeasure-nonprofit-success.html.

Leete, L. (2006). Work in the nonprofit sector. In Powell, W. W. \& Steinberg, R. (Eds.). The Nonprofit Sector: A Research Handbook, (Ed. $\left.2^{\text {nd }}\right)$. New Haven, CT: Yale University Press.

Lin, W. \& Van Ryzin, G. G. (2012). Web and mail surveys: An experimental comparison of methods for nonprofit research. Nonprofit and Voluntary Sector Quarterly, 41(6), 1014-1028.

Lipman-Blumen, J. (2005). The Allure of Toxic Leaders: Why We Follow Destructive Leaders and Corrupt Politicians - and How We Can Survive Them. New York, NY: Oxford University Press.

Luther S. S., Cicchetti, D. \& Becker, B. (2000). The construct of resilience: A critical evaluation and guidelines for future work. Child Development, 71(3), 543562.

Maak, T. \& Pless, N. M. (2006). Responsible leadership in a stakeholder society: A relational perspective. Journal of Business Ethics, 66(1), 99-115. 
MacLaughlin, S. (2015). Charitable giving report: How nonprofit fundraising performed in 2014. Blackbaud. Retrieved March 30, 2015 from https:/www.blackbaud.com/files/corpmar/cgr/how-nonprofit-fundraisingperformed-in-2014.pdf.

Masten, A. S., \& Coatsworth, J. D. (1998). The development of competence in favorable and unfavorable environments: Lessons from research on successful children. American Psychologist, 53, 205-220.

Meyer, J. P., Stanley, D. J., Herscovitch, L. \& Topolnytsky, L. (2002). Affective continuance and normative commitment to the organization: A metaanalysis of antecedents, correlates and consequences. Journal of Vocational Behavior, 61, 20-53.

Mazzola, J. J., Walker, E. J. Shockley, K. M. \& Spector, P. E. (2011). Examining stress in graduate assistants: Combining qualitative and quantitative survey methods. Journal of Mixed Methods Research, 5, 198-211.

McKinnon, D. P. \& Fairchild, A. J. (2009). Current directions in mediation analysis. Current Directions in Psychological Science, 18(1), 16-20.

Meyer, J. P., Stanley, D. J., Herscovitch, L. \& Topolnytsky, L. (2002). Affective, continuance, and normative commitment to the organization: A metaanalysis of antecedents, correlates, and consequences. Journal of Voactional Behavior, 6, 20-52.

Meyers, L.S., Gamst, G. \& Guarino, A. J. (2006). Applied Multivariate Research: Design and Interpretation. Thousand Oaks, CA: Sage Publications, Inc. 
Miles, J. \& Shevlin, M. (2010). Applying Regression and Correlation: A Guide for Students and Researchers. Thousand Oaks, CA: Sage Publications, Inc.

Mitte, K. (2008). Memory bias for threatening information in anxiety and anxiety disorders: A meta-analytic review. Psychological Bulletin, 134(6), 886911.

Morse, J. M., Barrett, M., Mayan, M., Olson, K. \& Spiers, J. (2002). Verification strategies for establishing reliability and validity in qualitative research. International Journal of Qualitative Methods, 1(2), 1-14.

Mowday, R. T. \& Steers, R. M. (1979). The measure of organizational commitment. The Journal of Vocational Behavior, 14, 224-247.

National Center for Charitable Statistics (NCCS). National Taxonomy of Exempt Entities. Retrieved October 18, 2013 from http://nces.urban.org/classification/NTEE.cfm.

Nisbett, R. E. \& Wilson, T. D. (1977). The halo effect: Evidence of unconscious alteration of judgments. Journal of Personality and Social Psychology, $35(4), 250-256$.

O'Neil, M. (2002). Nonprofit Nation: A New Look at the Third America. San Francisco, CA: Jossey-Bass.

Organ, D. W. (1997). Organizational citizenship behavior: It's construct clean-up. Human Performance, 10(2), 85-97.

Padilla, A., Hogan, R. \& Kaiser, R. B. (2007). The toxic triangle: Destructive leaders, susceptible followers, and conducive environments. The Leadership Quarterly, 18(3), 176-194. 
Patton, M. Q. (2002). Qualitative Research \& Evaluation Methods (Ed. $3^{\text {rd) }}$. Thousand Oaks, CA: Sage Publications, Inc.

Pelletier, K. L. (2009). Effects of favored status and identification with victim on perceptions of and reactions to leader toxicity. (Doctoral dissertation). Retrieved from ProQuest LLC. (UMI 3383643).

Podsakoff,, P. M., Ahearne, M., \& MacKenzie, S. B. (1997). Organizational citizenship behavior and the quantity and quality of work group performance. Journal of Applied Psychology, 82(2), 262-270.

Podsakoff, P. M. \& MacKenzie, S. B. (1997). Impact of organizational citizenship behavior on organizational performance: A review and suggestions for future research. Human Performance, 10(2), 133-151.

Podsakoff, P. M., MacKenzie, S. B., Paine, J. B. \& Bachrach, D. G. (2000). Organizational Citizenship Behaviors: A Critical Review of the Theoretical and Empirical Literature and Suggestions for Future Research. Journal of Management, 26(3), 513-563.

Poon, J. M. L. (2011). Effects of abusive supervision and coworker support on work engagement. International Conference on Economics, Business and Management, $22,65-70$.

Pope, C., Ziebland, S. \& Mays, N. (2000). Qualitative research in health care: Analysing qualitative data. British Medical Journal, 320, 114-116. 
Preacher, K. J., Curran, P. J. \& Bauer, D. J. (2006). Computational tools for probing interactions in multiple linear regression, multilevel modeling, and latent curve analysis. Journal of Educational and Behavioral Statistics, 31(3), 437-448.

Rafferty, A. E. \& Restubog, S. L. D. (2011). The influence of abusive supervisors on followers' organizational citizenship behaviors: The hidden costs of abusive supervision. British Journal of Management, 22, 270-285.

Rea, L. M. \& Parker, R. A. (2005). Designing and Conducting Survey Research: A Comprehensive Guide $\left(\right.$ Ed. $\left.3^{\text {rd }}\right)$. San Francisco, CA: Jossey-Bass.

Reed, G. E. (2004, Jul/Aug). Toxic leadership. Military Review. Retrieved from http://www.carlisle.army.mil/usawc/dclm/Toxic_Leadership.pdf.

Reed, G. E. \& Bullis, R. C. (2009). The impact of toxic leadership on senior military officers and civilian employees. Armed Forces \& Society, 36(1), 5-18.

Reed, G. E. \& Olsen, R. A. (2010, Nov/Dec). Toxic leadership: Part deux. Military Review. Retrieved from http://usacac.army.mil/CAC2/MilitaryReview/Archives/En glish/MilitaryReview_201012 31_art011.pdf.

Restubog, S. L. D., Scott, K. L. \& Zagenczyk, T. J. (2011). When distress hits home: The role of contextual factors and psychological distress in predicting employees' responses to abusive supervision. Journal of Applied Psychology, 6(4), 713-729.

Santos, J. R. A. (1999). Cronbach's Alpha: A tool for assessing the reliability of scales. Journal of Extension, 37(2). 
Schepers, C., De Geiter, S., Pepermans, R., Du Bois, C., Caers, R. \& Jegers, M. (2005). How are employees of the nonprofit sector motivated? A research need. Nonprofit Management and Leadership, 16(2), 191-208.

Schmidt, A. A. (2008). Development and validation of the toxic leadership scale. Retrieved from ProQuest Digital Theses. (UMI 1453699).

Sharma, S., Durand, R. M. \& Gur-Arie, O. (1981). Identification and analysis of moderator variables. Journal of Marketing Research, 18, 291-300.

Shaw, J. B., Erickson, A., \& Harvey, M. (2011). A method for measuring destructive leadership and identifying types of destructive leaders in organizations. The Leadership Quarterly, 22(4), 575-590.

Shenton, A. K. (2004). Strategies for ensuring trustworthiness in qualitative research projects. Education for Information, 22, 63-75.

Smith, C. A, Organ, D. W. \& Near, J. P. (1983). Organizational citizenship behavior: Its nature and antecedents. Journal of Applied Psychology, 68(4), 653-663.

Steele, J. P. (2011). Antecedents and consequences of toxic leadership in the U.S. Army: A two year review and recommended solutions. Center for Army Leadership Technical Report. Retrieved April 27, 2015 from http://usacac.army.mil/cac2/Repository/CASAL_TechReport20113_ToxicLeadership.pdf.

Srivastava, A. \& Thomson, S. B. (2009). Framework analysis: A qualitative methodology for applied policy research. Journal of Administration and Governance, $4(2), 72-79$. 
Tabachnick, B. G. \& Fidell, L. S. (2001). Using Multivariate Statistics (Ed. $4^{\text {th }}$ ). Boston, MA: Allyn and Bacon.

Tepper, B. J. (2000, Apr). Consequences of abusive supervision. The Academy of Management Journal, 43(2), 178-190.

Tepper, B. J., Duffy, M. K. \& Shaw, J. D. (2001). Personality moderators of the relationship between abusive supervision and subordinates' resistance. Journal of Applied Psychology, 86(5), 974-983.

Tepper, B. J., Duffy, M. K., Henle, C. A. \& Lambert, L. S. (2006). Procedural injustice, victim precipitation, and abusive supervision. Personnel Psychology, 59, 101-123.

Tepper, B. J. (2007). Abusive supervision in work organizations: Review, synthesis, and research agenda. Journal of Management, 33(3), 261-289.

Tsankavoa, N., Renthal, W., Kumar, A. \& Nestler, E. J. (May, 2007). Epigenetic regulation in psychiatric disorders. Nature Reviews Neuroscience, 8, 355367.

Unger, M. (2011). The social ecology of resilience: Addressing contextual and cultural ambiguity of a nascent construct. American Journal of Orthopsychiatry, $81(1), 1-17$.

Urban Institute (2013). http://nccs.urban.org/classification/NTEE.cfm Urban Institute (2014). http://ncesweb.urban.org/PubApps/dd2.php?close=1\&form $=$ BMF $+12 / 2014$ 
Western, S. (2008). Leadership: A Critical Text. Thousand Oaks, CA: Sage Publications, Ltd.

Whicker, M. L. (1996). Toxic Leaders. Westport, CT: Quorum Books.

Wilensky, A. S. \& Hansen, C. D. (2001). Understanding the work beliefs of nonprofit executives through organizational stories. Human Resource Development Quarterly, 12(3), 223-239.

Williams, D. F. (2005). Toxic Leadership in the U.S. Army. Retrieved from http:/timemilitary.files.wordpress.com/2011/09/toxic-paper.pdf.

Wittmer, D. (1991). Serving the people or serving for pay: Reward preferences among government, hybrid sector and business managers. Public Productivity and Management Review, 14(4), 369- .

Wu, T. (2009). Abusive supervision and employee emotional exhaustion: Dispositional antecedents and boundaries. Group \& Organizational Management, 34(2), 143-169.

Zellars, K. L., Tepper, B. J. \& Duffy, M. K. (2002). Abusive Supervision and subordinates' organizational citizenship behavior. Journal of Applied Psychology, 87(6), 1068-1076. 
Appendix A

Complete List of National Taxonomy of Exempt Entities (NTEE) Major Groups 
National Taxonomy of Exempt Entities (NTEE) Major Groups (Urban Institute, 2013)

NTEE major group $(A-Z)$

A

Arts, Culture, and Humanities

B

Education

C Environmental Quality, Protection, and Beautification

D Animal-Related

E Health

F Mental Health, Crisis Intervention

G Diseases, Disorders, Medical Disciplines

H Medical Research

I Crime, Legal Related

J Employment, Job Related

K Food, Agriculture, and Nutrition

L Housing, Shelter

M Public Safety

N Recreation, Sports, Leisure, Athletics

O Youth Development

P Human Services - Multipurpose and Other

Q International, Foreign Affairs, and National Security

R Civil Rights, Social Action, Advocacy

S Community Improvement, Capacity Building 
$\mathbf{T}$

$\mathbf{U}$

V

W

$\mathbf{X}$

Y

$\mathbf{Z}$
Philanthropy, Voluntarism, and Grantmaking Foundations

Science and Technology Research Institutes, Services

Social Science Research Institutes, Services

Public, Society Benefit - Multipurpose and Other

Religion Related, Spiritual Development

Mutual/Membership Benefit Organizations, Other

Unknown 
Appendix B

Survey Layout 


\section{$\underline{\text { Survey Items and Prompts }}$}

"Have you ever worked for someone in a nonprofit organization that you felt was/is very difficult or abusive?" Yes/No. If no, then the survey takes them to "Thank you for your time and for your work in the sector."

If "yes" then Please answer the following questions from your perspective when you worked for this difficult or abusive person. This can be any time in your career in a nonprofit organization.

1 What type of organization were you in at the time of the experience you are recalling - dropdown with choices from the NTEE

2 What level in organization were you at the time of the experience you are recalling - dropdown

3 Ethnicity -dropdown

4 Gender -dropdown

5 Highest education completed at time of the experience you are recalling dropdown

6 Age at time of the experience you are recalling -write in

7 Age now -write in

Remember that all of the following questions are asking about the time and events that you have chosen because you felt that your supervisor was difficult or you had issues with him or her.

Each the following toxic leadership questions will use the 7 response Likert scale shown below questions 8-32.

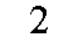

strongly agree agree
3 somewhat somewhat disagree agree disagree
6 strongly disagree

$8 \mathrm{My}$ boss is an inconsiderate person

9 My boss is arrogant

10 My boss is self-centered

11 My boss rarely shows a high level of respect for others 
12 My boss does not share power with the people with whom he or she works

13 My boss wants to dominate/control everything

14 My boss sees every negotiation issue as a win/lose conflict

15 My boss holds grudges

16 My boss could best be described as mean

17 My boss demonstrates no concern for anyone outside his/her own unit

18 My boss is pig headed ie extremely stubborn

19 My boss does not show trust in subordinates by assigning them important tasks

20 My boss is a micro-manager

21 My boss is autocratic

22 Anyone who challenges my boss is dealt with brutally

23 My boss enjoys making people suffer

24 My boss tends to show excessive favoritism

25 My boss does NOT trust others to do tasks properly

$26 \mathrm{My}$ boss tends to act in ways that divide employees against one another

27 My boss attempts to exert total control over everyone

28 I have often seen my boss bully another employee

29 My boss places brutal pressure on subordinates

30 My boss is a tyrant

31 My boss has personal favorites

32 My boss does not care about things happening in other units

33 Did you consider leaving the organization during the experience you recalled above? Yes/No 
34 Did you leave? Yes/No

35 Please explain in as much detail as possible why you decided to remain in the organization? This is an open-ended question.

Please respond to the following questions thinking about how you felt during the experience you referred to above, as though you were in that situation now.

The following items use the this 7 point Likert scale:

\begin{tabular}{rlrrrrr}
1 & 2 & 3 & \multicolumn{1}{c}{4} & 5 & \multicolumn{1}{c}{6} & \multicolumn{1}{c}{7} \\
strongly & moderately & slightly & neither & slightly & moderately & strongly \\
disagree & disagree & disagree & $\begin{array}{l}\text { disagree } \\
\text { or agree }\end{array}$ & agree & agree & agree
\end{tabular}

The following items began with: I...

36 Help others out if someone falls behind in his/her work

37 Willingly share my expertise with colleagues

38 Try to act like a peacemaker when colleagues have disagreements

39 Take steps to try to prevent problems with colleagues

40 Willingly give my time to help colleagues who have work-related problems

41 "Touch base" with colleagues before initiating actions that might affect them

42 Encourage others when someone is down

43 Provide constructive suggestions about how colleagues could improve their effectiveness

44 Is willing to risk disapproval to express my beliefs about what's best for my colleagues

45 Attend and actively participate in team meetings

46 Always focus on what was wrong with my situation, rather than the positive side

47 Consume a lot of time complaining about trivial matters

48 Always find fault with what colleagues are doing 
49 I was willing to put in a great deal of effort beyond that normally expected in order to help the organization be successful.

50 I talked up this organization to my friends as a great organization to work for.

51 I feel very little loyalty to the organization.

52 I would have accepted almost any type of job assignment in order to keep working for the organization.

53 I found that my values and the organization's values were very similar.

54 I was proud to tell others that I was part of the organization.

55 I could just as well have worked for a different organization as long as the type of work was similar.

56 The organization really inspired the very best in me in the way of job performance.

57 It would have taken very little change in my circumstances to have caused me to leave the organization.

58 I was extremely glad that I chose the organization to work for over others I was considering at the time I joined.

59 There was not too much to be gained by sticking with the organization indefinitely.

60 Often, I found it difficult to agree to the organization's policies on important matters relating to its employees.

61 I really cared about the fate of the organization.

62 For me this was the best of all possible organizations for which to work.

63 Deciding to work for the organization was a definite mistake on my part. 
Appendix C

Open-ended Question Codes and Frequencies 
Open-ended Question Codes and Frequencies

\begin{tabular}{|c|c|}
\hline Code & Frequency \\
\hline supervisor left & 40 \\
\hline like work & 22 \\
\hline looking for other job & 21 \\
\hline commitment to mission & 20 \\
\hline need pay & 19 \\
\hline personal responsibility & 16 \\
\hline like colleagues & 15 \\
\hline moved in org & 13 \\
\hline believe in mission & 13 \\
\hline can't find other job & 13 \\
\hline bad job market & 12 \\
\hline not directed at me & 12 \\
\hline will work itself out & 12 \\
\hline want experience this job provides & 11 \\
\hline like benefits & 9 \\
\hline love mission & 8 \\
\hline fear of damage to career by supervisor & 7 \\
\hline good at protecting myself & 7 \\
\hline Promoted & 6 \\
\hline will protect colleagues from toxic person & 6 \\
\hline colleagues banded together & 4 \\
\hline passionate about mission & 4 \\
\hline lost confidence in myself from it & 4 \\
\hline need level of pay & 3 \\
\hline leadership encouraged to stay & 3 \\
\hline appreciated my supervisor support despite toxicity & 3 \\
\hline don't want to start over & 2 \\
\hline Opportunity & 2 \\
\hline retiring soon & 2 \\
\hline like pay & 2 \\
\hline sought help from org leadership & 2 \\
\hline lucky to have a job & 1 \\
\hline like this field & 1 \\
\hline supervisor allows for career development & 1 \\
\hline need benefits & 1 \\
\hline difficult job market for my age & 1 \\
\hline situation got better & 1 \\
\hline
\end{tabular}



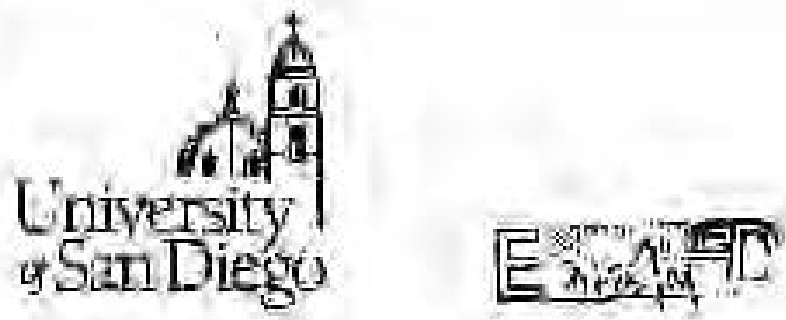

\section{institudional Review Board \\ Project Arton Summary}

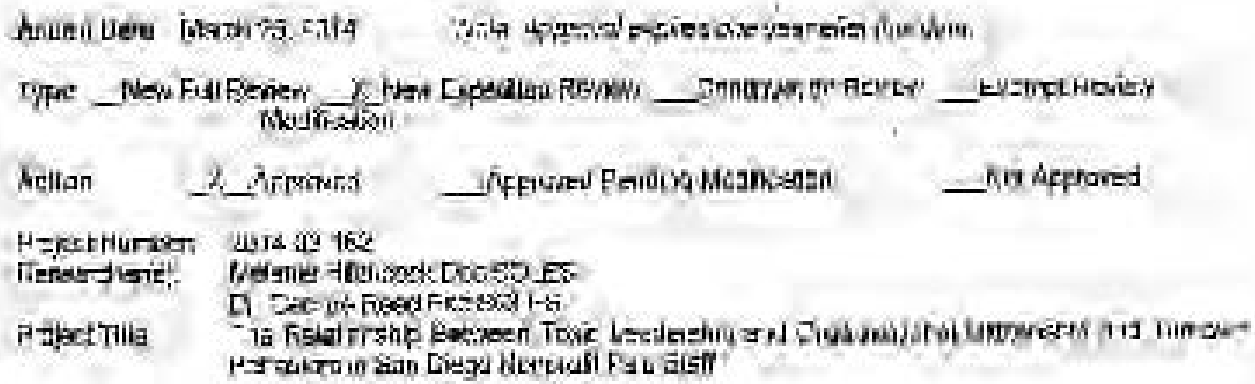

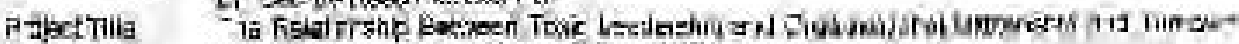

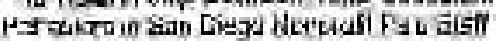

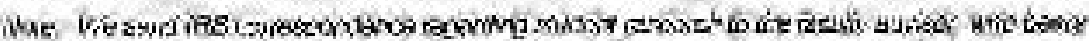

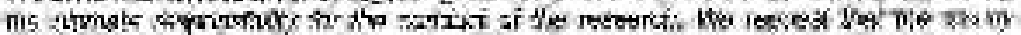

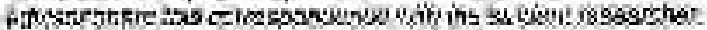

\section{Modihuriana-Reodientel-or Resesina for Non-Aparoval}

rings:

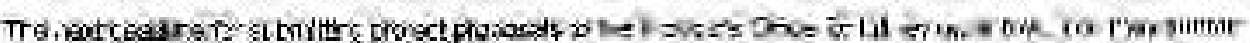

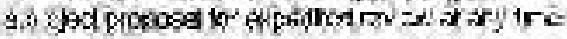

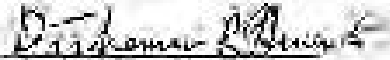

[r. ThInEs]. Heir inin

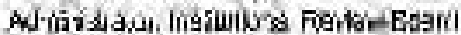

Unkerts al sgn Cisie:

ismmtangserncieameni.

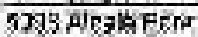

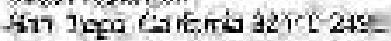




\section{SIGNATURE PAGE}

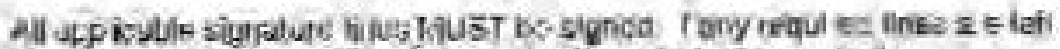

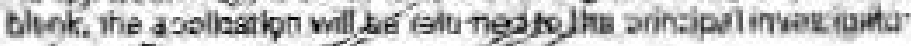

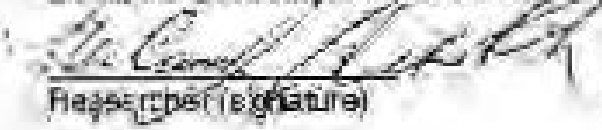

SOLES ZW Fat 20 in.

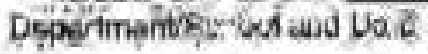

Melairles Hilrodiande

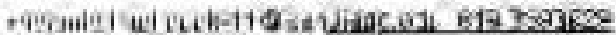
Passicher inticted! FEOUIFED, Crrail Phone-

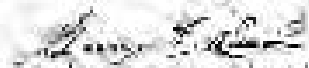
SOLEE Fornuty 37, 2014

Filvily moviar iogrits

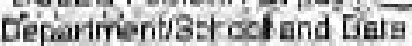

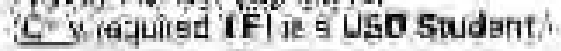

Dr. Baorga E. Head

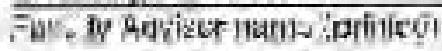

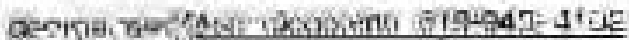
MEQUREE: ECrail Phume

bis

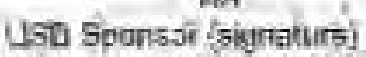
svait Those

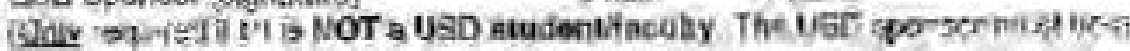
iulbine 6 mplcyeg afusci

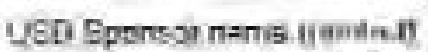<smiles>CC1CC1</smiles><smiles>C=CCC1CC1CCC</smiles><smiles>[CH]1C[CH-]C1</smiles>
Sepatranissiced End Oub

SzFsdicdilagethe Rarusetritative Dals

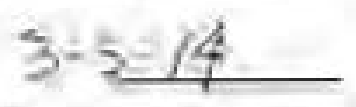

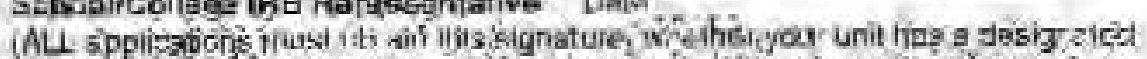

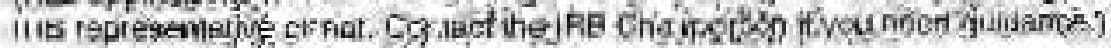

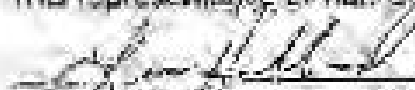

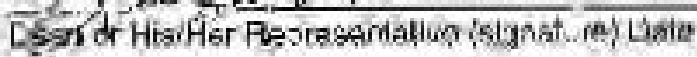

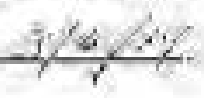

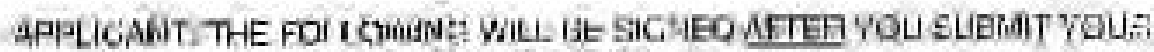
APPLU:ATILIN IO IHE PAOYOST'S OFFICE

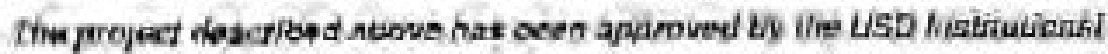
Aerreix stand

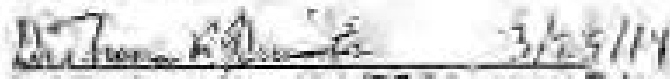

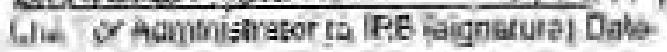



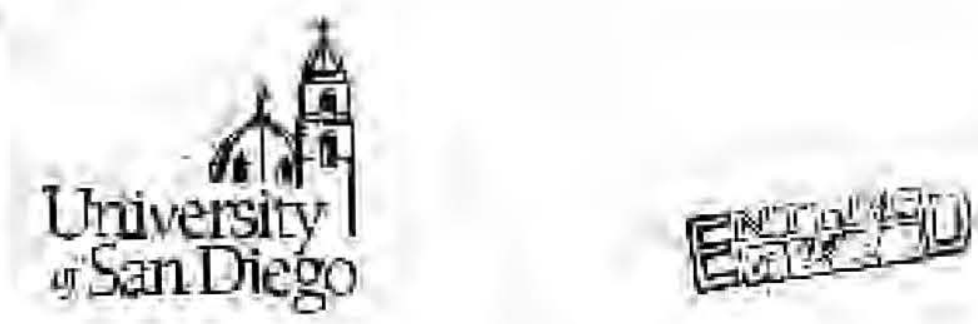

\section{Institutional Review Board Project Actón Summary}

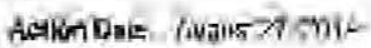

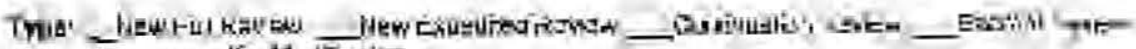

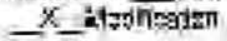

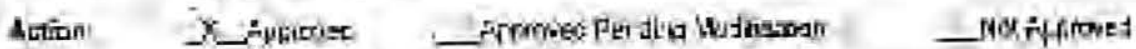

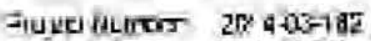

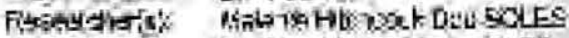

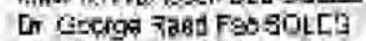

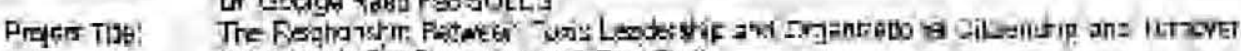

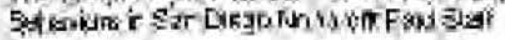

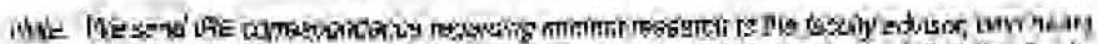

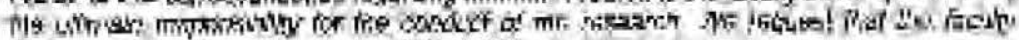

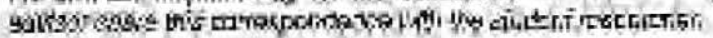

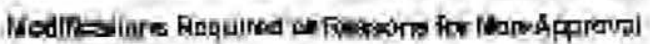

Here

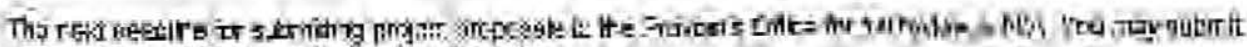

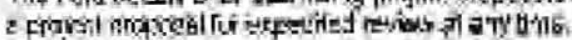

और $=-7$

is Tierse Rke Tan

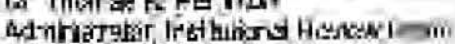

Jnerover ow Bief:

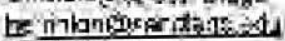

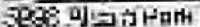

Sit' ERtip Cafothanerio-2142

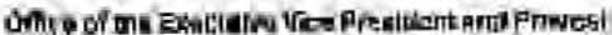

Kugles avalinidindion Garles, Renom 2 is

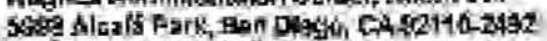

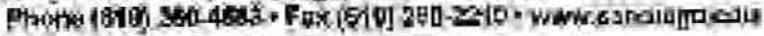



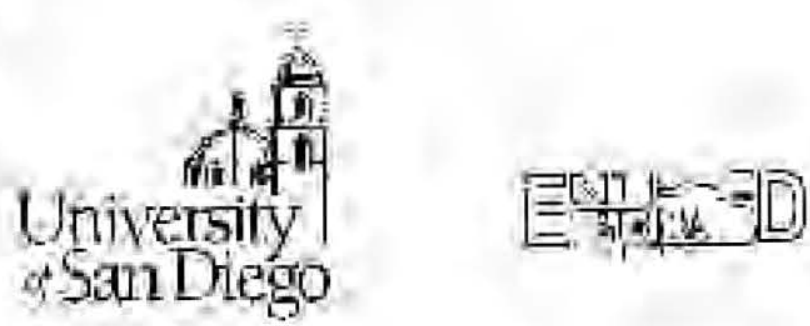

\section{Institutional Review Bount Projact Action Summary}

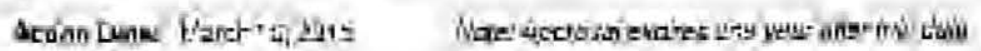

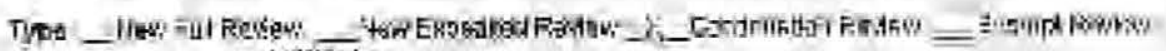
- nindestrer

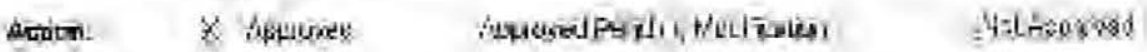

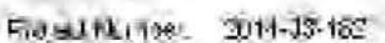

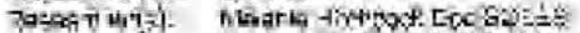

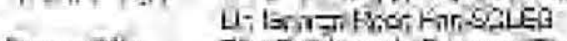

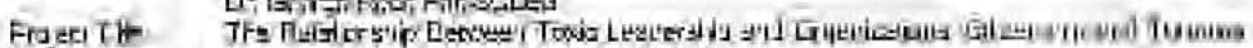

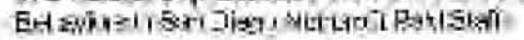

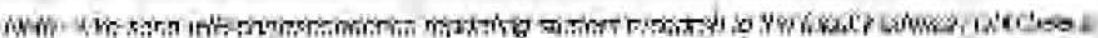

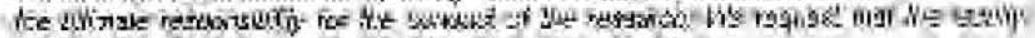

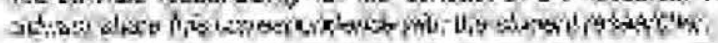

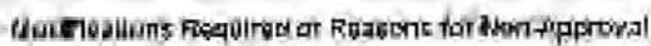

f the

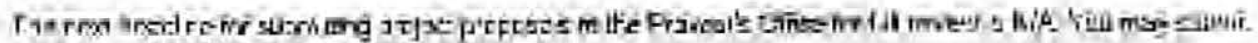

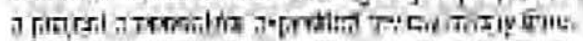

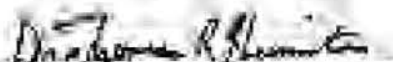

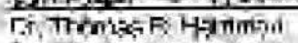

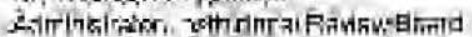

Lraveboses Itge

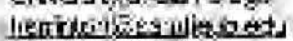

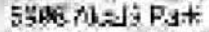

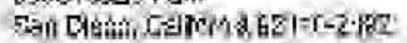

The ot the EuedilieVine Pres ase apd Travo-

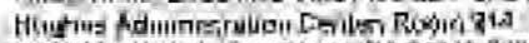

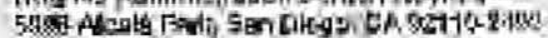

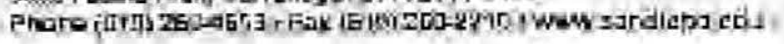




\section{UNAVR 3TY oF aAU DIEGO \\ reft.tunai Reviaw Boak ( RB) \\ REQUESI FOR GONTHUATION OF AN APPRONEO RESEARCFF PHOIECT

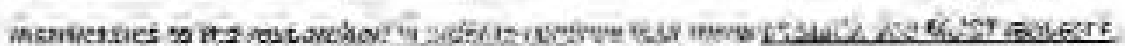

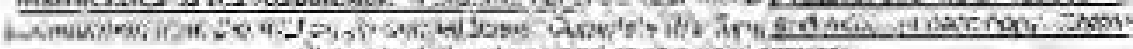

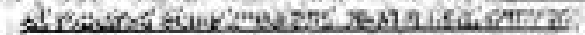

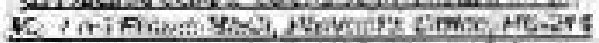

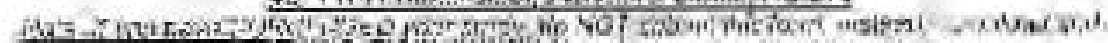

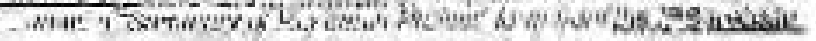

\section{Name gr PI: Molsitie Hitahiogrk}

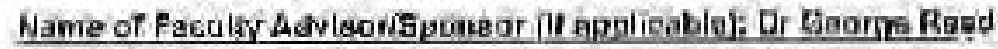

\section{Prolect in * 2014-63-182}

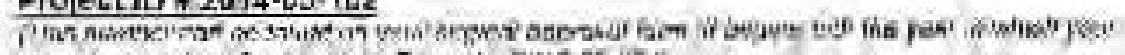

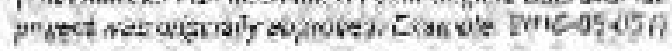

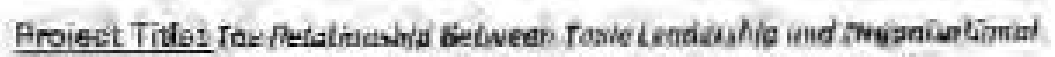

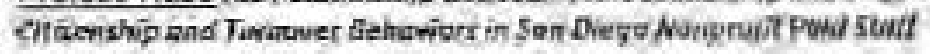

Lavei of initias Aporonal iesoch ONr)

Lxperited Exerr 21

nill

A. Pricgrpse gr Finsoarich.

Dera hove bean collected lian. 474 parisipard

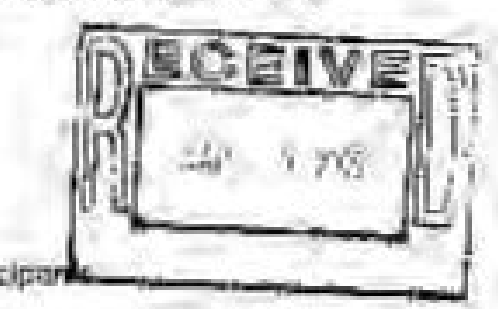

\section{B. Hunsm Sublects:}

informad Comeant Fá ton on file: tries:

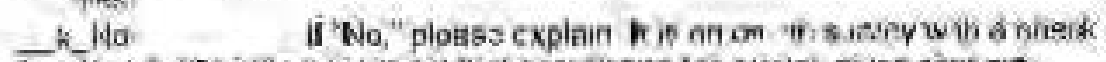

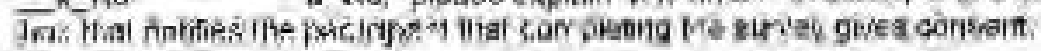

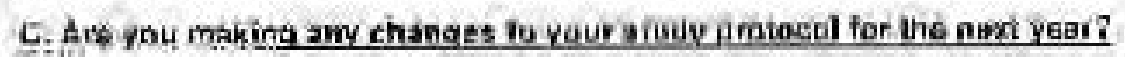

$$
\text { - }=\text { Na }
$$

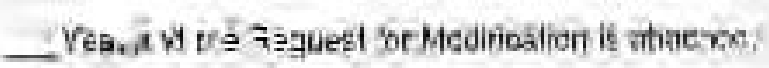

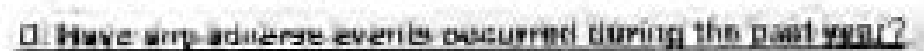

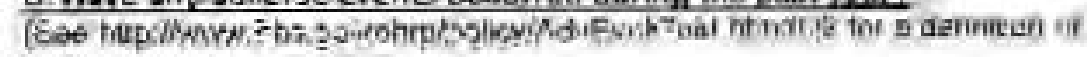
adworse ener:-s

- 7 - Ha

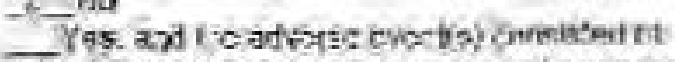

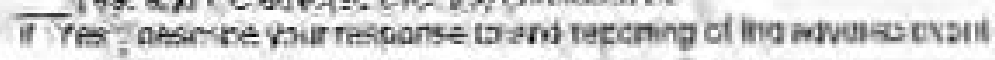




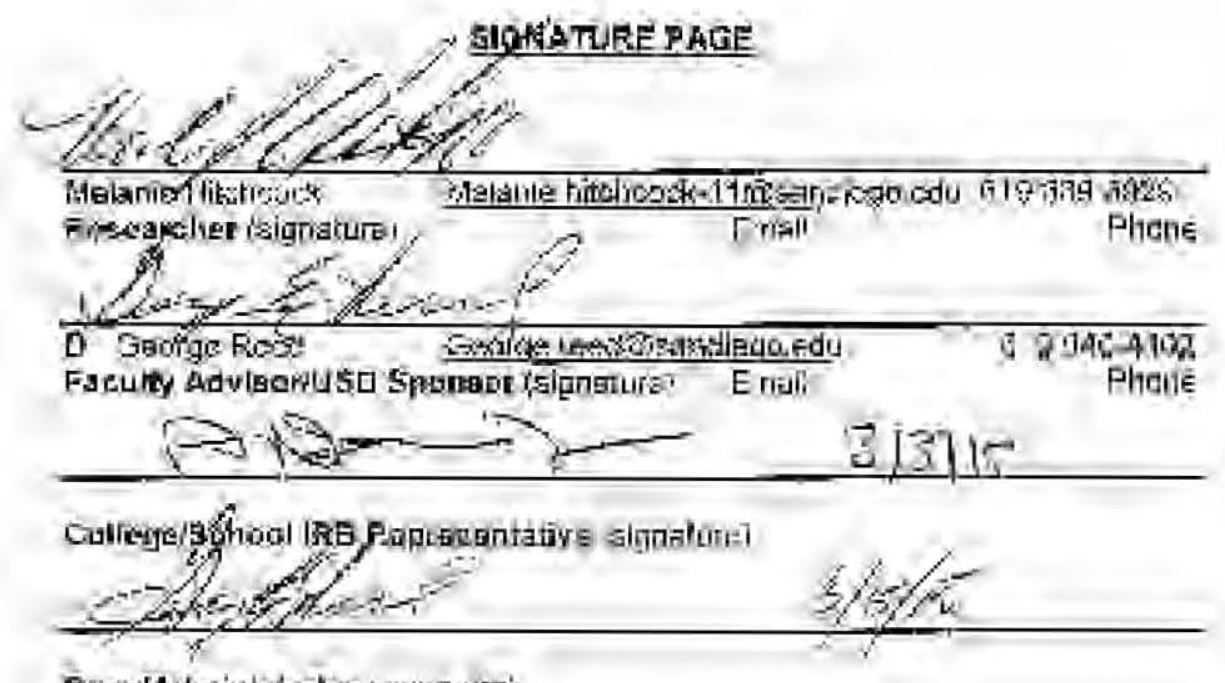

PuandAdministritor ; suguaure;

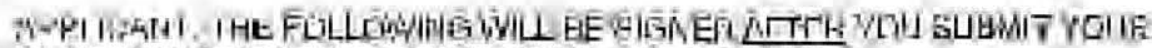

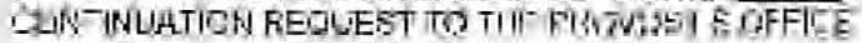

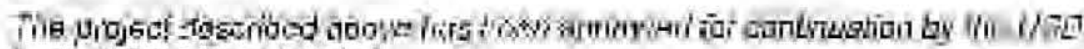

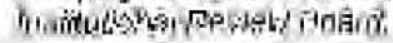

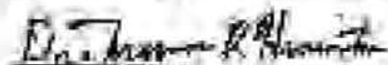
$3 / 6 / 6 / 5$

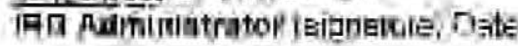

